\title{
No Catalytic Performance Analysis of Gasoline Engine Tapered Variable Cell Density Carrier Catalytic Converter
}

\section{Qingsong Zuo}

Xiangtan University

Xiaomei Yang ( 313236787@qq.com )

Xiangtan University https://orcid.org/0000-0002-4003-469X

\section{Bin Zhang}

Xiangtan University

\section{Qingwu Guan}

Technique center.Hunan Tyen Machinery Co

\section{Zhuang Shen}

Xiangtan University

\section{Yongchuan Xie}

Xiangtan University

Qiming Li

Xiangtan University

\section{Research Article}

Keywords: Catalytic converter, NO catalysis, NO2 mass fraction, vehicle emission, Gas uniformity, Pressure drops

Posted Date: May 27th, 2021

DOI: https://doi.org/10.21203/rs.3.rs-458071/v1

License: (c) (1) This work is licensed under a Creative Commons Attribution 4.0 International License. Read Full License

Version of Record: A version of this preprint was published at Environmental Science and Pollution Research on August 5th, 2021. See the published version at https://doi.org/10.1007/s11356-021-15504y. 
1 NO Catalytic Performance Analysis of Gasoline Engine Tapered Variable

\title{
Cell Density Carrier Catalytic Converter
}

\author{
Qingsong Zuo ${ }^{\mathrm{a}}$, Xiaomei Yang ${ }^{\mathrm{a}}$, Bin Zhang, *, Qingwu Guan ${ }^{\mathrm{b}}$, Zhuang Shen ${ }^{\mathrm{a}}$, Yongchuan Xie,
}

Qiming $\mathrm{Li}^{\mathrm{a}}$

a. School of Mechanical Engineering, Xiangtan University, Xiangtan, 411105, China

b. Technique Center, Hunan Tyen Machinery Co., Ltd., Hengyang, 421000, China

Institute of Engineering, Xiangtan 411104, China

* binzhang0627@xtu.edu.cn.

Abstract: Improving the flow field uniformity of catalytic converter can promote the catalytic conversion of $\mathrm{NO}$ to $\mathrm{NO}_{2}$. Firstly, the physical and mathematical models of improved catalytic converter are established, and its accuracy is verified by experiments. Then, the NO catalytic performance of standard and improved catalytic converters is compared, and the influences of structural parameters on its performance are investigated. The results showed that: (1) The gas uniformity, pressure drop and NO conversion rate of the improved catalytic converter are increased by $0.0643,6.78 \%$ and $7.0 \%$ respectively. (2) As the cell density combination is $700 \mathrm{cpsi} / 600 \mathrm{cpsi}$, NO conversion rate reaches the highest, $73.7 \%$, and the gas uniformity is 0.9821. (3) When the tapered height is $20 \mathrm{~mm}$, NO conversion rate reaches the highest, $72.4 \%$, the gas uniformity is 0.9744 . (4) When the high cell density radius is $20 \mathrm{~mm}$, NO conversion rate reaches the highest, $72.1 \%$, the gas uniformity is 0.9783 . (5) When the tapered end face radius is $20 \mathrm{~mm}$, NO conversion rate reaches the highest, $72.0 \%$, the gas uniformity is 0.9784 . The results will provide a very important reference value for improving NO catalytic and reducing vehicle emission.

Keywords: Catalytic converter; $\mathrm{NO}$ catalysis; $\mathrm{NO}_{2}$ mass fraction; vehicle emission; Gas uniformity; Pressure drops 


\section{Introduction}

Environmental pollution brings serious ecological problems (Matsuzawa et al. 2001; Baumard et al. 1998), and automobile exhaust pollution is one of the sources of serious environmental pollution, so it is urgent to reduce automobile emissions (Zhang et al. 2021; Sun et al. 2021; Lichtfouse et al. 1997). Many countries have formulated strict emission standards to improve environmental quality (Qian et al. 2019a, 2019b; Park et al. 2019). At present, some ways to reduce emission pollution, such as improving fuel, combustion mode and adding post-processor have been proposed (Zhong et al. 2018, 2016). Among them, catalytic converters have been proved to be an indispensable device to reduce automobile exhaust pollutants (E et al. 2020; Manojkumar et al. 2020; Subhashish et al. 2019). Previous studies have shown that catalytic converters can reduce $95 \% \mathrm{CO}, \mathrm{HC}$ and $\mathrm{NOx}$ under the condition that the operating environment meets the requirements (Santos et al. 2008; Matthew et al. 2016). However, due to the uneven flow field in the standard catalytic converter in practice, the purification of pollutants is limited (Mu et al. 2019a; Shen et al. 2019). Besides, it also causes sintering of the catalyst, affecting its later use (Gao et al. 2019; Liang et al. 2019). Therefore, it is necessary to further improve the uniformity of flow field in catalytic converters (Andrew et al. 2014).

For catalytic converters, Hesham et al. (2018) proposed that insulating material was placed in the carrier channel to investigated the distribution of the internal flow field. They found that the gas uniformity was improved by 5\%. Day et al. (2020) surveyed various catalysts in catalytic converters. They revealed that compared with noble metal catalysts, $\mathrm{Cu}$ was the most powerful and active catalyst for $\mathrm{CO}$. $\mathrm{Mu}$ et al. (2019b) proposed a rationalized B-spline expansion pipe structure. The results revealed that the pressure drop was reduced by $12 \%$, and the gas uniformity was better. Miles et al (2017) researched Alumina with $3 \mathrm{~nm}$ cerium dioxide nanoparticles (ceria NPs). The research indicated that supported $3 \mathrm{~nm}$ ceria NPs were found to lower the light-off temperature for $\mathrm{CO}$ by 200 and $100^{\circ} \mathrm{C}$ compared to inactivated and activated 
ceria micro-powders, respectively. Almeida et al. (2014) investigated the impact of temperature on the aging of catalytic converters, and claimed that higher temperatures would reduce the conversion efficiency and accelerate the aging of the catalytic converters. Liu et al. (2020) measured the distribution of catalytic converter particles by DMS500 and analyzed the particle characteristics. The results showed that TWC could reduce particles by $20-35 \%$ and GPF by $70-85 \%$. Liu et al. (2021) studied the effect of exhaust gas temperature on the purification of particulate matter. The results showed that after the exhaust gas passed through the catalytic converter, the particles of 4-8 $\mathrm{nm}$ were reduced by $96 \%$, while the purification effect of particles larger than $50 \mathrm{~nm}$ was not obvious. Ayodhya et al. (2018) studied the arrangement order of postprocessing equipment. The results showed that a good after-treatment setup should have its devices placed in the order: Diesel oxidation catalyst followed by Diesel particulate filter and Selective catalytic reduction. Bogarra et al. (2017) studied the catalysis of $\mathrm{HC}$ compounds, and found that when the temperature reached $350^{\circ} \mathrm{C}$, HC compounds could effectively catalyze and effectively reduce the particles less than $20 \mathrm{~nm}$. Kumar et al. (2019) carried out experiments on diesel methanol nitromethane mixture. The results showed that the best performance and emission results were observed when diesel oil was $92.5 \%$, methanol was $5 \%$ and nitromethane was 2.5\%. Zhong et al. (2021) studied the influence of $\mathrm{NO}_{2} / \mathrm{NOx}$ ratio on diesel particulate filter. the catalytic performance of NO conversion was limited by mass transfer in Diesel oxidation catalyst catalytic coating, while it was almost non-existent in catalytic diesel particulate filter.

In summary, at present, some scholars have paid attention to the flow characteristics of catalytic converters, but more attention was paid to the influence of different factors on catalytic converters. Takeru et al. (2017) found, compared with the standard carrier structure, the catalyst durability of the radial variable cell density carrier was better, and the NOx reaction temperature was reduced by $10^{\circ} \mathrm{C}$. Xu et al. (2009) claimed the structure of the tapered end-face carrier was more favorable to the uniformity of exhaust. Considering the actual problems of purification effect and catalyst sintering, a more optimized catalytic 
converter model must establish.

Therefore, the improved catalytic converter model with tapered end face radial variable cell density carrier is established, and its accuracy is verified by experiments in this work. Then, the purification performance and flow characteristic of standard and improved catalytic converters are compared, and the effects of different structural parameters on the improved catalytic converter are analyzed. Finally, the gray correlation analysis method is used to explore the influence degree of different structural parameters. To achieve the goal of homogenizing the flow field in the catalytic converter and improving the purification performance. The research results will provide a very important reference value for improving the purification performance and service life of catalytic converters.

\section{Model construction and performance comparative analysis}

\subsection{Geometric model}

The geometrical model of the improved catalytic converter is shown in Fig. 1, and the parameters are shown in Table 1. The exhaust flows in from the inlet pipe, and some exhaust flows to the edge of the carrier under the action of the expansion pipe and the tapered end face. In addition, the resistance of the medium carrier with high cell density is greater than that of the edge, which makes the exhaust flows to the edge with less resistance. The carriers are all porous media, the surface of which is coated with precious metal catalyst $\mathrm{Pt}$, and the pollutants are catalyzed in the carrier area to achieve purification. Finally, exhaust is discharged from the outlet pipe.

Table 1 Carrier structure parameters

\begin{tabular}{cc}
\hline Item & Values \\
\hline Tapered height $(\mathrm{h})$ & $10 \mathrm{~mm}$ \\
Tapered end face diameter (d) & $10 \mathrm{~mm}$ \\
\hline
\end{tabular}


High cell density carrier diameter (D)

High /Low cell density

High /Low specific surface area

High /Low porosity
$30 \mathrm{~mm}$

$500 \mathrm{cpsi} / 400 \mathrm{cpsi}$

$2995 / 2728$
88

\subsection{Mathematical model}

To facilitate the establishment of mathematical model, it is necessary to make reasonable assumptions to simplify the model, as follow: (a) No heat loss of steel shell and liner; (b) The exhaust is an incompressible ideal gas; (c) Only 8 kinds of exhaust components: $\mathrm{NO}, \mathrm{H}_{2} \mathrm{O}, \mathrm{N}_{2}, \mathrm{O}_{2}, \mathrm{CO}_{2}, \mathrm{CO}, \mathrm{HC}$ and $\mathrm{NO}_{2}$; (d) All reactions occur only on the surface of the carrier (Zuo et al. 2019a).

(1) Carrier pressure drop

The carrier region is a fully developed laminar flow, which is simulated as a porous medium, making it an additional pressure loss term of the flow momentum equation ( $\mathrm{Su}$ et al. 2013): 


$$
S_{i}=\frac{\partial p}{\partial x_{i}}=-\left(\sum_{j=1}^{3} F_{i j} u v_{j}+\sum_{j=1}^{3} C_{i j} \frac{1}{2} \rho\left|v_{j}\right| v\right)
$$

101

102

103

104

105

106

108

109

110

111

112

113

114

115

116

Where $p$ is pressure, $\mathrm{Pa} ; u$ is dynamic viscosity, $\mathrm{Pa} \cdot \mathrm{s} ; v$ is the velocity, $\mathrm{m} \cdot \mathrm{s}^{-1} ; \rho$ is gas density, $\mathrm{kg} \cdot \mathrm{m}^{-3} ; F$ and $C$ are viscosity and inertia loss coefficient matrices respectively; $i, j$ are the direction of $\mathrm{x}, \mathrm{y}$, and $\mathrm{z}$ in the rectangular coordinate system.

The total carrier pressure drop mainly includes $\Delta p_{1}$ caused by the friction of carrier channel and $\Delta p_{2}$ caused by the inlet and outlet of the channel (Su et al. 2013).

$$
\begin{gathered}
\Delta p_{1}=\frac{A \cdot \mu \cdot v \cdot L}{d_{h}^{2}} \\
\Delta p_{2}=\frac{B}{2} \rho v^{2}
\end{gathered}
$$

Where for uncoated square channel $A=28.4 ; d_{h}$ is hydraulic diameter of carrier channel, $\mathrm{m} ; L$ is the maximum length of carrier, m; the coefficient $B$ is 0.5 .

(2) Reaction mechanism (Zuo et al. 2019b)

(a) NO catalyzed reaction:

$$
2 \mathrm{NO}+\mathrm{O}_{2} \stackrel{\text { Catalyzer }}{\longleftrightarrow} 2 \mathrm{NO}_{2}
$$

(b) Reaction rate equation:

$$
K=\alpha \exp \left(-\frac{E}{\mathrm{R}_{0} T}\right)
$$

Where $K$ is the reaction rate, $\alpha$ is the pre-factor, $\mathrm{mol} \cdot \mathrm{K} \cdot\left(\mathrm{m}^{2} \cdot \mathrm{s}\right)^{-1} ; E$ is reaction activation energy, $\mathrm{J} \cdot \mathrm{mol}^{-1}$;

$\mathrm{R}_{0}$ is the universal gas constant, $\mathrm{R}_{0}=8.314 \mathrm{~J} \cdot(\mathrm{mol} \cdot \mathrm{K})^{-1}$; $T$ is the exhaust temperature, $\mathrm{K}$.

(3) Composition conservation equation (Deng et al. 2017):

$$
\frac{\partial\left(\rho u Y_{\beta}\right)}{\partial x}+\frac{\partial\left(\rho v Y_{\beta}\right)}{\partial y}=-\left[\frac{\partial}{\partial x}\left(\rho S_{\beta} \frac{\partial Y_{\beta}}{\partial x}\right)+\frac{\partial}{\partial y}\left(\rho S_{\beta} \frac{\partial Y_{\beta}}{\partial y}\right)\right]+R_{\beta}
$$

Where $Y_{\beta}$ is the mass fraction of component $\beta, \% ; S_{\beta}$ is the diffusion coefficient of component $\beta, \mathrm{m}^{2} \cdot \mathrm{s}^{-1} ; R_{\beta}$ 
is the formation or consumption rate of component $\beta, \mathrm{kmol} \cdot\left(\mathrm{m}^{3} \cdot \mathrm{s}\right)^{-1}$.

Exhaust uniformity is measured by exhaust uniformity index $\gamma$ (Su et al. 2013):

$$
\gamma=1-\frac{1}{2 n} \sum_{t=1}^{n} \frac{\sqrt{\left(v_{t}-v_{m}\right)^{2}}}{v_{m}}
$$

Where $n$ is the number of carrier channels; $v_{t}$ and $v_{m}$ are respectively the velocity of channel $t$ and the average velocity of the carrier; The $\gamma$ value varies between 0 and 1.0, and the closer it is to 1.0 , the more uniform the flow will be.

No conversion rate $\eta$ (Zuo et al. 2019b):

$$
\eta=\frac{\mathrm{NO}_{\text {in }}-\mathrm{NO}_{\text {out }}}{\mathrm{NO}_{\text {in }}}
$$

Where $\mathrm{NO}_{\text {in }}$ is the quality fraction of imported $\mathrm{NO}$ and $\mathrm{NO}_{\text {out }}$ is the quality fraction of exported $\mathrm{NO}$.

The catalytic reaction mechanism of NO is shown in Table 2 (Deng et al. 2017).

Table $2 \mathrm{NO}-\mathrm{O}_{2}$ reaction mechanism

\begin{tabular}{cccc}
\hline No. & Elementary reactions & Pre-exponential $\left(\mathrm{s}^{-1}\right)$ & Activation energy $(\mathrm{kJ} / \mathrm{mol})$ \\
\hline$R_{1}$ & $\mathrm{NO}+1 / 2 \mathrm{O}_{2} \rightarrow \mathrm{NO}_{2}$ & $9 \mathrm{e}+11$ & 110.9 \\
$R_{2}$ & $\mathrm{NO}_{2} \rightarrow \mathrm{NO}+1 / 2 \mathrm{O}_{2}$ & $3.2 \mathrm{e}+12$ & 162 \\
\hline
\end{tabular}

\subsection{Simulated boundary conditions}

The computational fluid dynamics software Fluent is used to simulate the catalytic converter. In the flow and combustion models, the standard $k-\varepsilon$ model and the species transport model are selected to solve the flow and chemical reaction models respectively. The second-order upwind scheme is selected to discretize each governing equation. The residual error of energy equation is $1 \times 10^{-6}$, while the residual errors of the other equations are $1 \times 10^{-3}$ (Cai et al. 2020). The inlet temperature is $575 \mathrm{~K}$, and the inlet velocity is $10.28 \mathrm{~m} \cdot \mathrm{s}^{-1}, 6.12 \mathrm{~m} \cdot \mathrm{s}^{-1}$ and $4.93 \mathrm{~m} \cdot \mathrm{s}^{-1}$, respectively. Setting outlet boundary condition as pressure outlet.

The composition and content of the inlet exhaust are shown in Table 3 (Deng et al. 2017). 


\begin{tabular}{ccccccc}
\hline $\mathrm{NO}(\%)$ & $\mathrm{O}_{2}(\%)$ & $\mathrm{H}_{2} \mathrm{O}(\%)$ & $\mathrm{C}_{3} \mathrm{H}_{6}(\%)$ & $\mathrm{CO}(\%)$ & $\mathrm{CO}_{2}(\%)$ & $\mathrm{N}_{2}(\%)$ \\
\hline 0.08 & 1.4 & 12.31 & 0.08 & 0.35 & 26.75 & 59.03 \\
\hline
\end{tabular}
simulation results should be study. Three mesh models with different grids numbers are established, axis length of the catalytic converter is defined as $\mathrm{Z}$, and the distance from a point on the axis to the inlet is defined as $z$, then the dimensionless distance expressed as $z / Z$. The radius of the carrier is $\mathrm{R}$, and the distance from a point to the central axis is $r$, then the radius dimensionless distance is expressed as $r / \mathrm{R}$.

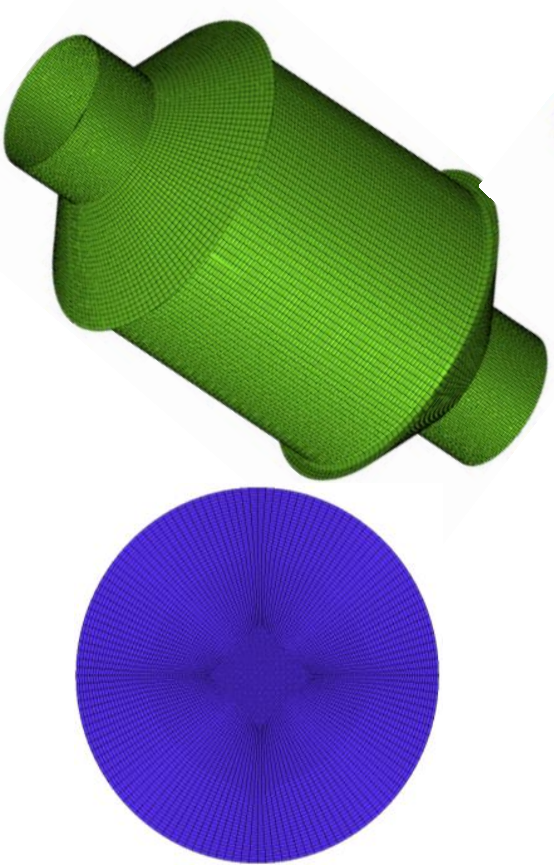

670,293

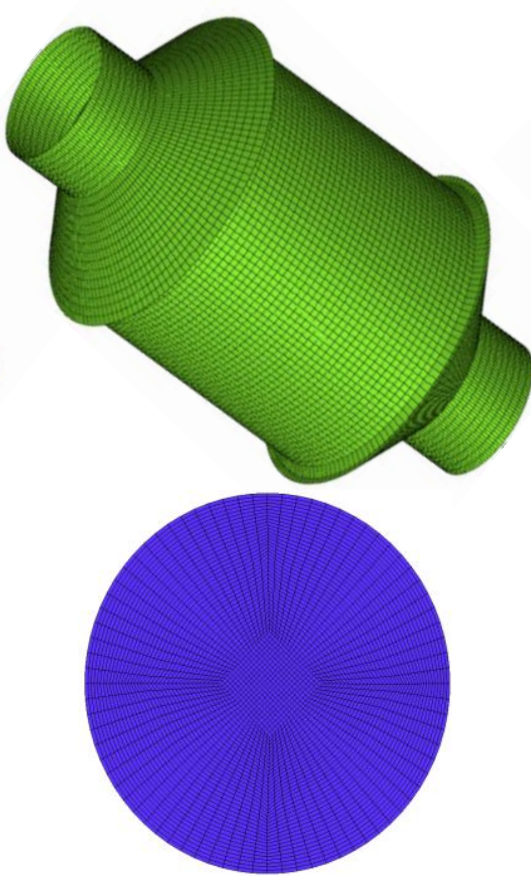

425,223

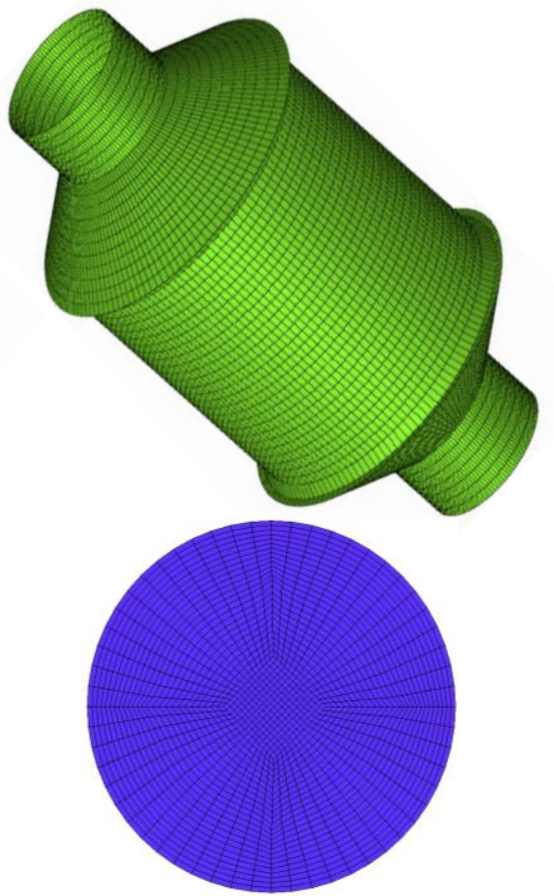

215,212

Fig. 2 Three different mesh models 
151

152

153

154

155

different mesh models are all the same, and the values differ little, all less than 5\%. Considering the calculation time and the accuracy of numerical results (Zhao et al. 2019; Tang et al. 2019), the model with 425,223 grids is adopted.

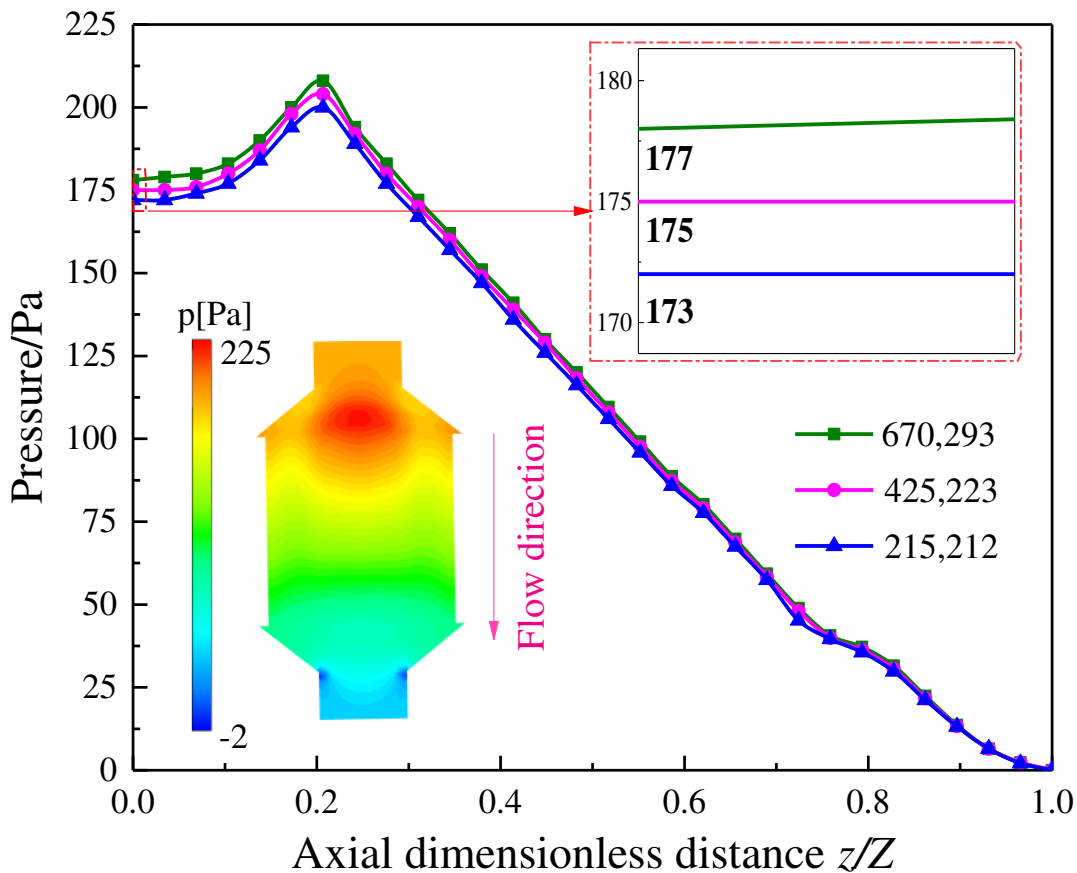

(a) Axial distribution of pressure

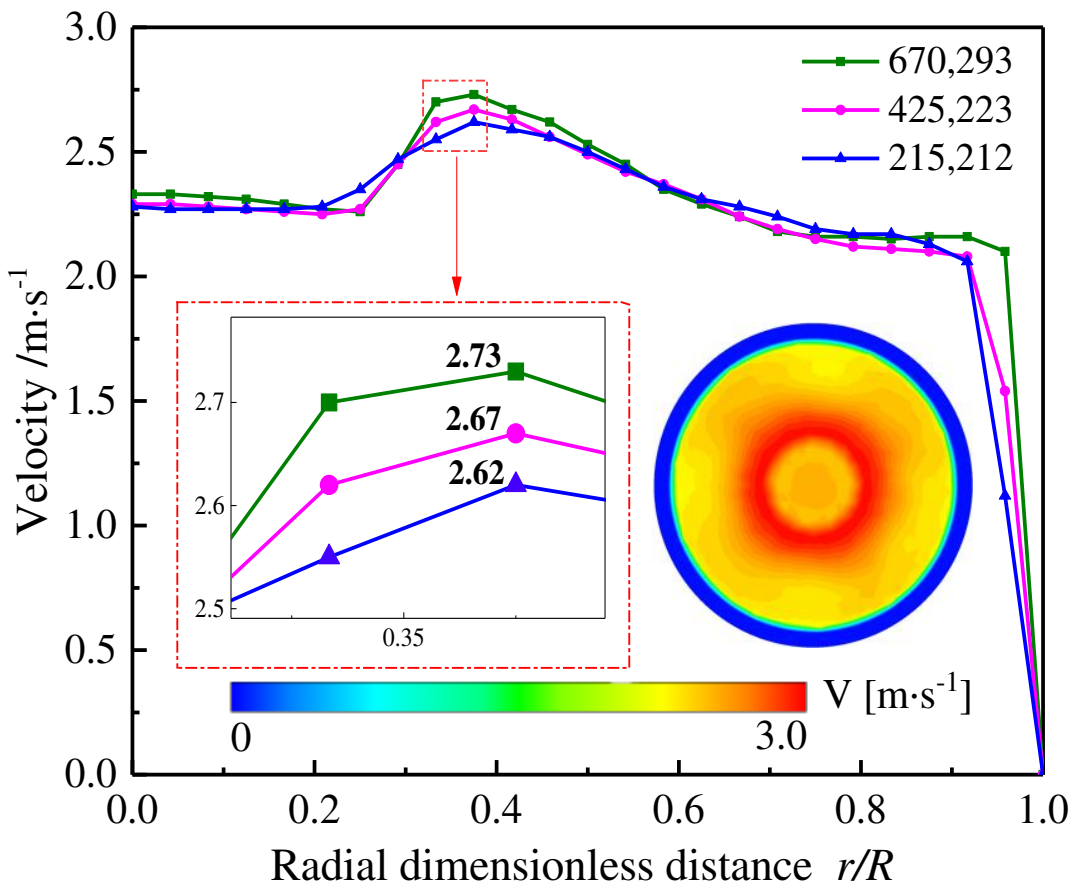

(b) Radial distribution of velocity

Fig. 3 Grid independence verification 


\subsection{Experimental verification}

To further verify the accuracy of the improved model, a bench test is conducted, as shown in Fig. 4.

The operating parameters of the gasoline engine in the experiment are shown in Table 4. The experimental ambient temperature is $288 \sim 293 \mathrm{~K}$ and the ambient pressure is $101.23 \mathrm{kPa}$.

Table. 4 Operation parameters of gasoline engine

\begin{tabular}{cccccc}
\hline Cases & Speed $\left(\mathrm{r} \cdot \mathrm{min}^{-1}\right)$ & Torque(Nm) & Power(kW) & Fuel consumption $\left(\mathrm{kg} \cdot \mathrm{h}^{-1}\right)$ & Excess air Ratio \\
\hline 1 & 2500 & 41.5 & 10.85 & 3.08 & 1.0086 \\
2 & 2500 & 30.4 & 7.95 & 2.52 & 1.0075 \\
3 & 2500 & 19.7 & 5.16 & 2.15 & 1.0213 \\
4 & 2500 & 15.6 & 4.09 & 1.89 & 1.0326 \\
5 & 2500 & 10.2 & 2.68 & 1.63 & 1.0711 \\
\hline
\end{tabular}

Fig. 4 Schematic of the experimental apparatus

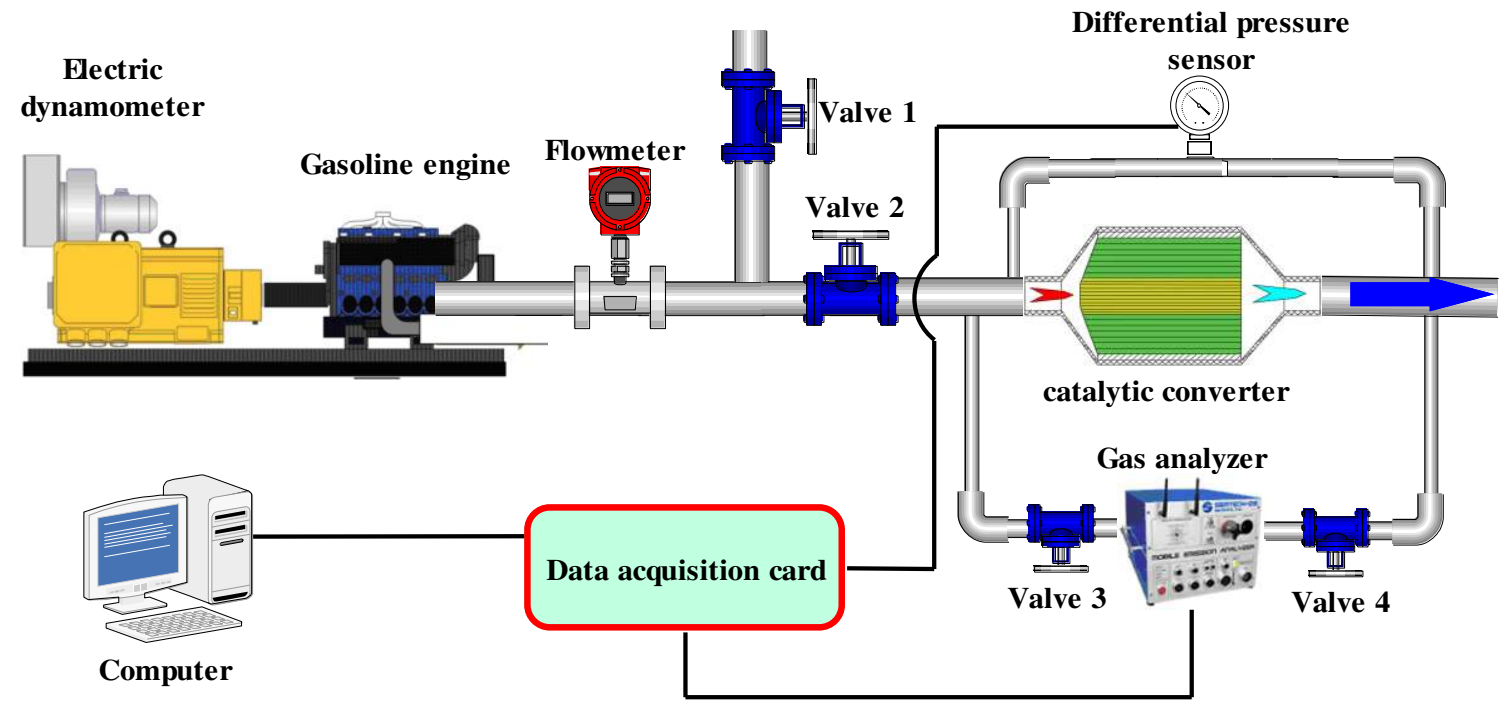

Fig. 5 shows the comparison between experimental values and simulated values under different working conditions. It can be found that the measured results of $\mathrm{NO}$ and pressure drop are in good agreement with the simulated results, and the maximum relative errors are both less than $5 \%$. Factors contributing to the error include: (1) The simulation model assumes that the flow in each group of exhaust 
169 ducts is uniform, while the actual flow in each group of exhaust ducts is not completely uniform; (2)

170 Experimental measurement error. Therefore, all the cases are considered as good calibration and provide a basis for further research.

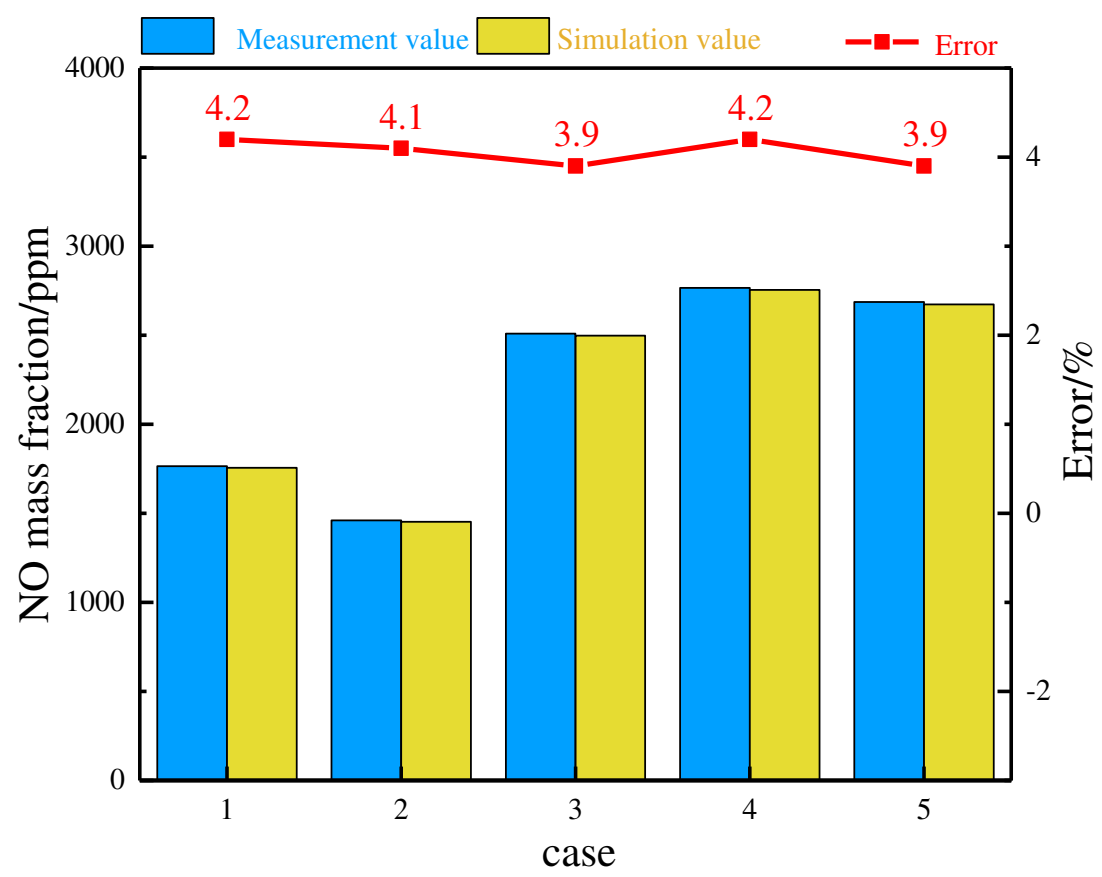

(a) NO mass fraction and error

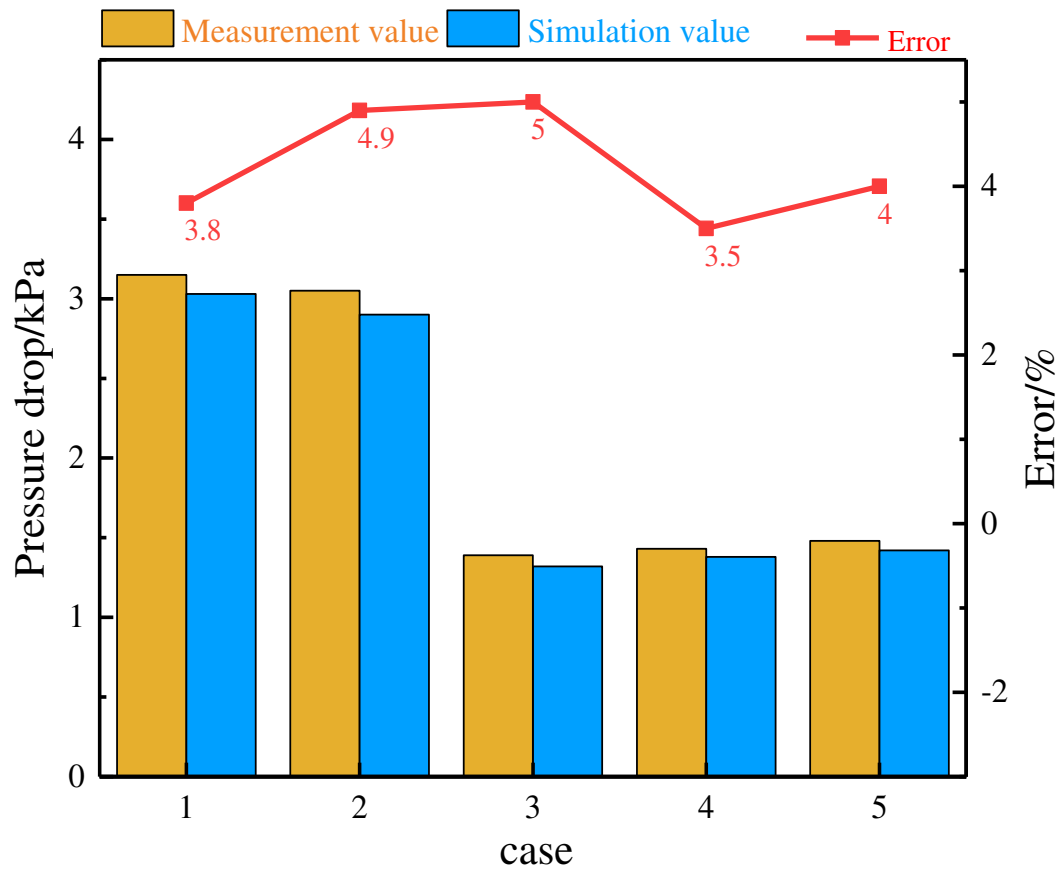

(b) Pressure drop and error

Fig. 5 Catalytic converter outlet NO mass fraction and pressure drop 


\subsection{Performance comparative analysis}

To demonstrate the flow characteristics and purification performance of the improved catalytic converter, the gas uniformity, carrier pressure drop and NO conversion rate of the standard and improved catalytic converters are compared. The carrier cell density of the standard catalytic converter is $400 \mathrm{cpsi}$, and other geometrical parameters are the same.

As can be found from Fig. 6(a), the $\gamma$ and carrier pressure drop of the improved catalytic converter are higher than those of the standard catalytic converter. Under the exhaust inlet velocity of $10.28 \mathrm{~m} \cdot \mathrm{s}^{-1}$, the $\gamma$ of the improved and standard catalytic converters are 0.9703 and 0.9060 , and the pressure drop is $177 \mathrm{~Pa}$ and $189 \mathrm{~Pa}$ respectively. The $\gamma$ and $p$ increased by 0.0643 and $6.78 \%$ respectively. Fig. 6(b) exhibits the radial distribution of the velocities. Obviously, the velocities of the standard catalytic converter decrease and change greatly along radius. The velocities of improved catalytic converter have a trend of decreasing gradually at first then increasing and finally decreasing along radius, and change small. This phenomenon is explained as follows. For standard catalytic converters, the exhaust mainly concentrates in the carrier middle and flows less to the edge under the influence of inertia. For improved catalytic converters, the resistance of the high cell density carrier is greater than that of the low cell density carrier, and the tapered end face acts as a guide to the exhaust, making more exhaust flow to the edge with less resistance. Therefore, the $\gamma$ of improved catalytic converters is higher. As the resistance of the high cell density carrier is large and the carrier has a tapered end face, which increases the resistance and leads to the increase of the carrier pressure drop of the improved catalytic converter, but the increase is small. 


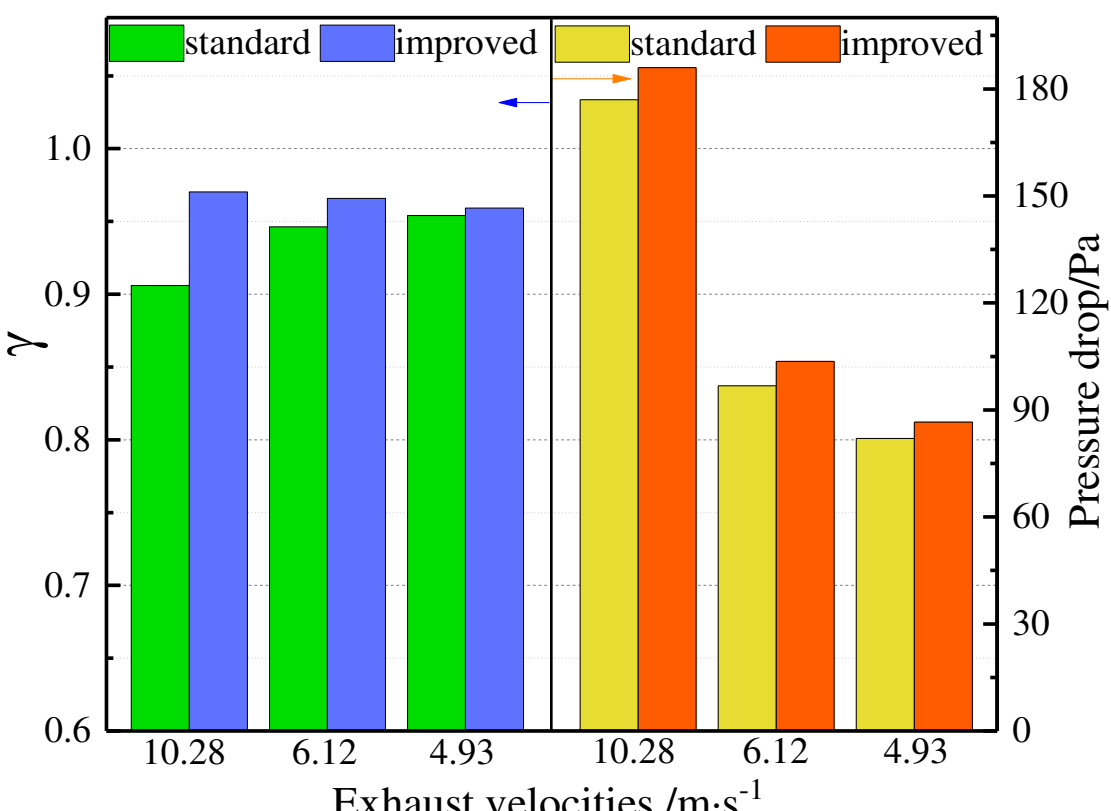

(a) Carrier pressure drop and gas uniformity under three cases

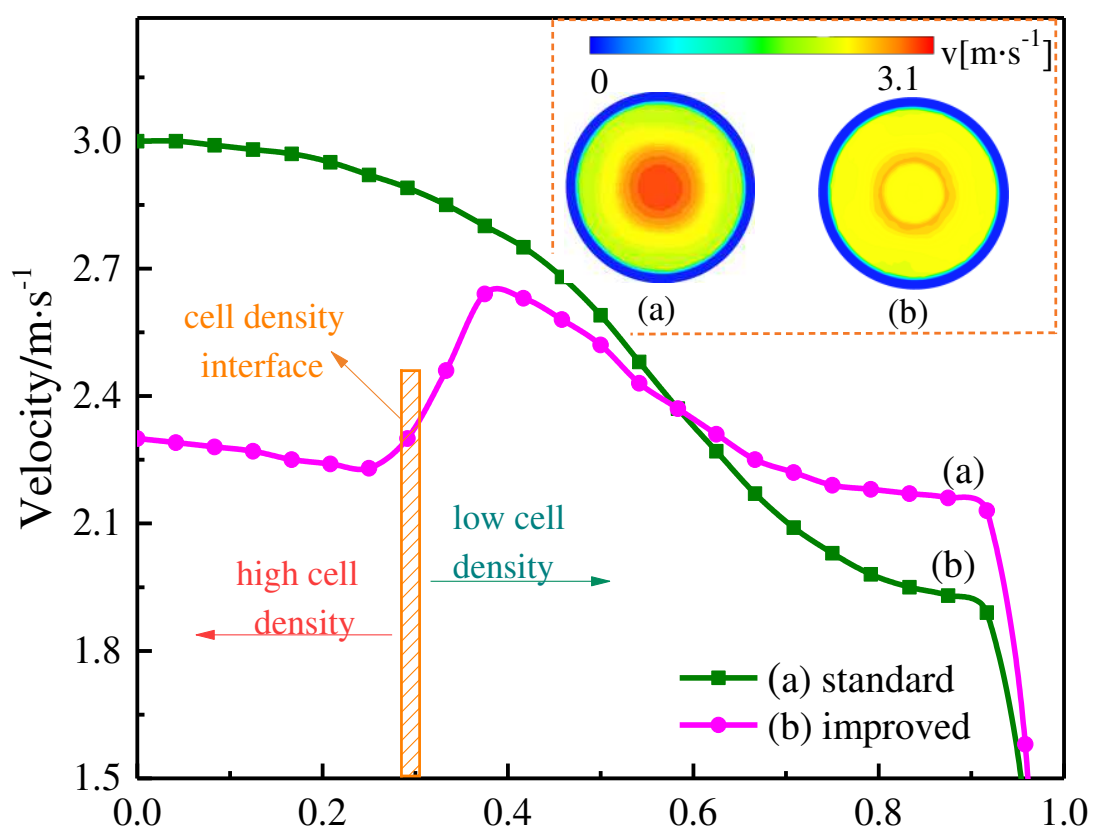

Radial dimensionless distance from centerline $r / R$

(b) Radial distribution of velocities at the carrier outlet

Fig. 6 Comparison of gas uniformity and carrier pressure drop

According to Fig. 7(a), the NO conversion rates of the improved catalytic converter are all higher than that of the standard catalytic converter. Under the exhaust inlet velocity of $10.28 \mathrm{~m} \cdot \mathrm{s}^{-1}$, the NO conversion rate of the improved catalytic converters is $73.1 \%$; compared with the traditional catalytic converter, which increases by $7.0 \%$. Fig. 7(b) shows the radial distribution of $\mathrm{NO}_{2}$ mass fraction under the exhaust inlet 
206

207

208

209 purification performance, the increase of pressure drop is not large, so it is an ideal catalytic converter.

velocity of $10.28 \mathrm{~m} \cdot \mathrm{s}^{-1}$. As can be found that the $\mathrm{NO}_{2}$ mass fraction of the standard catalytic converter increases gradually along radius, and the distribution is uneven. While the $\mathrm{NO}_{2}$ mass fraction of the improved catalytic converter tends to decrease first and then increase, and the distribution is more uniform.

This phenomenon is attributed to the following reasons. The contact probability and contact time of NO with catalyst decrease with the increase of velocity, resulting in the lower $\mathrm{NO}_{2}$ mass fraction. The velocity of standard catalytic converter decreases along the radial direction and changes greatly, which leads to the gradual increase of $\mathrm{NO}_{2}$ mass fraction and the difference is large. However, the improved catalytic converter has lower velocity and larger specific surface area, which makes NO catalysis more sufficient, leading to a higher $\mathrm{NO}_{2}$ mass fraction and more uniform distribution. Therefore, the NO conversion rate of the improved catalytic converter is higher.

In summary, the improved catalytic converter can effectively improve the flow characteristics and

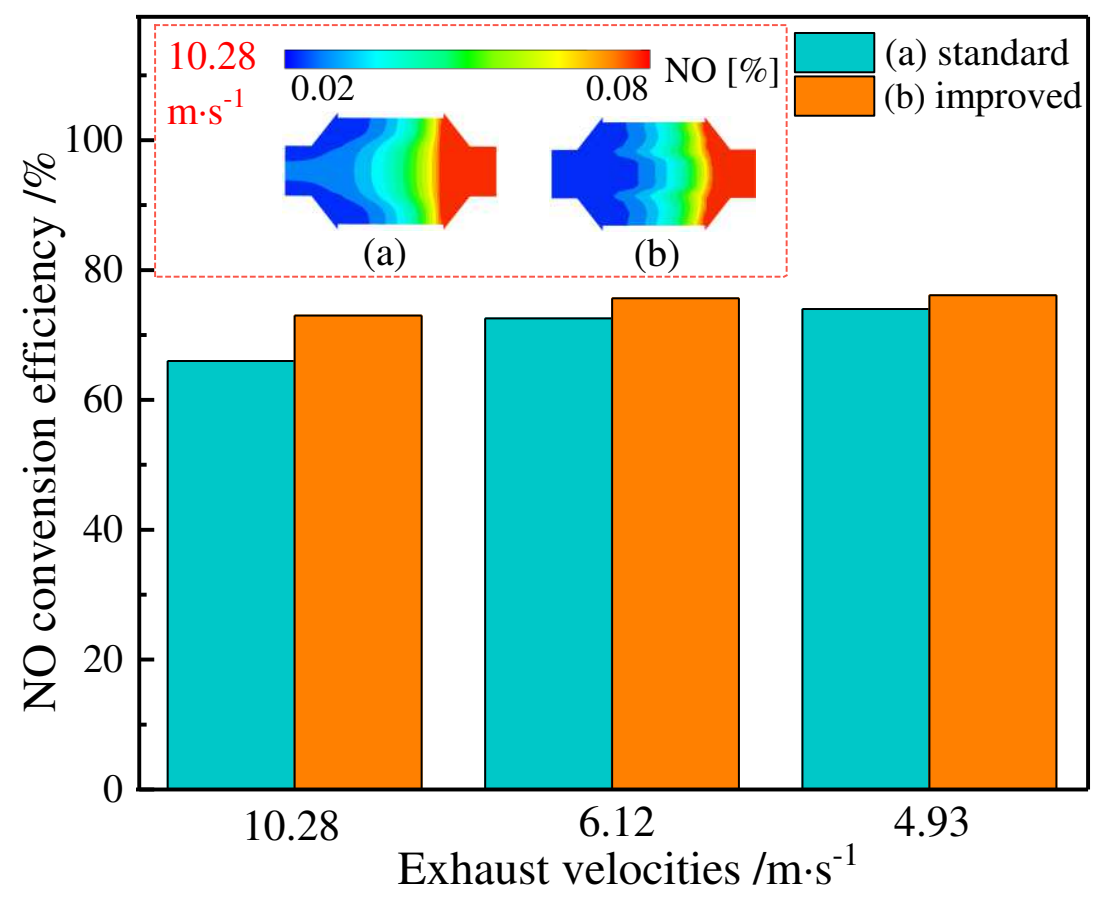

(a) NO conversion rates under three cases 


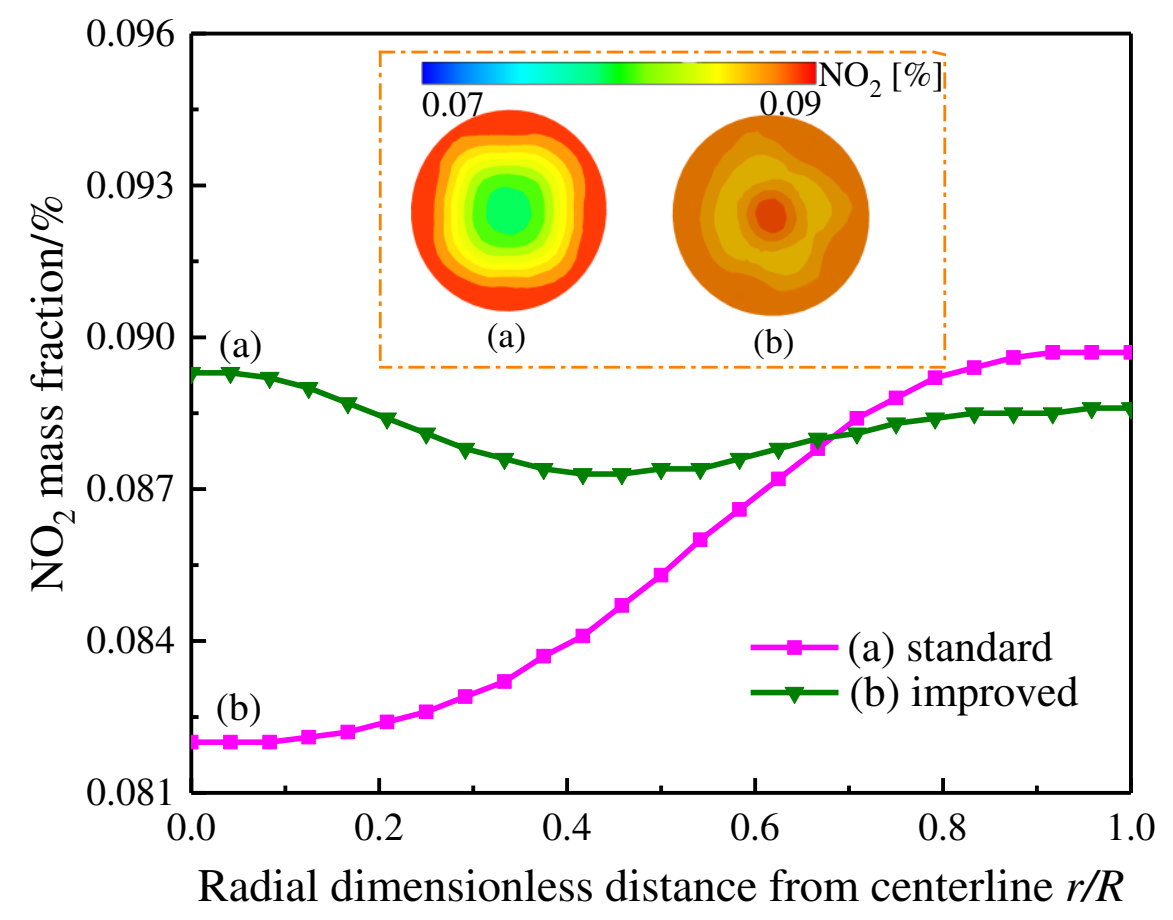

(b) Radial distribution of $\mathrm{NO}_{2}$ mass fraction at exit

Fig. 7 Comparison of $\mathrm{NO}$ conversion rate and $\mathrm{NO}_{2}$ mass fraction

\section{Results and discussion}

To design a more ideal tapered variable cell density carrier catalytic converter, the effect of structural parameters on its performance must be discussed. Compared with the standard carrier structure, the improved catalytic converter is mainly changed in the carrier inlet end face and the carrier density. Therefore, this work focuses on exploring the influence rules of cell density combination, tapered height, high cell density radius and tapered end face radius.

\subsection{Influence of cell density combination}

Keeping the other structure of the improved catalytic converter unchanged, the catalytic converters with different cell density combinations are simulated under three working conditions. The parameters of cell density combination are shown in Table $\mathbf{5}$.

Table 5 Cell density combination parameters

Cases High/Low cell density(cpsi) High/Low porosity(\%) High/Low specific surface area




\begin{tabular}{llll}
\hline 1 & $300 / 200$ & $78 / 82$ & $2411 / 2021$ \\
2 & $400 / 200$ & $85 / 82$ & $2728 / 2021$ \\
3 & $400 / 300$ & $85 / 78$ & $2728 / 2411$ \\
4 & $500 / 300$ & $72 / 78$ & $2995 / 2411$ \\
5 & $500 / 400$ & $72 / 75$ & $2995 / 2728$ \\
6 & $600 / 400$ & $70 / 75$ & $3236 / 2728$ \\
7 & $600 / 500$ & $70 / 72$ & $2728 / 2411$ \\
8 & $700 / 500$ & $67.7 / 72$ & $3429 / 2995$ \\
9 & $700 / 600$ & $67.7 / 70$ & $3429 / 3236$ \\
\hline
\end{tabular}

Fig. 8(a) shows the influence of different cell density combinations on the carrier outlet velocity under the exhaust inlet velocity of $10.28 \mathrm{~m} \cdot \mathrm{s}^{-1}$. As can be found, with the increase of radius, the velocities decrease gradually at first, then increases rapidly near the cell density interface, and then decreases again. The major reason is that most of the exhaust flows along the axial direction and less along the radial direction due to the influence of inertia, resulting in the velocity decreases along the radius. However, the carrier resistance suddenly decreases at the cell density interface, resulting in the velocity increase rapidly. It can also be found that when the high and low cell densities are different, the larger the cell density combination, the smaller the velocity variation near the cell density interface. $500 \mathrm{cpsi} / 400 \mathrm{cpsi}$ is higher than $400 \mathrm{cpsi} / 200$ cpsi, but the velocity variation of $500 \mathrm{cpsi} / 400 \mathrm{cpsi}$ is smaller than that of $400 \mathrm{cpsi} / 200 \mathrm{cpsi}$. Besides, when the low cell density is the same, the velocity variation enhances with the high cell density increases. Under the low cell density is $400 \mathrm{cpsi}$, the high cell density increases from $500 \mathrm{cpsi}$ to $600 \mathrm{cpsi}$, the velocity variation greatly. The reason is that as the cell density combination is large, the resistances of high and low cell density are both high, which makes the relative resistance difference smaller, resulting in a small velocity variation. When the low cell density is the same, the larger the high cell density, the greater the 

reduces the uniformity.

resistance difference, which leads to the bigger velocity variation.

It can be found from Fig. 8(b) that with the increase of cell density combination, $\gamma$ shows a cyclic change of decreasing first and then increasing. When the high and low cell densities are different, $\gamma$ increases gradually with the increase of cell density combination. The cell density of $700 \mathrm{cpsi} / 600 \mathrm{cpsi}$ is the highest, and its $\gamma$ reaches the highest, which is 0.9821 at the exhaust inlet velocity of $10.28 \mathrm{~m} \cdot \mathrm{s}^{-1}$. The main reason is that the higher the carrier cell density, the greater the resistance of carrier, which makes more exhaust flow to the edge and distributes more evenly. However, when the low cell density of cell density combination is the same, the smaller the high cell density, the better the gas uniformity. When the low cell density is $500 \mathrm{cpsi}, \gamma$ decreases from 0.9710 to 0.9377 when the high cell density increases from $600 \mathrm{cpsi}$ to $700 \mathrm{cpsi}$. This is because when the low cell density is the same, the higher the high cell density, the greater the resistance difference, which leads to the great variation of velocity at the cell density interface and

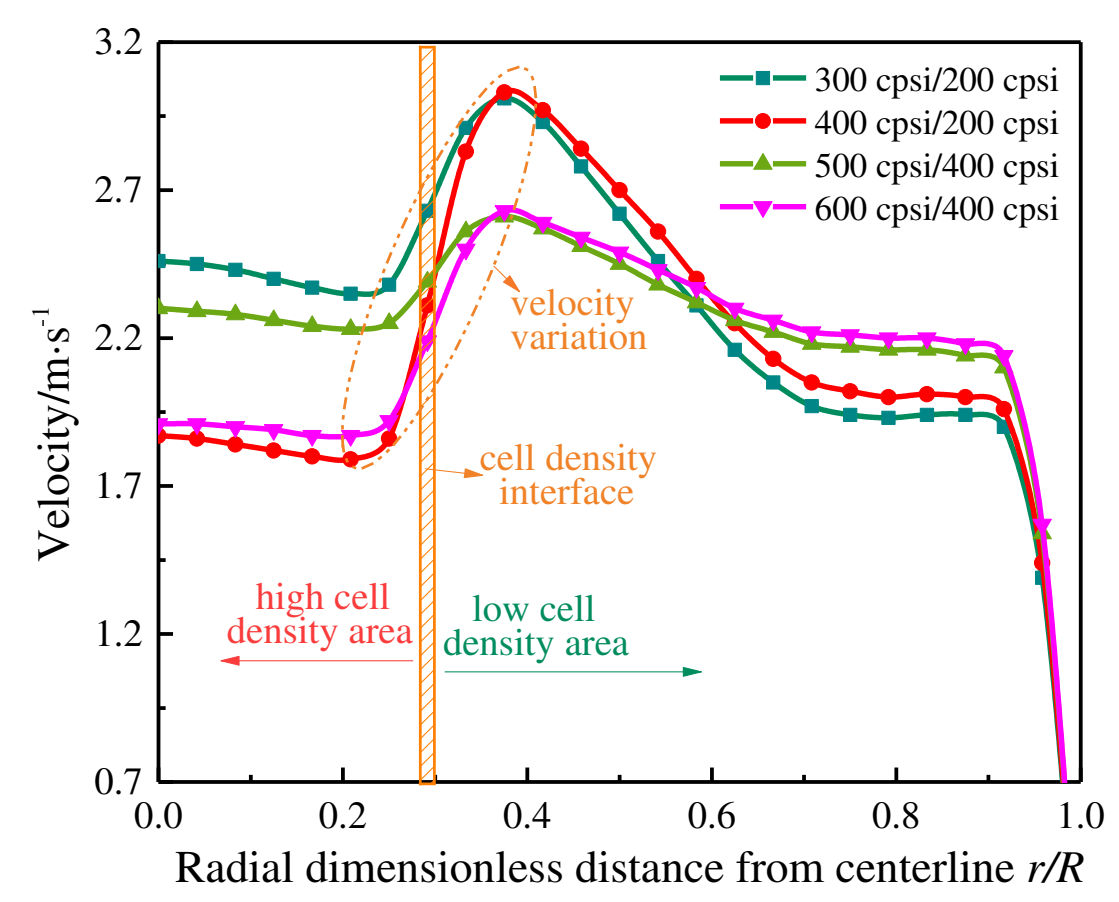

(a) Radial distribution of carrier outlet velocity 


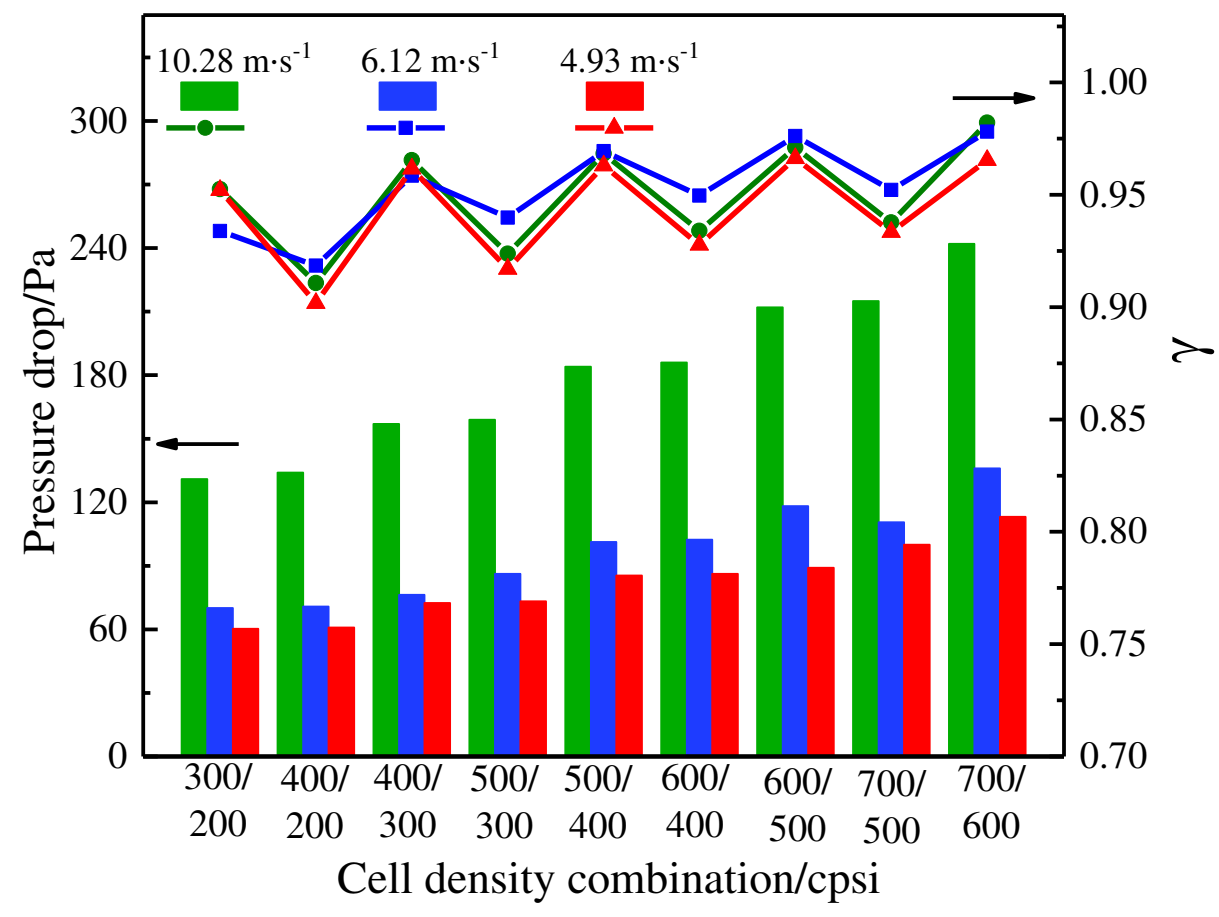

(b) Carrier pressure drop and gas uniformity

Fig. 8 Gas uniformity and carrier pressure drop

It is clear from Fig. 8(b) that the larger the cell density combination, the greater the carrier pressure

drop. When the cell density is $700 \mathrm{cpsi} / 600 \mathrm{cpsi}$, the carrier pressure drop reached the maximum value of

$232 \mathrm{~Pa}$. The reason is that the higher the cell density, the greater the resistance along the path, so that the carrier pressure drop increases.

Fig. 9(a) shows the influence of different cell density combinations on NO conversion rate under three

cases. It can be found that with the increase of cell density combination, NO conversion rate shows a cyclic the cell density increases from $400 \mathrm{cpsi} / 200 \mathrm{cpsi}$ to $700 \mathrm{cpsi} / 600 \mathrm{cpsi}$, NO conversion rate increases from $66.6 \%$ to $73.7 \%$ under the exhaust inlet velocity of $10.28 \mathrm{~m} \cdot \mathrm{s}^{-1}$. The reason is that the greater the cell density combination, the larger the specific surface area of the carrier and the smaller the velocity, which increases the contact probability and time between NO and catalyst, leads to NO conversion rate increase. However, 
when the low cell density of cell density combination is the same, NO conversion rate decreases with the high cell density increases. Under the low density is the same as $200 \mathrm{cpsi}$, when the high cell density increased from 300 cpsi to 400 cpsi, NO conversion rate fell to $66.9 \%$ from $66.6 \%$. This is because when the low cell density is the same, increasing the high cell density will cause more exhaust to flow through the low cell density region, which leads to the limitation of $\mathrm{NO}$ catalysis in the low cell density region, thus reducing NO conversion rate.

Fig. 9(b) exhibits the impact of different cell density combinations on the $\mathrm{NO}_{2}$ mass fraction at the outlet at the exhaust inlet velocity of $10.28 \mathrm{~m} \cdot \mathrm{s}^{-1}$. It can be found that when the high and low cell densities are different, the larger the cell density combination, the higher the $\mathrm{NO}_{2}$ mass fraction. The $\mathrm{NO}_{2}$ mass fraction of $600 \mathrm{cpsi} / 400 \mathrm{cpsi}$ is higher than that of $400 \mathrm{cpsi} / 200 \mathrm{cpsi}$. The reason is that the larger the cell density combination, the larger the specific surface area and the lower the velocity, which makes the NO catalysis more sufficient and the $\mathrm{NO}_{2}$ mass fraction higher.

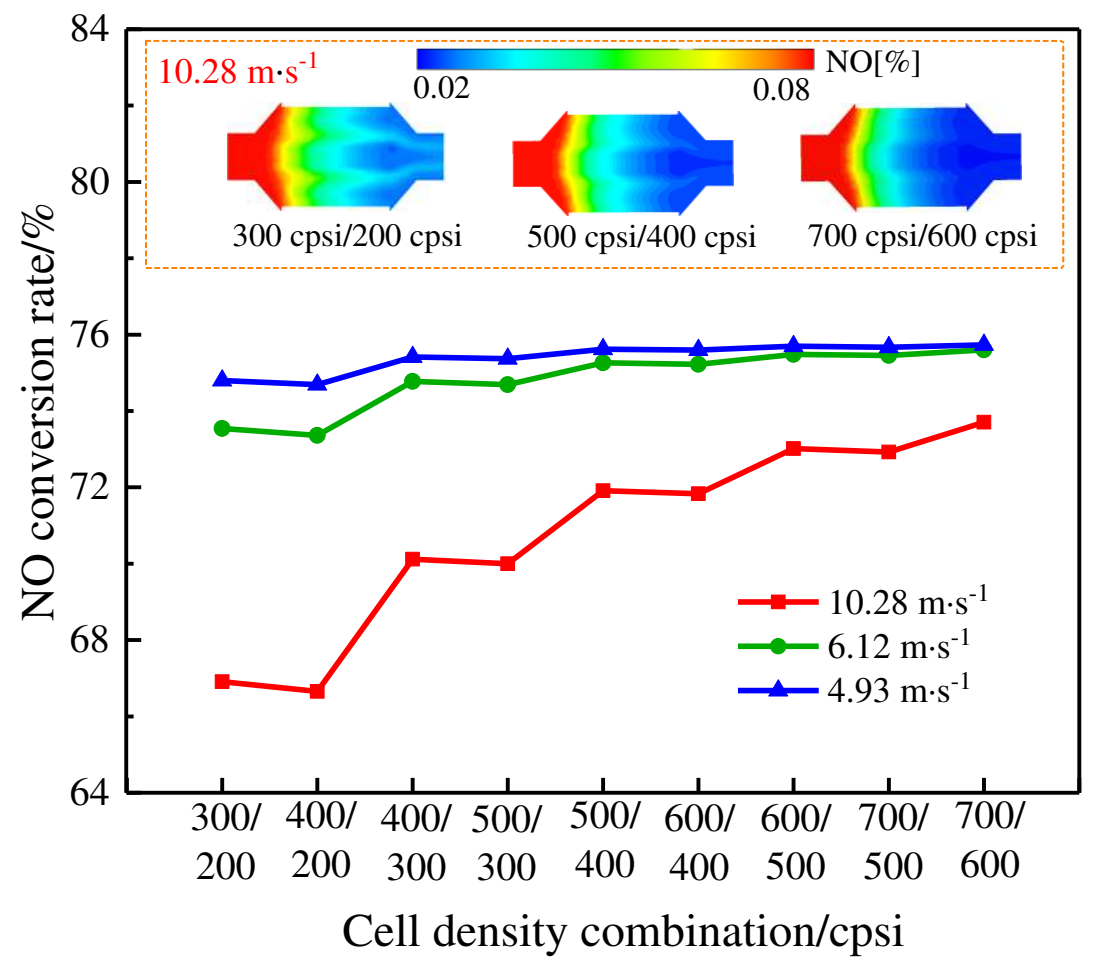

(a) NO conversion rate 


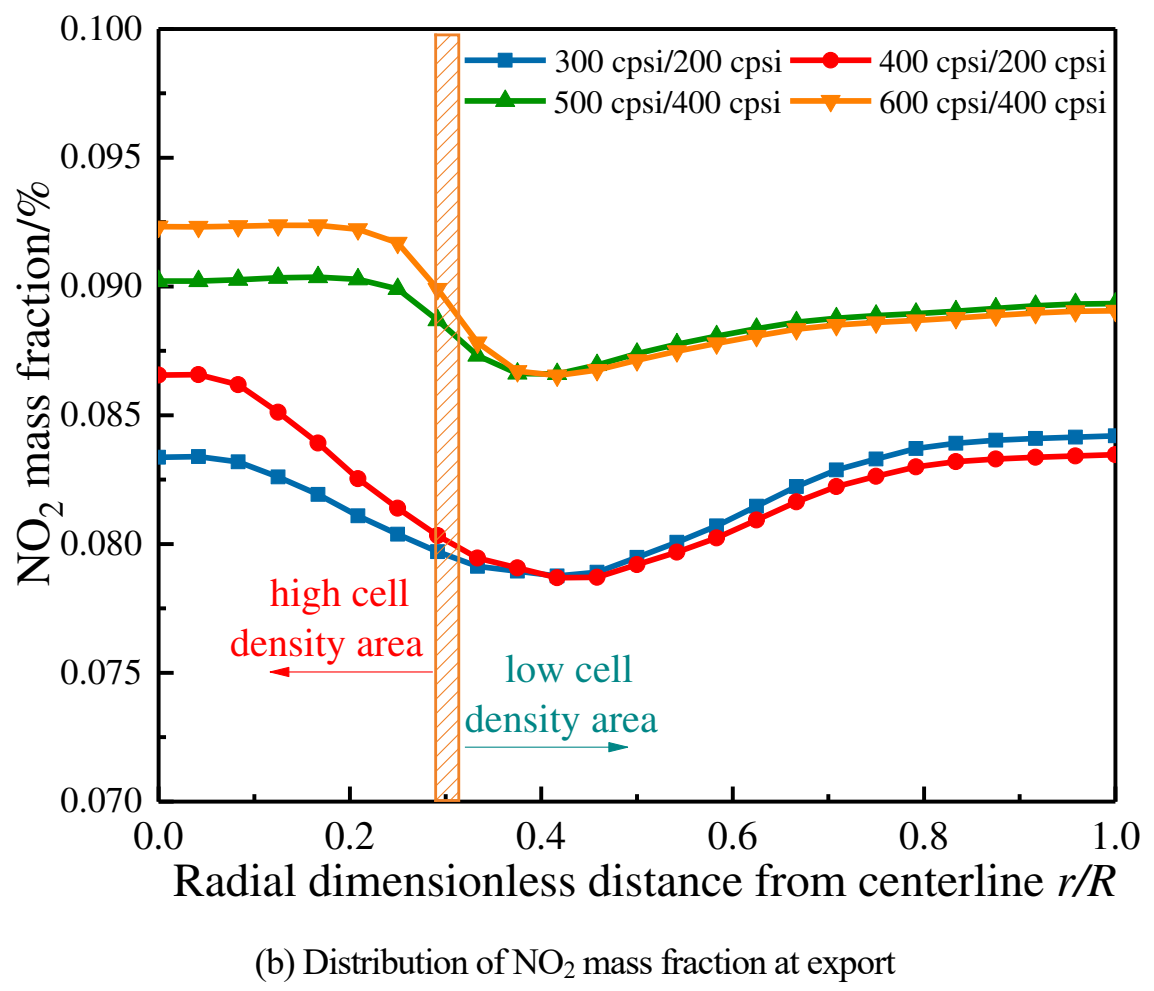

(b) Distribution of $\mathrm{NO}_{2}$ mass fraction at export

Fig. $9 \mathrm{NO}$ conversion rate and $\mathrm{NO}_{2}$ mass fraction

It can also be found from Fig. 9(b) that when the low cell density is the same, the lower the high cell

low cell density of $200 \mathrm{cpsi}$, the $\mathrm{NO}_{2}$ mass fraction of $300 \mathrm{cpsi} / 200 \mathrm{cpsi}$ is higher than that of $400 \mathrm{cpsi} / 200$

cpsi in low cell density region. This is because when the low cell density is the same, the higher the high

cell density, the higher the velocity in the low cell density area, which leads to insufficient NO catalysis and

thus lowers the $\mathrm{NO}_{2}$ mass fraction. Therefore, it is beneficial to improve the performance of catalytic

converters by appropriately increasing the cell density combination and decreasing the high cell density.

\subsection{Influence of tapered height}

Fig. 10(a) shows the influence of different tapered heights on the radial distribution of the velocity at the carrier outlet when the exhaust inlet velocity of $10.28 \mathrm{~m} \cdot \mathrm{s}^{-1}$. As can be found, when the tapered height is lower than $20 \mathrm{~mm}$, the velocity exhibits a trend of gradually decreasing first, then increasing near the cell density interface, and then decreasing gradually. However, when the tapered height is greater than $25 \mathrm{~mm}$, 
velocity decreases gradually along the radial due to the influence of inertia, and the carrier resistance decreases suddenly at the cell density interface, leading to its increase rapidly. The conductivity increases with the tapered height enhances, and when the tapered height is higher than $25 \mathrm{~mm}$, more exhaust is diverted to the edge of the carrier, resulting in a gradual increase in velocity.

Fig. 10(b) shows the influence of tapered height on gas uniformity and pressure drop under three cases. It can be found that $\gamma$ increases gradually with the tapered height enhance under the exhaust inlet velocity of $10.28 \mathrm{~m} \cdot \mathrm{s}^{-1} \cdot \gamma$ increases from 0.9544 to 0.9774 when the tapered height enhances from $5 \mathrm{~mm}$ to $25 \mathrm{~mm}$. The main reason is that when the exhaust inlet velocity is $10.28 \mathrm{~m} \cdot \mathrm{s}^{-1}$, the higher the tapered height, the greater the flow conductivity, so that more exhaust is diverted to the low cell density region, which improves the velocity in the low cell density region and the gas uniformity. However, when the exhaust inlet velocity is $6.12 \mathrm{~m} \cdot \mathrm{s}^{-1}$ and $4.93 \mathrm{~m} \cdot \mathrm{s}^{-1}, \gamma$ decreases with the increase of tapered height. The main reason is that the kinetic energy of exhaust is small, and it is easy to change the flow direction due to the guide surface, which makes the velocity in the low cell density region too high, leads to the decrease of gas uniformity.

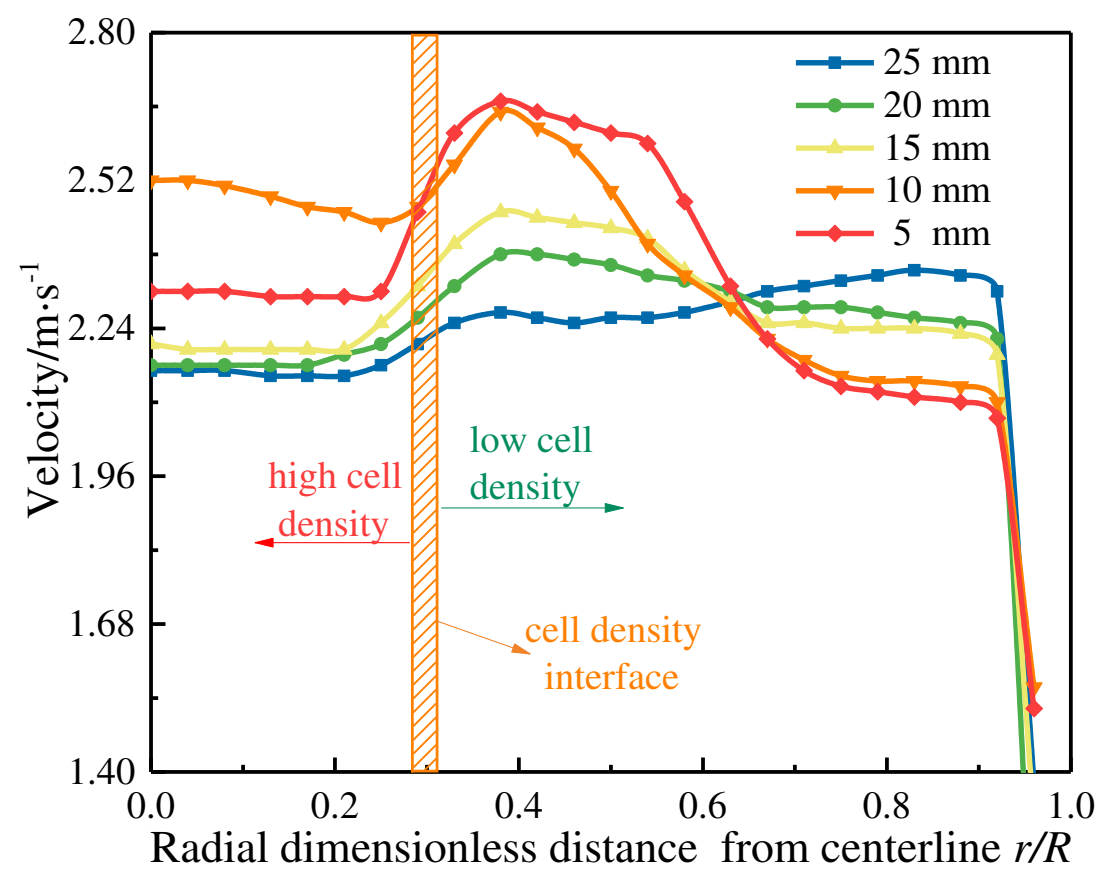

(a) Radial distribution of velocity at carrier exit 


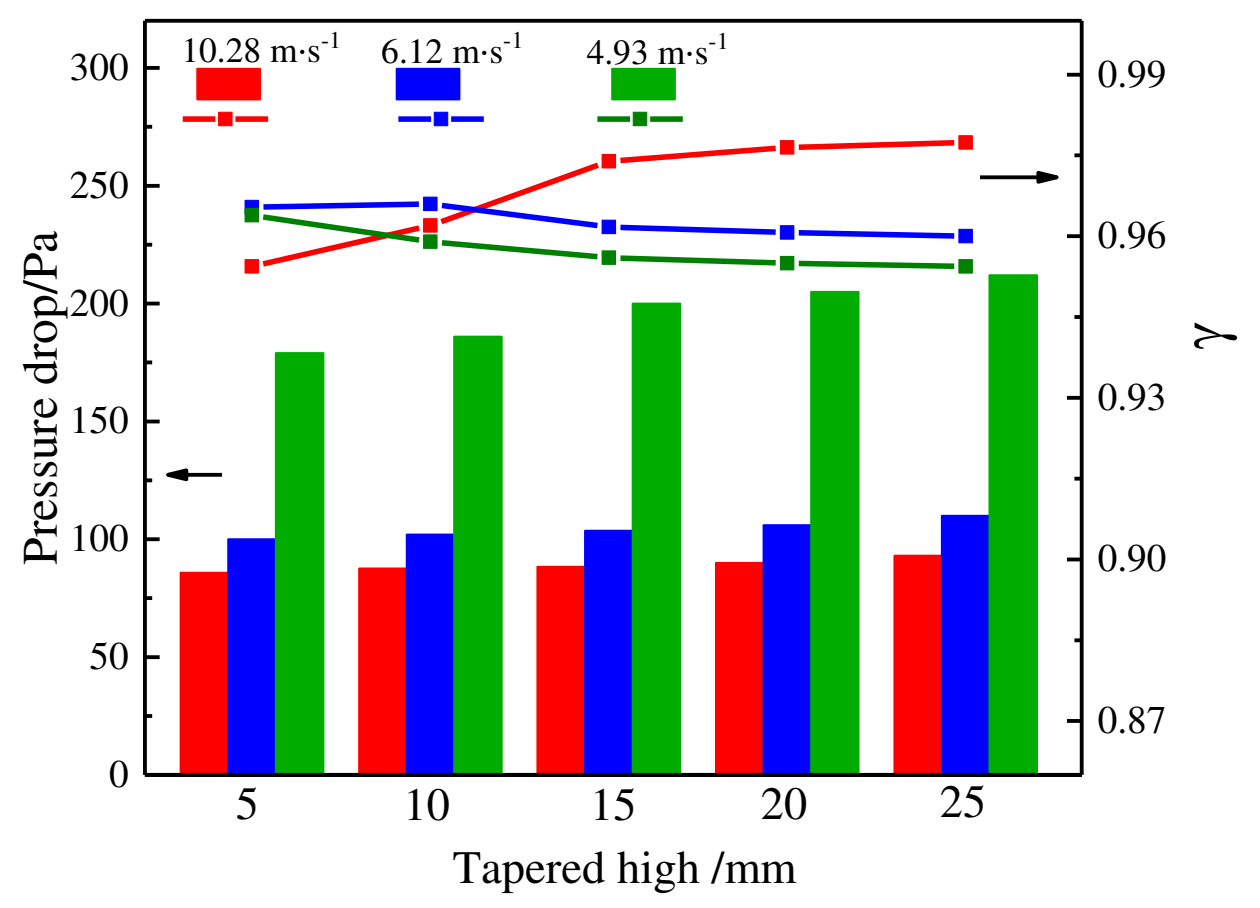

(b) Gas uniformity and carrier pressure drop

Fig. 10 Gas uniformity and carrier pressure drop

From Fig. 10(b), It can be found that the carrier pressure drop increases with the increase of tapered

height. The carrier pressure drop increases from $179 \mathrm{~Pa}$ to $212 \mathrm{~Pa}$ when the tapered height enhances from

$5 \mathrm{~mm}$ to $25 \mathrm{~mm}$ at the exhaust inlet velocity of $10.28 \mathrm{~m} \cdot \mathrm{s}^{-1}$. This is because the higher the tapered height, the larger the total carrier length, which increases the flow resistance.

Fig. 11(a) exhibits the influence of tapered height on NO conversion rate under three cases. As can be found, NO conversion rate shows a trend of gradually increasing and then decreasing with the increase of the tapered height at the exhaust inlet velocity of $10.28 \mathrm{~m} \cdot \mathrm{s}^{-1}$. As the tapered height increases from $5 \mathrm{~mm}$ to $25 \mathrm{~mm}$, NO conversion rate increases from $71.4 \%$ to $72.4 \%$ and then decreases to $72.0 \%$, and reaches the maximum at $20 \mathrm{~mm}$. The chief reason is that when the tapered height increases, the total reaction surface area of the support increases and the velocity decreases, which makes the contact probability and time between NO and catalyst increase, and leads to the NO conversion rate increases. However, when the tapered height is greater than $20 \mathrm{~mm}$, more exhaust is diverted to the low cell density area, and the velocity is high, which restricts the NO catalytic activity and decreases the NO conversion rate. It can also be found 
from Fig. 11(a) that the tapered height has little impact on the NO conversion rate when the exhaust inlet velocity is $6.12 \mathrm{~m} \cdot \mathrm{s}^{-1}$ and $4.93 \mathrm{~m} \cdot \mathrm{s}^{-1}$. This is because when the exhaust velocity is low, the contact probability and contact time between $\mathrm{NO}$ and catalyst are sufficient, and $\mathrm{NO}$ catalysis is mainly affected by temperature, which makes the change of tapered height have little impact on NO conversion rate.

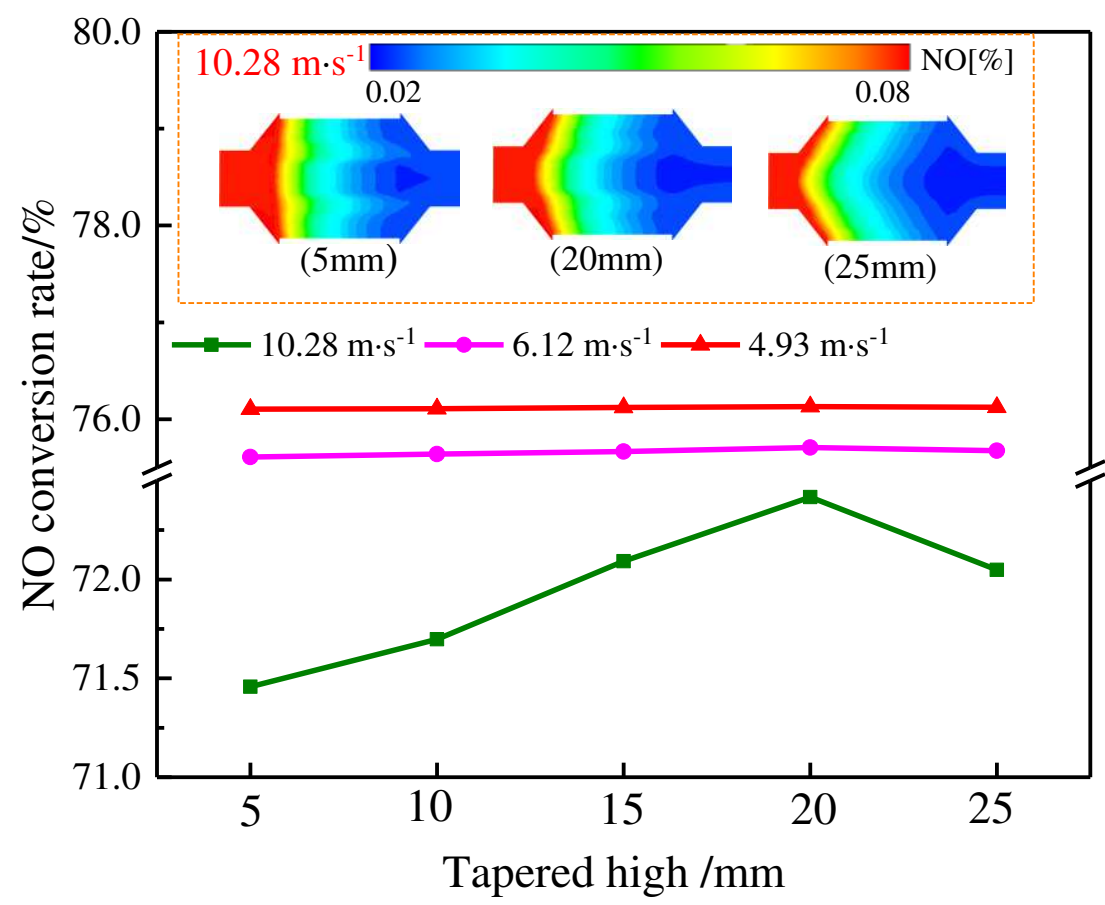

(a) $\mathrm{NO}$ conversion rate

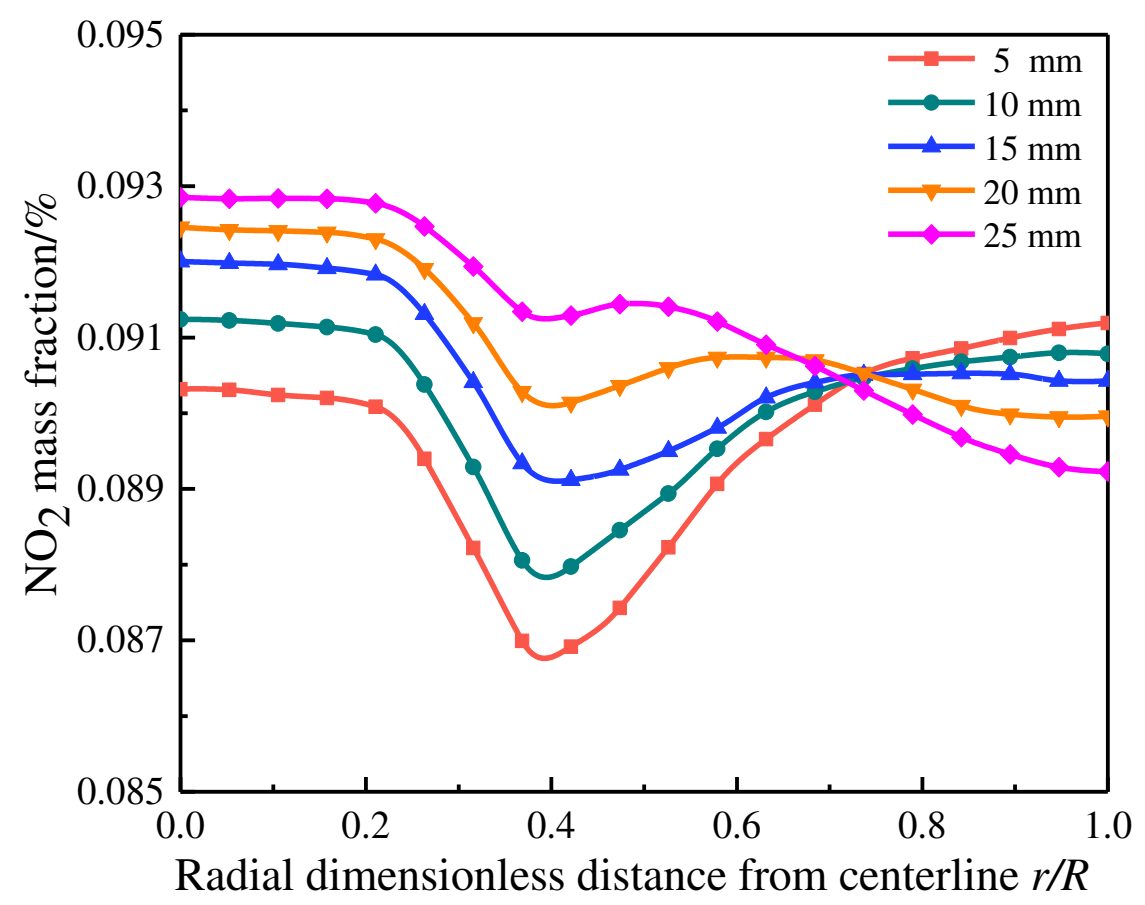

(b) Radial distribution of $\mathrm{NO}_{2}$ mass fraction at carrier outlet

Fig. $11 \mathrm{NO}$ conversion rate and $\mathrm{NO}_{2}$ mass fraction 
Fig. 11(b) shows the influence of different tapered heights on the radial distribution of $\mathrm{NO}_{2}$ mass fraction at the outlet at the exhaust inlet velocity of $10.28 \mathrm{~m} \cdot \mathrm{s}^{-1}$. It can be found that when the tapered heights are less than $15 \mathrm{~mm}$, the $\mathrm{NO}_{2}$ mass fraction decreases and then increases along the radial direction of the outlet. However, when the tapered heights are higher than $20 \mathrm{~mm}$, the $\mathrm{NO}_{2}$ mass fraction decreases, then increases and finally decreases. The reason is that when the tapered height is less than $15 \mathrm{~mm}$, the velocity increases rapidly near the cell density interface and then decreases gradually, which makes the contact probability and contact time between NO and catalyst decrease gradually and then increase gradually, resulting in the $\mathrm{NO}_{2}$ mass fraction decreasing first and then increasing gradually. However, as the tapered height is higher than $20 \mathrm{~mm}$, more exhaust is guided to the edge, which leads to the limitation of NO catalysis in the edge area and the lower $\mathrm{NO}_{2}$ mass fraction.

\subsection{Influence of high cell density radius}

Fig. 12(a) shows the influence of high cell density radius on the radial distribution of carrier outlet velocity at the exhaust inlet velocity of $10.28 \mathrm{~m} \cdot \mathrm{s}^{-1}$. As shown in Fig. 12(a), the exhaust velocity shows a trend of first gradually decreasing, then increasing and finally decreasing along the radius. The reason is the same as the explanation of Fig. 8(a). It can be found that the velocity at the edge increases as the high cell density radius increases. The maximum velocity at the edge increases from $2.1 \mathrm{~m} \cdot \mathrm{s}^{-1}$ to $2.4 \mathrm{~m} \cdot \mathrm{s}^{-1}$ as the high cell density radius enhances from $15 \mathrm{~mm}$ to $35 \mathrm{~mm}$. This is because the larger the high cell density radius, the more exhaust flows to the low cell density area with less resistance, and the velocity increases. Therefore, the velocity at the edge should be appropriately reduced as the high cell density radius is $25 \mathrm{~mm}$

Fig. 12(b) shows the influence of high cell density radius on gas uniformity and carrier pressure drop under three cases. It can be found that $\gamma$ increases at first and then decreases with the increase of high cell density radius at the exhaust inlet velocity of $10.28 \mathrm{~m} \cdot \mathrm{s}^{-1}$. As the high cell density radius enhances from 5 $\mathrm{mm}$ to $35 \mathrm{~mm}, \gamma$ increases from 0.9442 to 0.9783 and then decreases to 0.9720 , and reaches the maximum 
at $25 \mathrm{~mm}$. The reason is that when the high cell density radius area is small, the velocity of the low cell density area changes greatly. On the contrary, the velocity changes greatly in the region with high cell density, thus reducing the flow field uniformity. It can also be found that the closer the high cell density radius is to $25 \mathrm{~mm}$, the lower the $\gamma$ under the exhaust inlet velocity of $6.12 \mathrm{~m} \cdot \mathrm{s}^{-1}$ and $4.93 \mathrm{~m} \cdot \mathrm{s}^{-1}$. The reason is that the kinetic energy of exhaust is small and the velocity is easily disturbed. When the high cell density radius is $25 \mathrm{~mm}$, the change of velocity caused by the change of cell density has a large influence range, thus reducing the uniformity.

It can also be found from Fig. 12(b) that the carrier pressure drop increases with the high cell density radius enhance. The carrier pressure drop increases from $182 \mathrm{~Pa}$ to $198 \mathrm{~Pa}$ as the high cell density radius increases from $5 \mathrm{~mm}$ to $25 \mathrm{~mm}$ under the exhaust inlet velocity of $10.28 \mathrm{~m} \cdot \mathrm{s}^{-1}$. This is because the larger the high cell density radius, the greater the resistance of the carrier along the path, which increases the pressure drop.

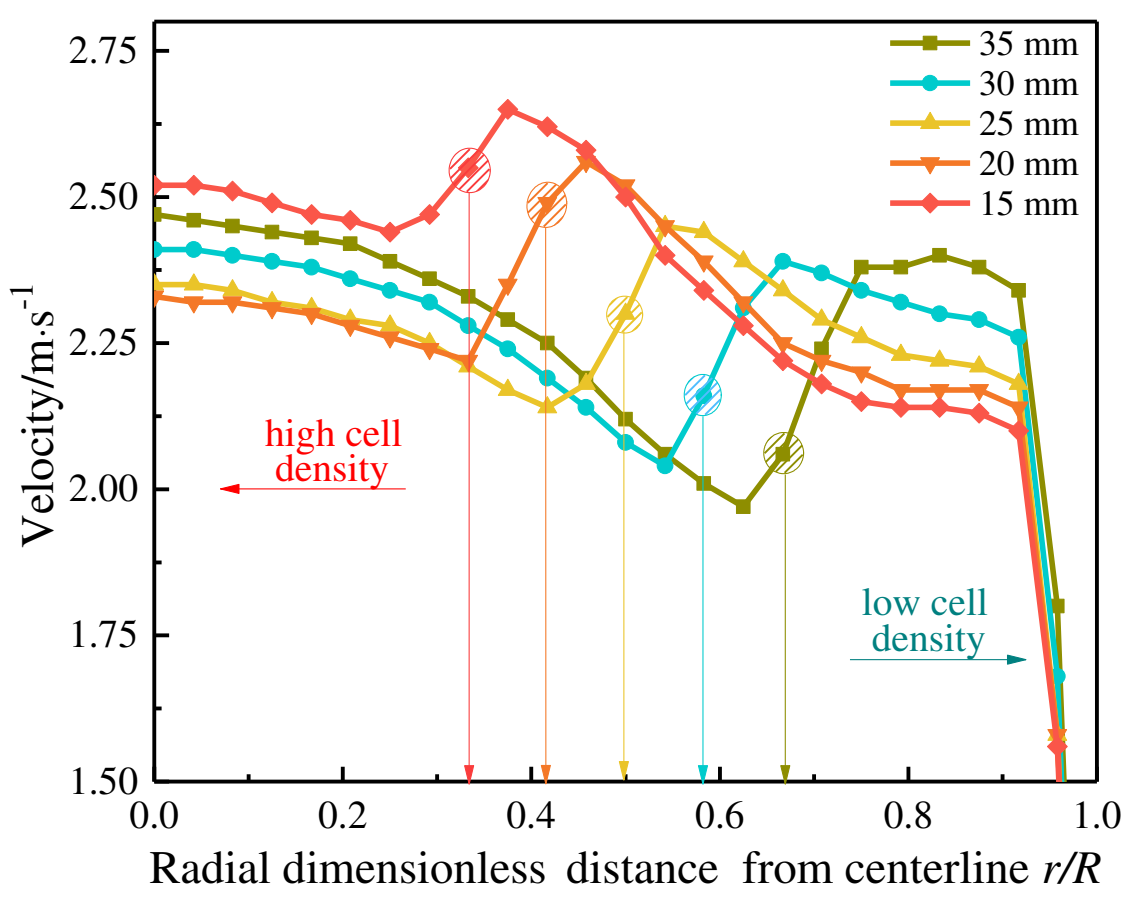

(a) Radial distribution of velocity at carrier exit 


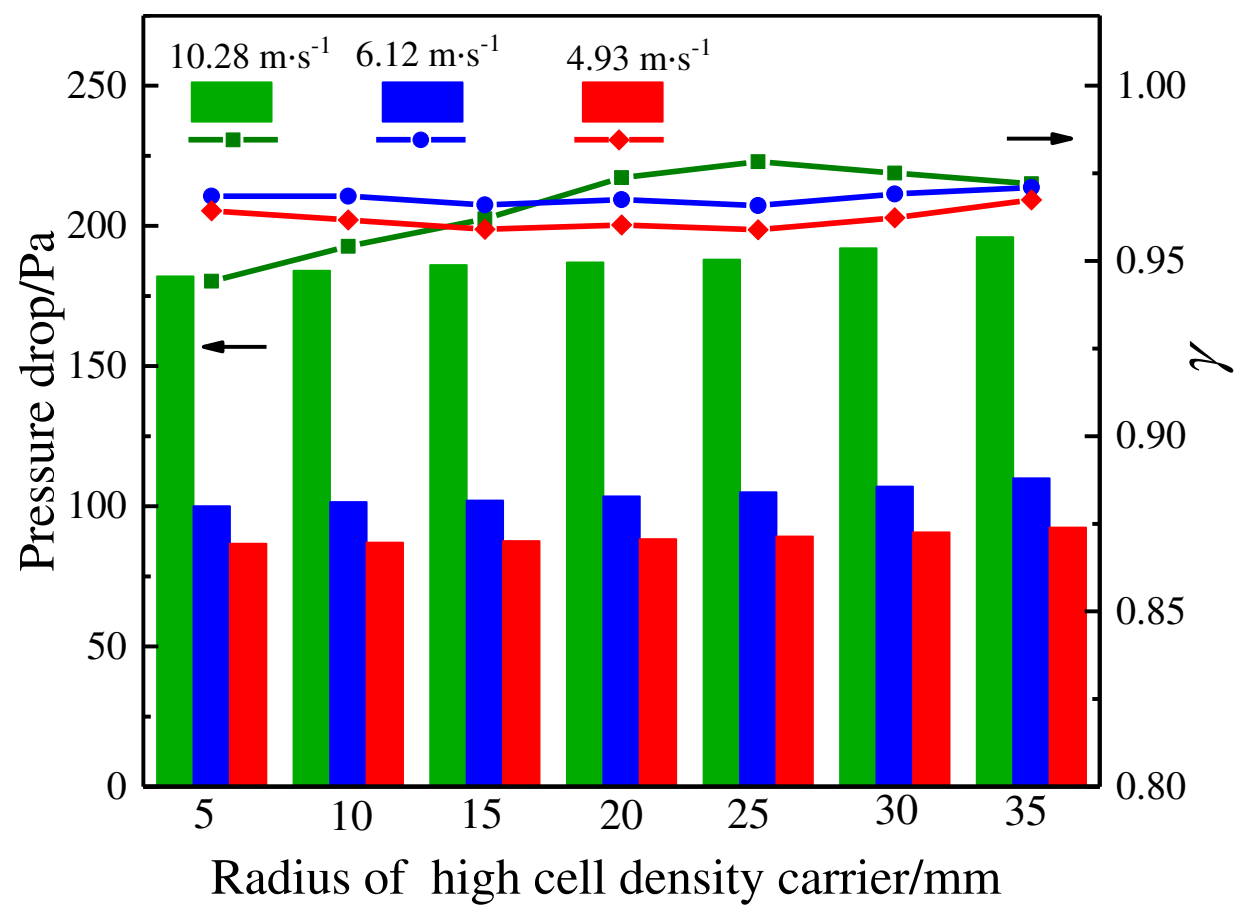

(b) Gas uniformity and carrier pressure drop

Fig. 12 Gas uniformity and carrier pressure drop

The influence of high cell density radius on NO conversion rate under three cases is shown in Fig. 13(a). As can be found, NO conversion rate increases first and then decreases with the high cell density radius increase. NO conversion rate increases from $71.4 \%$ to $72.1 \%$ and then decreases to $71.5 \%$ as the high cell density radius enhances from $5 \mathrm{~mm}$ to $35 \mathrm{~mm}$ at the inlet velocity of $10.28 \mathrm{~m} \cdot \mathrm{s}^{-1}$, and reaches the maximum value at $20 \mathrm{~mm}$. This issue is explained as follows. When the high cell density radius is small, the velocity is large in the region of high cell density and near the cell density interface, which restricts NO catalysis in this region. However, when the high cell density radius is larger, the velocity is larger in the area of low cell density, which leads to insufficient NO catalysis in this area, thus reducing the NO conversion rate. The velocity is more uniform when the high cell density radius is $20 \mathrm{~mm}$, and the overall catalysis of $\mathrm{NO}$ is more sufficient.

Fig. 13(b) shows the influence of different high cell density radius on the radial distribution of $\mathrm{NO}_{2}$ at the outlet under the exhaust inlet velocity of $10.28 \mathrm{~m} \cdot \mathrm{s}^{-1}$. It is obvious that when the high cell density radius 
399

400

401

402

403

404

405

406

407

408

409

is less than $10 \mathrm{~mm}$, the $\mathrm{NO}_{2}$ mass fraction exhibits a trend of gradually decreasing and then increasing,

which is small in the area of dimensionless radius from 0 to 0.65 . However, when the high cell density radius is greater than $30 \mathrm{~mm}$, the $\mathrm{NO}_{2}$ mass fraction shows a trend of gradually increasing and then decreasing, and it is small in the area of dimensionless radius from 0.65 to 1 . This phenomenon is explained for the following reasons. When the high cell density radius is small, the velocity is large in the region of high cell density and the cell density interface, which makes the $\mathrm{NO}_{2}$ mass fraction small in the region of dimensionless radius from 0 to 0.65 . However, when the high cell density radius is larger, the velocity is larger in the region of low cell density, resulting in a lower $\mathrm{NO}_{2}$ mass fraction in the region from 0.65 to 1.

The radial distribution of $\mathrm{NO}_{2}$ mass fraction is higher, and more uniform when the high cell density radius is $20 \mathrm{~mm}$, and the NO conversion rate is higher. Therefore, the high cell density radius of $20 \mathrm{~mm}$ is selected, the NO conversion rate is the highest, the gas uniformity is higher.

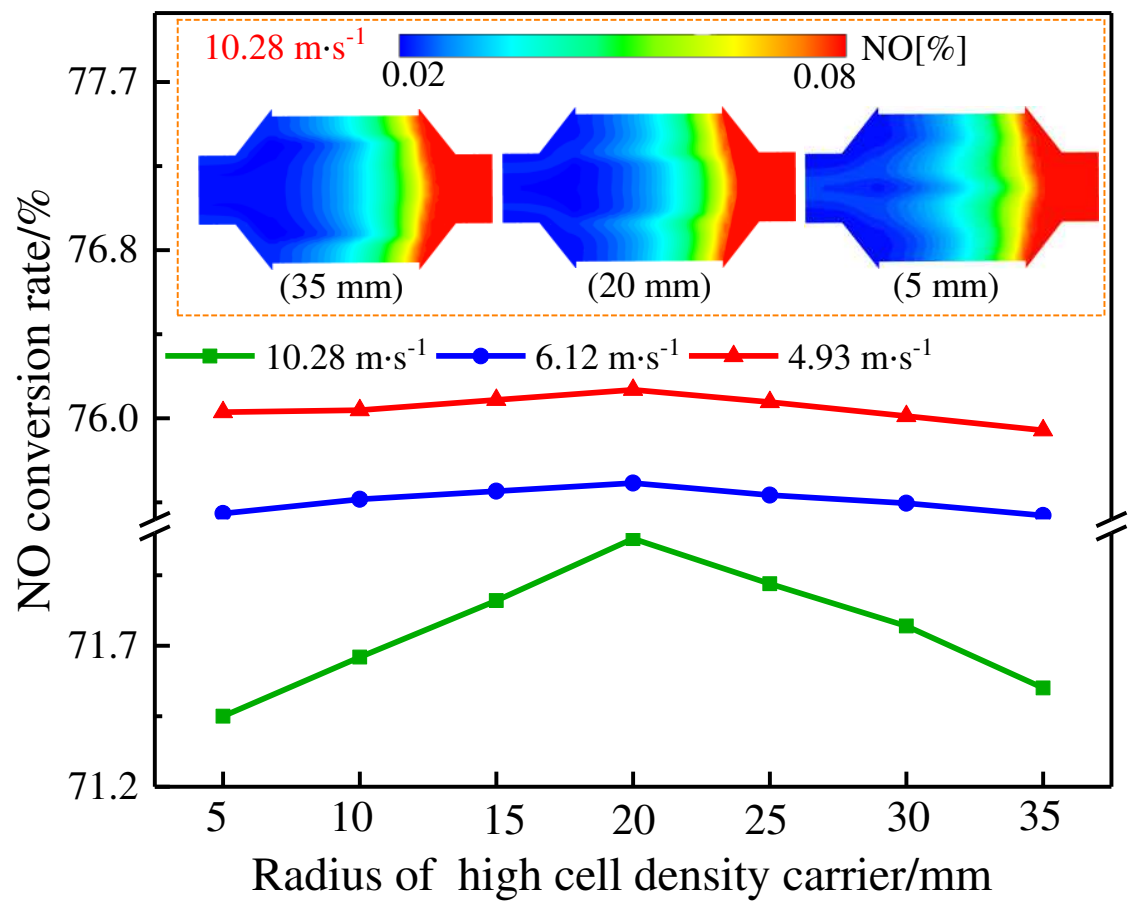

(a) $\mathrm{NO}$ conversion rate 


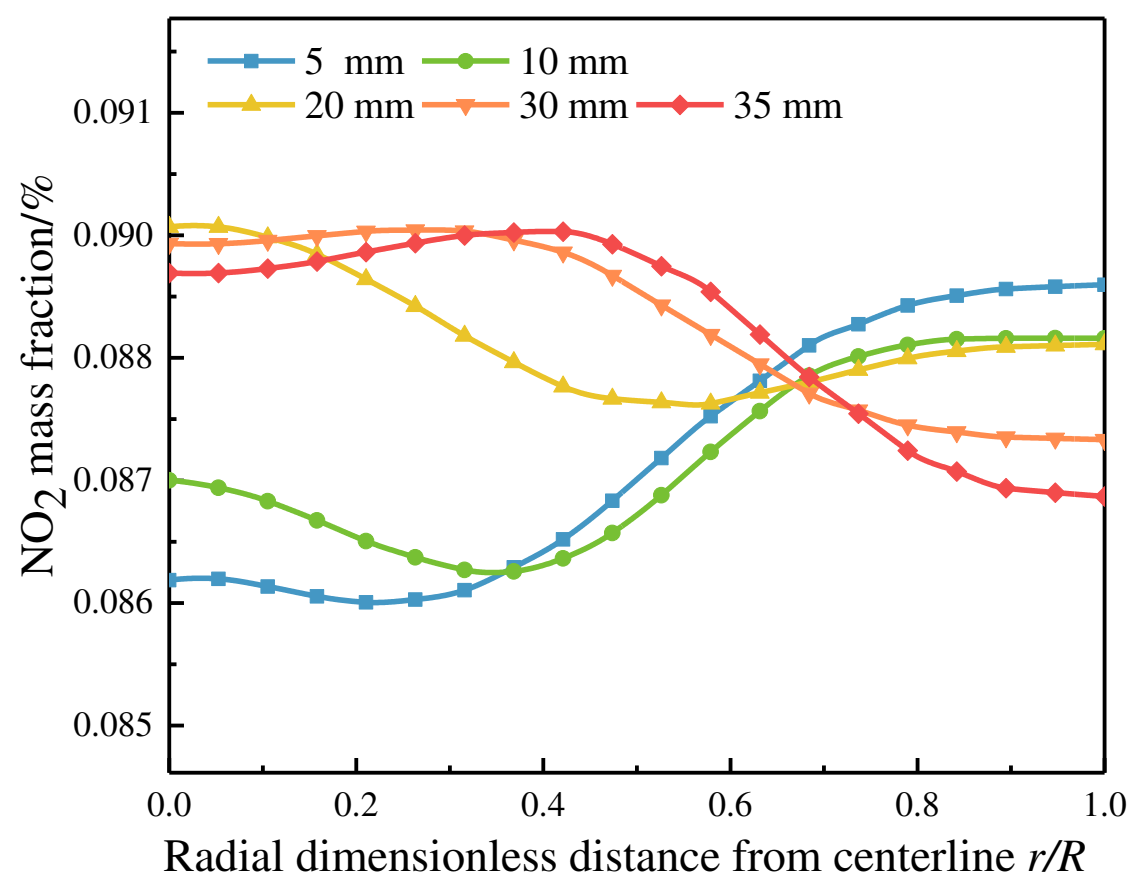

(b) Radial distribution of $\mathrm{NO}_{2}$ mass fraction at the outlet

Fig. $13 \mathrm{NO}$ conversion rate and $\mathrm{NO}_{2}$ mass fraction

\subsection{Influence of tapered end face radius}

Fig. 14(a) shows the influence of different tapered end face radius on the radial distribution of the velocity at carrier outlet under the exhaust inlet velocity of $10.28 \mathrm{~m} \cdot \mathrm{s}^{-1}$. It is obvious that, when the tapered end face radius is greater than $30 \mathrm{~mm}$, the velocity in the low cell density area decreases first and then increases, and the change is large. However, when the tapered end face radius is less than $10 \mathrm{~mm}$, the velocity decreases and the change is larger, which is smaller at the edge. This phenomenon is mainly caused by the following reasons. The larger the tapered end face radius, the closer the conduction position of the tapered to the edge and the greater the conduction capacity. When the tapered end face radius is $30 \mathrm{~mm}$ (the dimensionless radius is 0.6 ), the conductivity of the tapered surface is strong, which makes the velocity of the area after the dimensionless radius 0.6 increase rapidly and the change gradient is large. When the tapered end face radius is $10 \mathrm{~mm}$ (the dimensionless radius is 0.2 ), the conductivity of the tapered surface is weak, so that the velocity decreases gradually after the dimensionless radius is 0.2 , and it is low at the 
edge. When the tapered end face radius is $25 \mathrm{~mm}$, the diversion intensity is moderate and the velocity distribution is uniform.

The influence of tapered end face radius on gas uniformity and carrier pressure drop under three cases is shown in Fig. 14(b). It is obvious that $\gamma$ increases first and then decreases with the tapered end face radius increases. When the exhaust inlet velocity is $10.28 \mathrm{~m} \cdot \mathrm{s}^{-1}, \gamma$ increased from 0.9500 to 0.9784 and then decreased to 0.9651 as the tapered end face radius increased from $5 \mathrm{~mm}$ to $35 \mathrm{~mm}$, and reached the maximum at $25 \mathrm{~mm}$. The main reason is illustrated by Fig. 14(a): When the tapered end face radius is large, the velocity increases first and then decreases in the low cell density region, which changes greatly; When the tapered end face radius is small, the velocity at the edge is small, thus affecting the gas uniformity. The velocity distribution is more uniform when the tapered end face radius is about $25 \mathrm{~mm}$. As can be found from Fig. 14(b), the carrier pressure drop gradually increases with the tapered end face radius increases, but the influence is small. The carrier pressure drop increases from $186 \mathrm{~Pa}$ to $189 \mathrm{~Pa}$ when the tapered end face radius increases from $5 \mathrm{~mm}$ to $35 \mathrm{~mm}$. The main reason is that increasing the tapered end face radius will increase a small part of the carrier, but the flow through the area with high cell density and the area with low cell density is basically unchanged, leading to the resistance being basically unchanged.

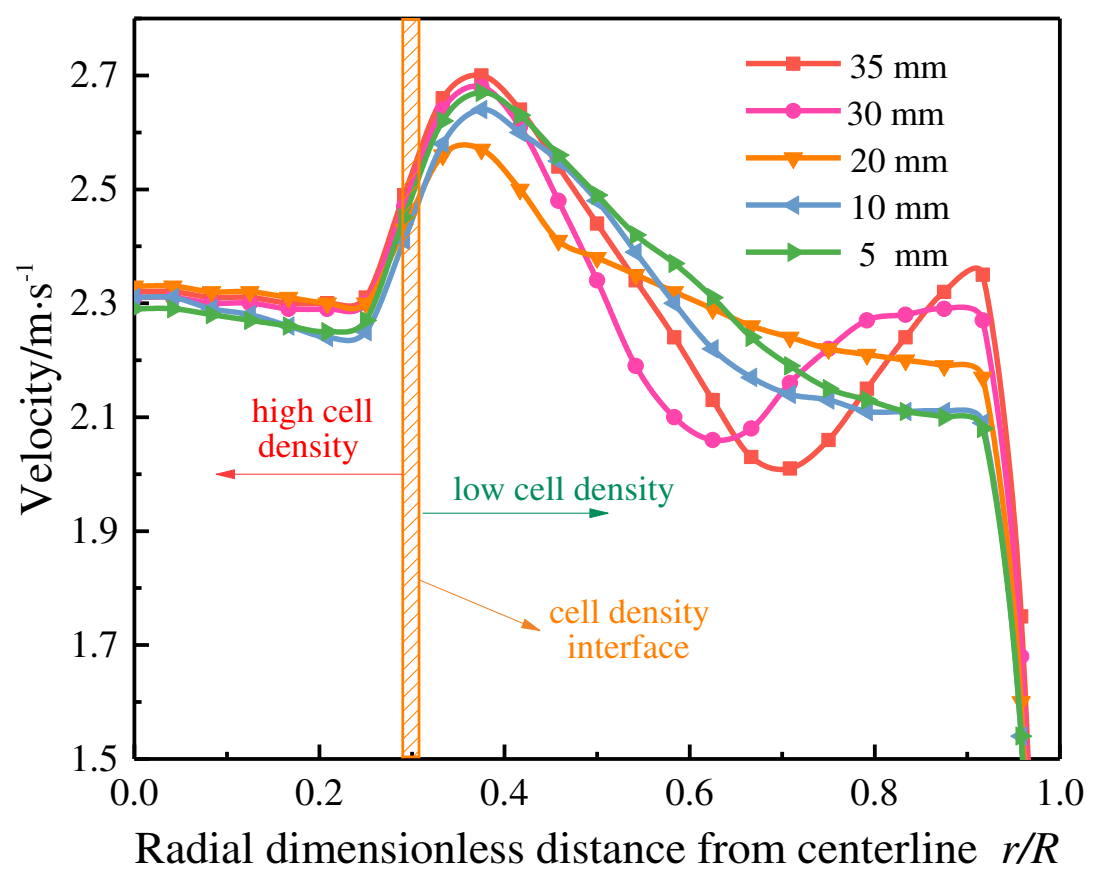

(a) Radial distribution of velocity at carrier exit 


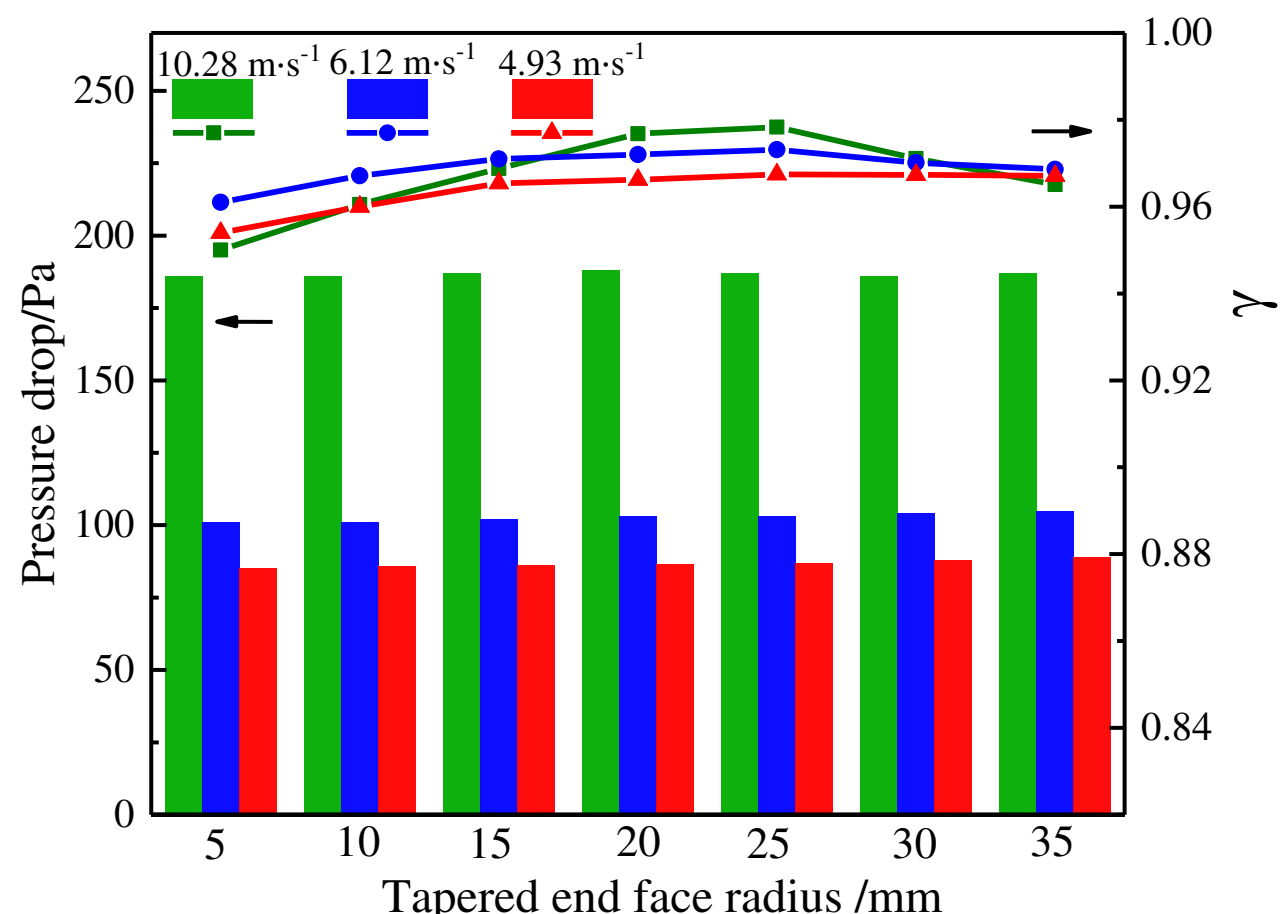

(b) Gas uniformity and carrier pressure drop

Fig. 14 Gas uniformity and carrier pressure drop

The effect of different tapered end face radius on NO conversion rate is shown in Fig. 15 (a). It can be found, NO conversion rate first increases and then decreases with the tapered end face radius increases. NO conversion rate increases from $71.2 \%$ to $72.0 \%$, and then decreases to $71.3 \%$ as the conical end radius increases from $5 \mathrm{~mm}$ to $35 \mathrm{~mm}$ under the exhaust inlet velocity of $10.28 \mathrm{~m} \cdot \mathrm{s}^{-1}$, and reaches the maximum value at $20 \mathrm{~mm}$. The main reason is that when the tapered end face radius is larger, the edge velocity is larger, which makes NO cannot be effectively catalyzed, resulting in a lower NO conversion rate. When the radius of the tapered end face radius is small, the velocity is larger in the area around the dimensionless radius of 0.4 , which makes NO catalysis insufficient. The velocity distribution is more uniform and NO catalysis is more sufficient when the tapered end face radius is $20 \mathrm{~mm}$. Under the condition of inlet velocity of $6.12 \mathrm{~m} \cdot \mathrm{s}^{-1}$ and $4.93 \mathrm{~m} \cdot \mathrm{s}^{-1}$, the tapered end face radius has little effect on NO conversion. The reason is the same to the explanation of Fig. 11(a). 
Fig. 15(b) shows the influence of different tapered end face radius on the radial distribution of $\mathrm{NO}_{2}$ mass fraction at the outlet under the exhaust inlet velocity is $10.28 \mathrm{~m} \cdot \mathrm{s}^{-1}$. When the tapered end face radius is less than $10 \mathrm{~mm}$, the $\mathrm{NO}_{2}$ mass fraction decreases first and then increases along the radius, and it is lower in the area near the dimensionless radius of 0.4 . When the tapered end face radius is larger than $30 \mathrm{~mm}$, it decreases first, then increases and finally decreases, and it is relatively low in the area of the dimensionless radius from 0.7 to 1 . This is because when the tapered end face radius is small, the velocity is larger in the dimensionless region around 0.4 , and when the tapered end face radius is large, the velocity is larger in the dimensionless 0.7 to 1 region, which leads to the restriction of $\mathrm{NO}$ catalysis and the low $\mathrm{NO}_{2}$ mass fraction.

The velocity distribution is more uniform when the tapered end face radius is $20 \mathrm{~mm}$, so that the radial distribution of $\mathrm{NO}_{2}$ mass fraction is more uniform. Therefore, when the tapered end face radius is $20 \mathrm{~mm}$, the velocity is more uniform and the NO conversion rate is higher.

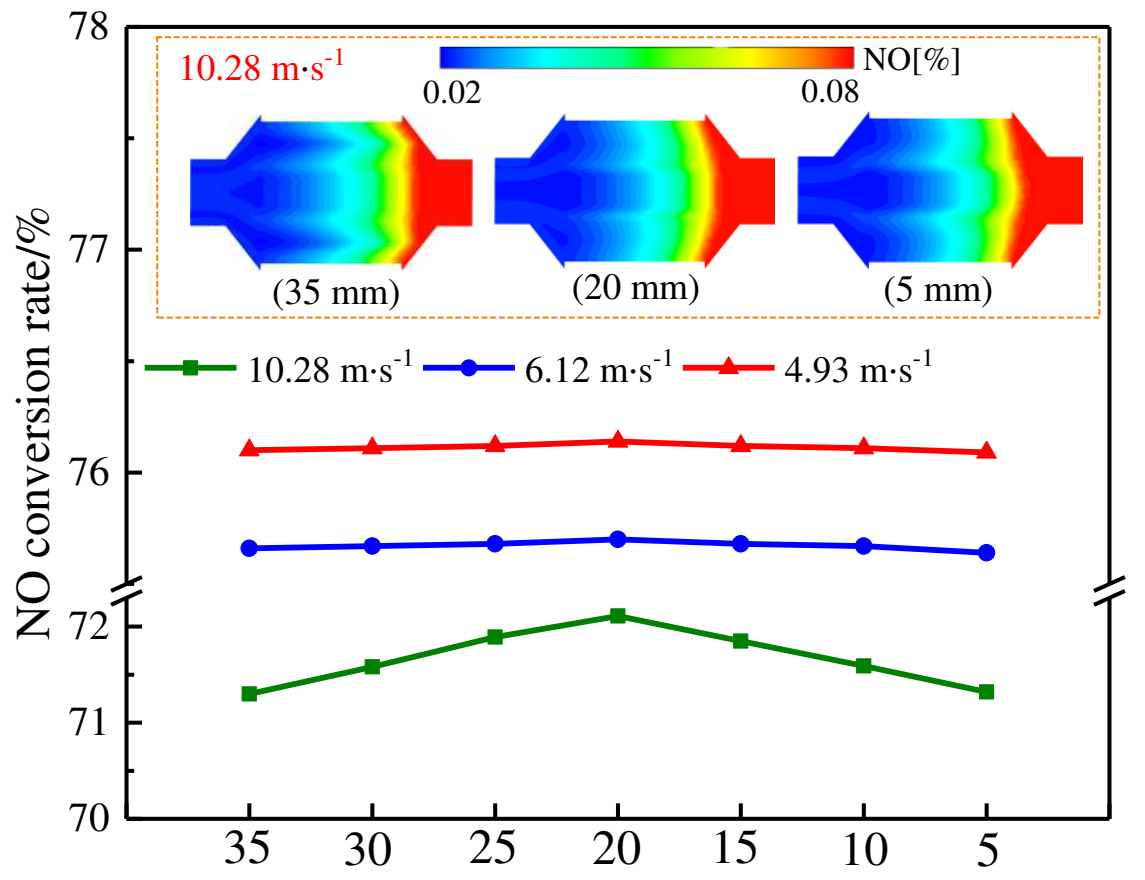

(a) $\mathrm{NO}$ conversion rate 


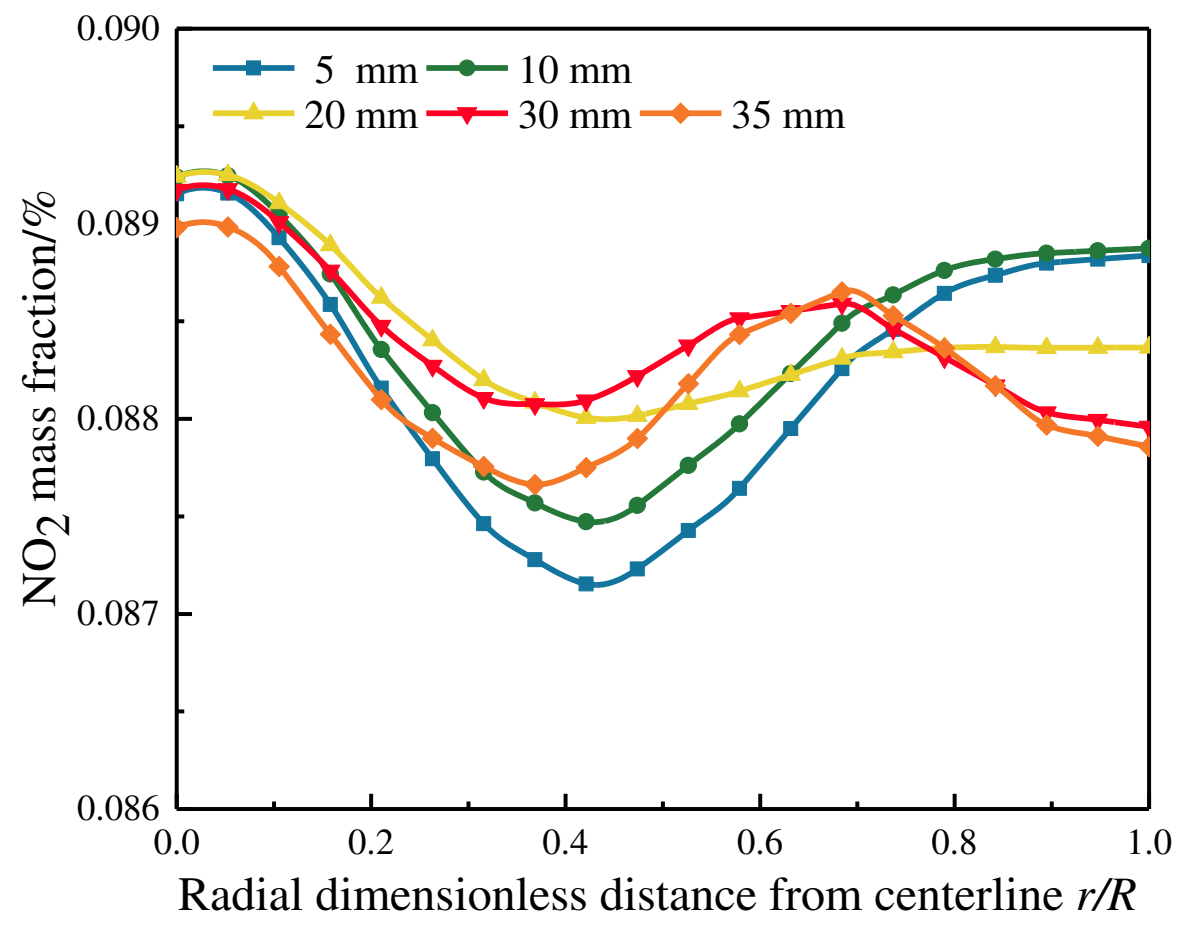

(b) Radial distribution of $\mathrm{NO}_{2}$ mass fraction at outlet

Fig. $15 \mathrm{NO}$ conversion rate and $\mathrm{NO}_{2}$ mass fraction

475

\section{Gray correlation analysis}

\subsection{Experimental design and calculation}

The influence degree of the above structural parameters on the catalytic converter performance is further investigated by using grey relational analysis method. According to the grey relational analysis (Zhang et al. 2017; Wang et al. 2020) low cell density ( $\left.x_{1}\right)$, high cell density $\left(x_{2}\right)$, high/low cell density ratio $\left(x_{3}\right)$, tapered height $\left(x_{4}\right)$, high cell density carrier radius $\left(x_{5}\right)$ and tapered end face radius $\left(x_{6}\right)$ are taken as the influencing factors eigenvectors. Carrier pressure drop $\left(y_{1}\right)$, gas uniformity $\left(y_{2}\right)$ and NO conversion rate $\left(y_{3}\right)$ are taken as reference feature vectors. Under the condition of exhaust inlet temperature of $575 \mathrm{~K}$ and velocity of $10.28 \mathrm{~m} \cdot \mathrm{s}^{-1}, 10$ representative experimental models are studied. And the gas uniformity, no conversion and pressure drop are analyzed. The simulation conditions and results are shown in Table 6.

Table 6 Simulation conditions and results

Cases $\quad x_{1}(\mathrm{cpsi}) \quad x_{2}(\mathrm{cpsi}) \quad x_{3} \quad x_{4}(\mathrm{~mm}) \quad x_{5}(\mathrm{~mm}) \quad x_{6}(\mathrm{~mm}) \quad y_{1} \quad y_{2}(\mathrm{~Pa}) \quad y_{3}(\%)$




\begin{tabular}{lccccccccc}
\hline 1 & 600 & 700 & 1.333 & 24 & 5.0 & 7.0 & 0.9794 & 227 & 82.97 \\
2 & 600 & 700 & 1.333 & 22 & 7.5 & 9.5 & 0.9815 & 225 & 74.69 \\
3 & 500 & 600 & 1.200 & 20 & 10.0 & 12.0 & 0.9440 & 219 & 73.03 \\
4 & 500 & 600 & 1.200 & 18 & 12.5 & 16.0 & 0.9720 & 213 & 73.29 \\
5 & 400 & 600 & 1.500 & 16 & 15.0 & 20.0 & 0.9707 & 185 & 72.07 \\
6 & 400 & 600 & 1.500 & 14 & 17.5 & 22.5 & 0.9687 & 182 & 71.95 \\
7 & 400 & 600 & 1.250 & 12 & 20.0 & 25.0 & 0.9843 & 180 & 71.93 \\
8 & 400 & 500 & 1.250 & 10 & 22.5 & 27.5 & 0.9826 & 180 & 71.87 \\
9 & 300 & 500 & 1.667 & 8 & 25.0 & 30.0 & 0.9659 & 158 & 69.69 \\
\hline 10 & 300 & 500 & 1.667 & 6 & 27.5 & 32.5 & 0.9463 & 157 & 69.43 \\
\hline
\end{tabular}

486

\subsection{Simulation results and analysis}

The influence degree of influencing factors on catalytic converter performance is expressed by the $R$ value, and the greater $R$ is, the greater the influence is (Zuo et al. 2016; Kadier et al. 2015) According to Fig. 16, the influence degree of each influencing factor on each reference index is as follows. For carrier pressure drop: low cell density $>$ high cell density $>$ high/low cell density ratio $>$ tapered height $>$ tapered end face radius $>$ high cell density carrier radius. For gas uniformity: low cell density $>$ high cell density $>$ high/low cell density ratio $>$ high cell density carrier radius $>$ tapered end face radius $>$ tapered height. For NO conversion rate: low cell density $>$ high cell density $>$ tapered height $>$ high cell density carrier radius $>$ high /low cell density ratio $>$ tapered end face radius. The low cell density is a key factor affecting the improved catalytic converter. This issue is explained as follows. The low cell density determines the resistance in the edge area, which affects the flow degree of the exhaust to the edge, thus affecting the gas uniformity. In addition, because most of the exhaust flows through the low cell density area, the resistance in the low cell density area directly affects the pressure drop of the overall carrier. Meanwhile, the low cell 
499

500

501

502

503

504

density area becomes the main site for NO catalyzing and directly affects the overall NO conversion rate. The research results provide a theoretical basis for structural optimization and system matching of catalytic converters.

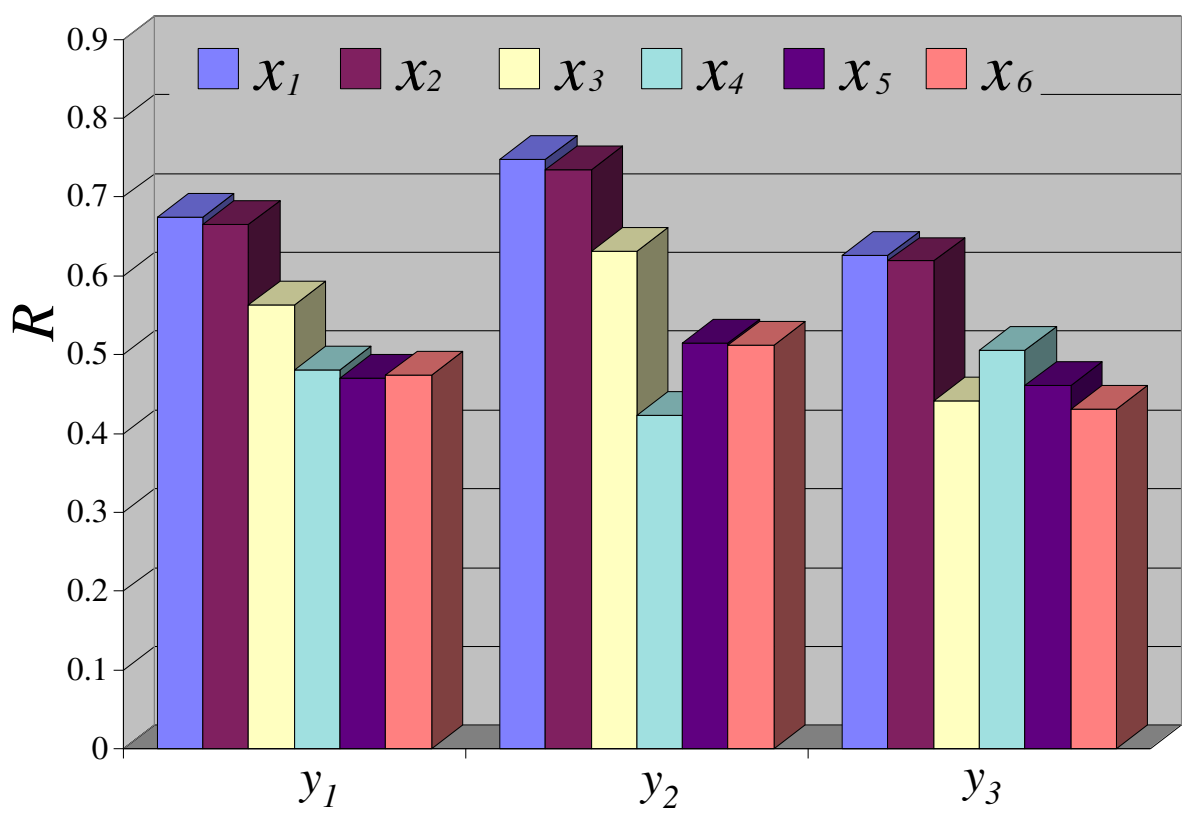

Fig. 16 Influence correlation degree

\section{Conclusion}

By establishing a new catalytic converter model, the uniformity of internal flow field is improved, to achieve the purpose of improving NO catalysis. In addition, the optimum structural parameters are determined by quantitative analysis of $\mathrm{NO}$ conversion rate and $\mathrm{NO}_{2}$ mass fraction at the outlet of the carrier, to further optimize the model. The specific results are as follows:

(1) Compared with the standard catalytic converter, the gas uniformity, NO conversion rate and carrier pressure drop of the improved catalytic converter increased by $0.0643,7.0 \%$ and $6.78 \%$, respectively. It improves NO catalytic and reduces vehicle emission.

(2) When the high and low cell densities are different, the performance is better when the cell density combination is larger. When the low cell density is the same, the smaller the high cell density, the better the performance. When the cell density combination is $700 \mathrm{cpsi} / 600 \mathrm{cpsi}$, its performance is better; the gas 
uniformity and NO conversion rate reach the highest, which are 0.9821 and $73.7 \%$, and the carrier pressure drop is $232 \mathrm{~Pa}$.

(3) When the tapered height increases from $5 \mathrm{~mm}$ to $25 \mathrm{~mm}$, the catalytic converter performance increases first and then decreases under the exhaust inlet velocity of $10.28 \mathrm{~m} \cdot \mathrm{s}^{-1}$. Its performance is better when the tapered height is $20 \mathrm{~mm}$; the $\mathrm{NO}$ conversion rate reaches the highest, $72.4 \%$, the gas uniformity and carrier pressure drop are 0.9774 and $212 \mathrm{~Pa}$, respectively. then decreases under the exhaust inlet velocity of $10.28 \mathrm{~m} \cdot \mathrm{s}^{-1}$. Its performance is better when the radius of catalytic converter.

Guan: Conceptualization, Methodology. Zhuang Shen: Formal analysis, Software. Yongchuan Xie:

Software. Qiming Li: Data curation. 
Not applicable

\section{Availability of data and materials}

540 All data generated or analyzed during this study are included in this published article.

\section{Competing interests}

542 The authors declare that they have no competing interests.

543

544

545

546

547

\section{Ethical Approval}

\section{Not applicable}

\section{Funding}

This work is supported by the National Natural Science Foundation of China (Grant No. 52076184), the Natural Science Foundation of Hunan Province (Grant No. 2020JJ6002), the Hunan Provincial Key Laboratory of Vehicle Power and Transmission System (Grant No. VPTS202004).

\section{Reference}

Almeida PR, Nakamura AL, Sodre JR. ( 2014) Evaluation of catalytic converter aging for vehicle operation with ethanol. Appl Therm Eng 71:335-341. https://doi.org/10.1016/j.applthermaleng.2014.06.069

Andrew R, Richard B, Philip S. (2014) Internal combustion engine cold-start efficiency: A review of the problem, causes and potential solutions. Energ Convers Manage 82:327-350. https://doi.org/10.1016/j.enconman.2014.03.002

Ayodhya AS, Narayanappa KG. (2018) An overview of after-treatment systems for diesel engines. Environ Sci Pollut Res 25(35):35034-35047. https://doi.org/10.1007/s11356-018-3487-8

Baumard P, Budzinski H, Garrigues P. (1998) Polycyclic aromatic hydrocarbons (PAHs) in sediments and mussels of the western Mediterranean Sea. Environ Toxicol Chem 17:765-776.

https://doi.org/10.1002/etc.5620170501

Bogarra M, Herreros J M, Hergueta C. (2017) Influence of Three-Way Catalyst on Gaseous and Particulate 
Matter Emissions During Gasoline Direct Injection Engine Cold-start. Johnson Matthey Tech 61(4):329-341. https://doi.org/10.1595/205651317X696315

563

564

565

566

567

568

569

570

571

572

573

574

575

576

577

578

579

580

581

582

583

Cai T, Zhao D, E JQ. (2020) Bluff-body effect on thermal and NOx emission characteristics in a microplanar combustor fueled with premixed ammonia-oxygen. Chem Eng Process 153. https://doi.org/10.1016/j.cep.2020.107979.

Deng YW, Zheng WP, E JQ, Zhang B, Zhao XH, Zuo QS, Zhang ZQ, Han DD. (2017) Influence of geometric characteristics of a diesel particulate filter on its behavior in equilibrium state. Appl Therm Eng 123:61-73. https://doi.org/10.1016/j.applthermaleng.2017.05.071

Dey S, Chandra Dhal G. (2020) Controlling carbon monoxide emissions from automobile vehicle exhaust using copper oxide catalysts in a catalytic converter. Mater Today Chem 17: https://doi.org/10.1016/j.mtchem.2020.100282.

E JQ, Zheng PY, Han DD, Zhao XH, Deng YW. (2020) Effect analysis on soot combustion performance enhancement in a rotary diesel particulate filter unit during continuous microwave heating. Fuel. https://doi.org/10.1016/j.fuel.2020.118043.

Gao JB, Tian GH, Sorniotti A, Karci AE, Palo RD. (2019) Review of thermal management of catalytic converters to decrease engine emissions during cold start and warm up. Appl Therm Eng 147:177187. https://doi.org/10.1016/j.applthermaleng.2018.10.037

Hesham A, Ibrahim, Wael HA, Sherif A. (2018) Experimental and numerical investigations of flow through $\begin{array}{lllll}\text { catalytic } & \text { converters. } & \text { Int } & \mathrm{J} & \text { Heat }\end{array}$ https://doi.org/10.1016/j.ijheatmasstransfer.2018.07.052

Kadier A, Abdeshahian P, Simayi Y, Ismail M, Hamid AA, Kalil MS. (2015) Grey relational analysis for comparative assessment of different cathode materials in microbial electrolysis cells. Energy 90(2):1556-1562. https://doi.org/10.1016/j.energy.2015.06.108 
Kumar C, Rana KB, Tripathi B. (2019) Effect of diesel-methanol-nitromethane blends combustion on VCR stationary CI engine performance and exhaust emissions. Environ Sci Pollut Res 26:6517-6531. https://doi.org/10.1007/s11356-018-04058-1

Liang YL, Ding XM, Dai JY, Zhao M, Zhong L, Wang JL, Chen YQ. (2019) Active oxygen-promoted NO catalytic on monolithic Pt-based diesel oxidation catalyst modified with Ce. Catal Today 327:64-72. https://doi.org/10.1016/j.cattod.2018.06.008

Lichtfouse E, Budzinski H, Garrigues P, Eglinton T. (1997) Ancient polycyclic aromatic hydrocarbons in modern soils: 13C, 14C and biomarker evidence. Organic Geochemistry 26:353-359. https://doi.org/10.1016/S0146-6380(97)00009-0

Liu HY, Li ZY, Xu HM, Ma X, Shuai SJ. (2020) Nucleation mode particle evolution in a gasoline direct injection engine with/without a three-way catalyst converter. Appl Energy 259. https://doi.org/10.1016/j.apenergy.2019.114211.

Liu HY, Li ZY, Zhang MZ, Xu HM, Ma X, Shuai SJ. (2021) Exhaust non-volatile particle filtration characteristics of three-way catalyst and influencing factors in a gasoline direct injection engine compared to gasoline particulate filter. Fuel 290. https://doi.org/10.1016/j.fuel.2020.120065.

Manojkumar R, Haranethra S, Muralidharan M, Ramaprabhu A. I.C. (2020) Engine emission reduction using catalytic converter by replacing the noble catalyst and using copper oxide as the catalyst. Mater Today: Proceedings. https://doi.org/10.1016/j.matpr.2020.02.804.

Matsuzawa S, Nasser-Ali L, Garrigues P. (2001) Photolytic behavior of polycyclic aromatic hydrocarbons in diesel particulate matter deposited on the ground. Environ Sci Technol 35(15):3139-3143. https://doi.org/10.1021/es001606q

Matthew SR, Kara MK. (2016) The problem of cold starts: A closer look at mobile source emissions levels. Transport Res D-Tr E 43:123-132. https://doi.org/10.1016/j.trd.2015.12.012 
Miles WM, William DJ. (2017) Catalytic oxidation of carbon monoxide by $\alpha$-alumina supported $3 \mathrm{~nm}$ cerium dioxide nanoparticles. Mol Catal 493:9-14. https://doi.org/10.1016/j.mcat.2017.06.015

Mu M, Li X, Qiu Y, Shi Y. (2019a) Study on a new gasoline particulate filter structure based on the nested cylinder and diversion channel plug. Energies 12(11):1-19. https://doi.org/10.3390/en12112045

Mu M, Sjöblom J, Ström H, Li X. (2019b) Analysis of the flow field from Connection Cones to Monolith Reactors. Energies 12(3):1-20. https://doi.org/10.3390/en12030455

Park H, Bae C, Ha C. (2019) A comprehensive analysis of multiple injection strategies for improving diesel combustion process under cold-start conditions. Fuel. https://doi.org/10.1016/j.fuel.2019.115762.

Qian Y, Li ZL, Yu L, Wang XL, Lu XC. (2019a) Review of the state-of-the-art of particulate matter emissions from modern gasoline fueled engines. Appl Energy 238:1269-1298. https://doi.org/10.1016/j.apenergy.2019.01.179

Qian Y, Wu ZY, Guo JJ, Li ZL, Jiang CX, Lu XC. (2019b) Experimental studies on the key parameters controlling the combustion and emission in premixed charge compression ignition concept based on diesel surrogates. Appl Energy 235:233-246. https://doi.org/10.1016/j.apenergy.2018.10.104

Santos H, Costa M. (2008) Evaluation of the conversion efficiency of ceramic and metallic three ways $\begin{array}{lllll}\text { catalytic } & \text { converters. } & \text { Energ } & \text { Convers }\end{array}$ https://doi.org/10.1016/j.enconman.2007.06.008

Shen ZG, Tian LL, Liu X. (2019) Automotive exhaust thermoelectric generators: Current status, challenges and future prospects. Energ Convers Manage 195:1138-1173. https://doi.org/10.1016/j.enconman.2019.05.087

Su QY, Xie L, Shuai SJ, Wang JX, Song JO, Li ZJ. (2013) Optimization of automotive catalytic converter by numerical modeling and simulation with detailed mechanism. Catal Today 216:292-298. https://doi.org/10.1016/j.cattod.2013.06.015 
Subhashish D, Ganesh CD, Devendra M, Ram P. (2019) Application of hopcalite catalyst for controlling carbon monoxide emission at cold-start emission conditions. J. Traffic Transp Eng 6(5):419-440. https://doi.org/10.1016/j.jtte.2019.06.002

Sun YZ, Zhao D, Zhu XW. (2021) Generation and Mitigation Mechanism Studies of Nonlinear Thermoacoustic Instability in a Modelled Swirling Combustor with a Heat Exchanger. Aerospace 8. https://doi.org/10.3390/aerospace8030060.

Takeru Y, Hiromasa S, Yuki A, Naohiro H. (2017) Development of a New Ceramic Substrate with Gas Flow Control Functionality. SAE Int J Engines 10:1588-1594. https://doi.org/10.4271/2017-01-0919

Tang AK, Cai T, Deng J, Zhao D, Huang QH, Zhou C. (2019) Experimental study of flame structure tranistions of premixed propane/air in micro-scale planar combustors. Energy 179:558-570. https://doi.org/10.1016/j.energy.2019.05.005

Wang ZQ, Hu YH, Xia XX, Zuo QS, Zhao B, Li ZX. (2020) Thermo-economic selection criteria of working fluid used in dual-loop ORC for engine waste heat recovery by multi-objective optimization. Energy 197. https://doi.org/10.1016/j.energy.2020. 117053.

Xu JM, Yuan ZQ, Dai TQ. (2009) Numerical simulation of catalytic converters with different carrier end shapes. Journal of Shanxi University of science and Technology 27 (06): 87-90. https://doi.org/10.3969/j.issn.1000-5811.2009.06.021

Zhang B, E JQ, Gong JK, Yuan WH, Zhao XH, Hu WY. (2017) Influence of structural and operating factors on performance degradation of the diesel particulate filter based on composite regeneration. Appl Therm Eng 121:838-852. https://doi.org/10.1016/j.applthermaleng.2017.04.155

Zhang ZQ, Ye JD, Tan DL, Feng ZQ, Luo JB, Tan Y, Huang YX. (2021) The effects of $\mathrm{Fe}_{2} \mathrm{O}_{3}$ based DOC and SCR catalyst on the combustion and emission characteristics of a diesel engine fueled with biodiesel. Fuel. https://doi.org/10.1016/j.fuel.2020.120039. 
Zhao D, Guan Y, Reinecke A. (2019) Characterizing hydrogen-fuelled pulsating combustion on thermodynamic properties of a combustor. Commun Phys 244 . https://doi.org/10.1038/s42005.019.0142.8.

Zhong C, Gong J, Wang S. et al. (2021) $\mathrm{NO}_{2}$ catalytic formation, consumption, and efflux in various types of diesel particulate filter. Environ Sci Pollut Res. https://doi.org/10.1007/s11356-020-11870-1.

Zhong WJ, Tamilselvan P, Wang Q, He ZX, Feng H, Yu X. (2018) Experimental study of spray characteristics of diesel/hydrogenated catalytic biodiesel blended fuels under inert and reacting conditions. Energy 153:349-358. https://doi.org/10.1016/j.energy.2018.04.045

Zhong WJ, Xuan TM, He ZX, Wang Q, Li D, Zhang X, Huang YY. (2016) Experimental study of combustion and emission characteristics of diesel engine with diesel/second-generation biodiesel blending fuels. Energ Convers Manage 121:241-250. https://doi.org/10.1016/j.enconman.2016.05.033

Zuo QS, Xie Y, E JQ, Zhu XN, Zhang B, Tang YY, Zhu CH, Wang ZQ, Zhang JP. (2019a) Effect of different exhaust parameters on NO conversion efficiency enhancement of a dual-carrier catalytic converter in the gasoline engine. Energy. https://doi.org/10.1016/j.energy.2019.116521.

Zuo QS, Xie Y, Guan QX, Zhu GH, Ye JQ, Zhu XN, Tang YY, Wang ZQ, Chen W. (2019b) Effect of critical dual-carrier structure parameters on performance enhancement of a dual-carrier catalytic converter and the gasoline engine system. Energ Convers Manage. https://doi.org/10.1016/j.enconman.2019. 112325.

Zuo W, E JQ, Liu XL, Peng QG, Deng YW, Zhu H. (2016) Orthogonal Experimental Design and Fuzzy Grey Relational Analysis for emitter efficiency of the micro-cylindrical combustor with a step. Appl Therm Eng 103:945-951. https://doi.org/10.1016/j.applthermaleng.2016.04.148 
Figures

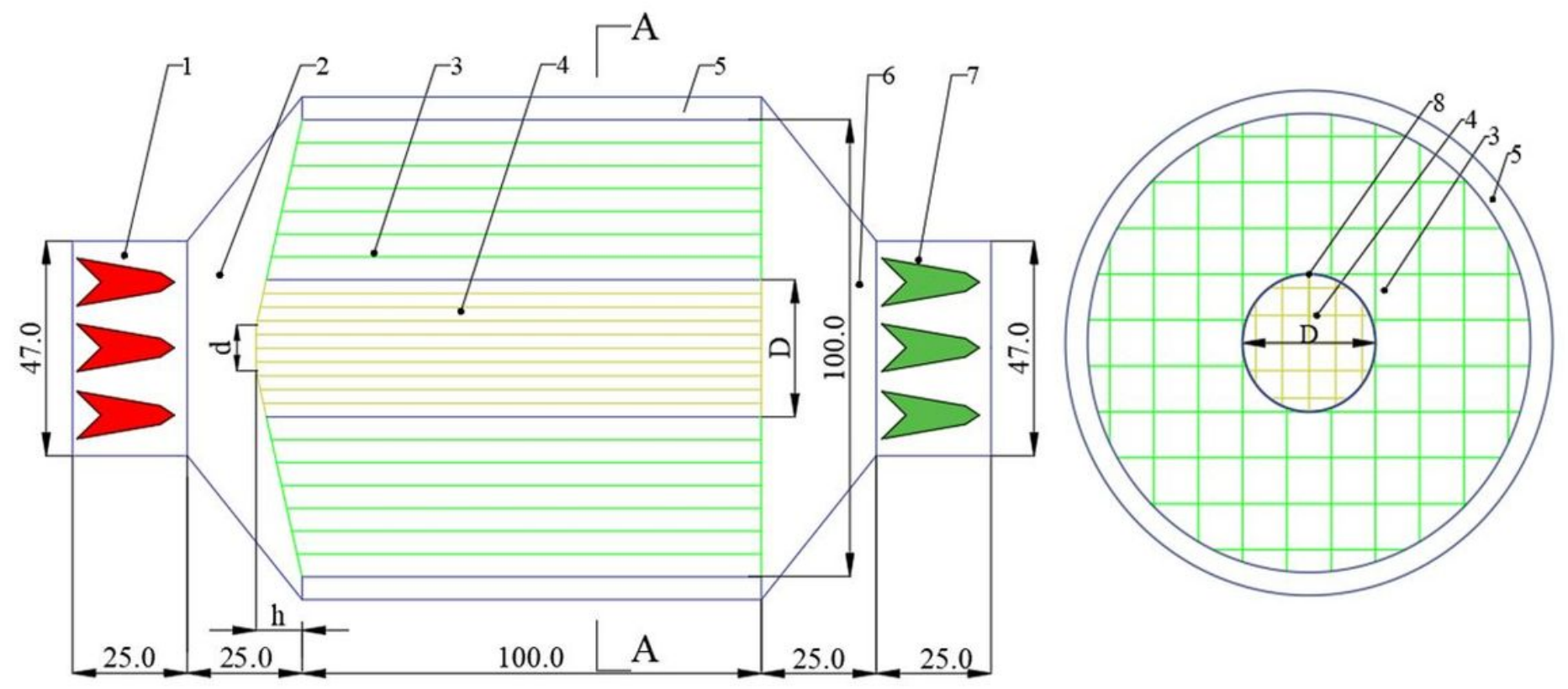

1-inlet pipe, 2-expansion pipe, 3-low cell density carrier, 4-high cell density carrier,

5-liner, 6-contraction pipe, 7-outlet pipe, 8-interface of high and low cell density

\section{Figure 1}

Structure of tapered variable cell density carrier catalytic converter 


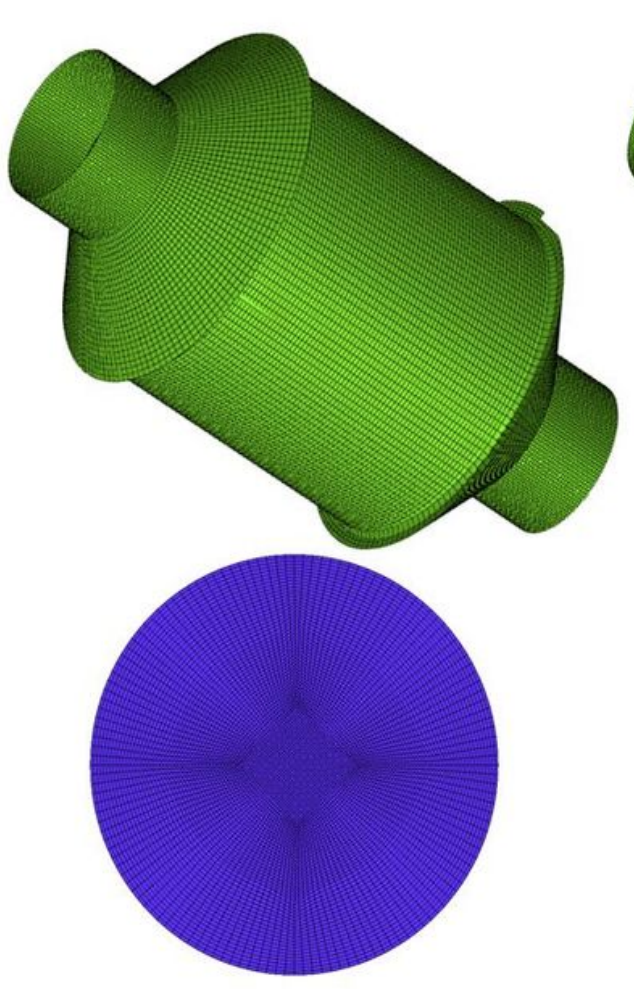

670,293

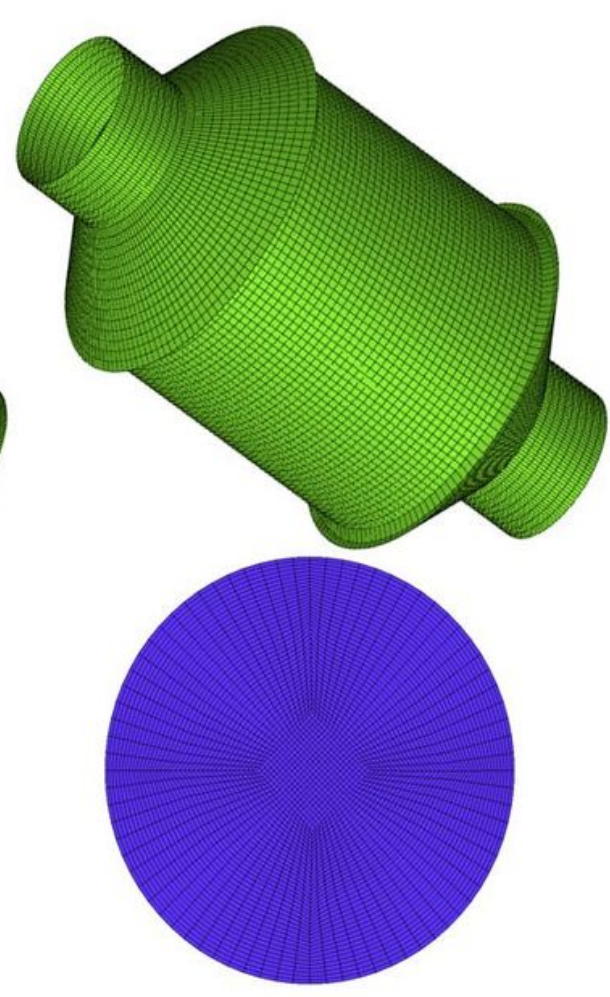

425,223

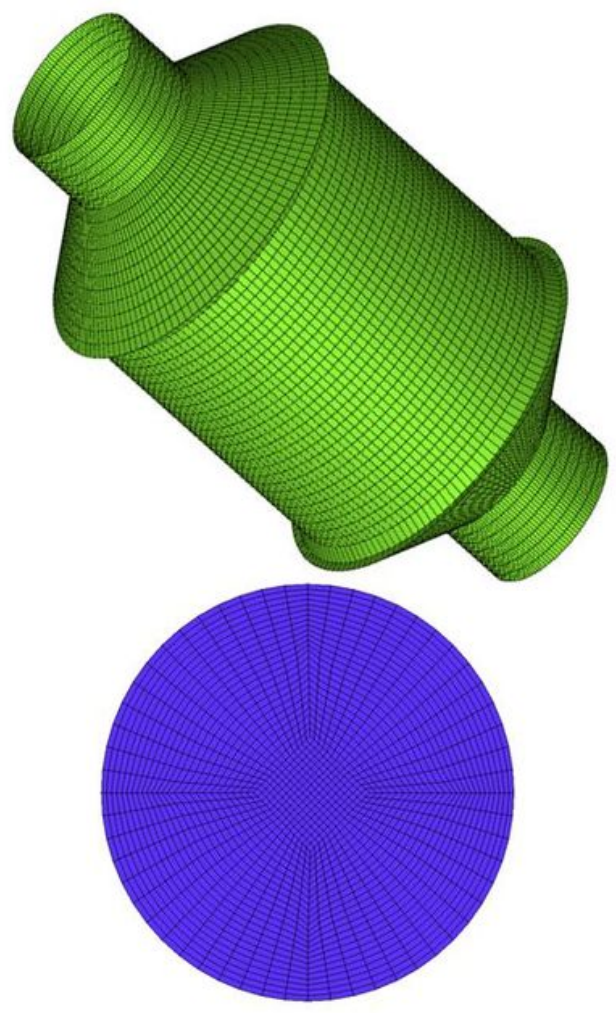

215,212

Figure 2

Three different mesh models 


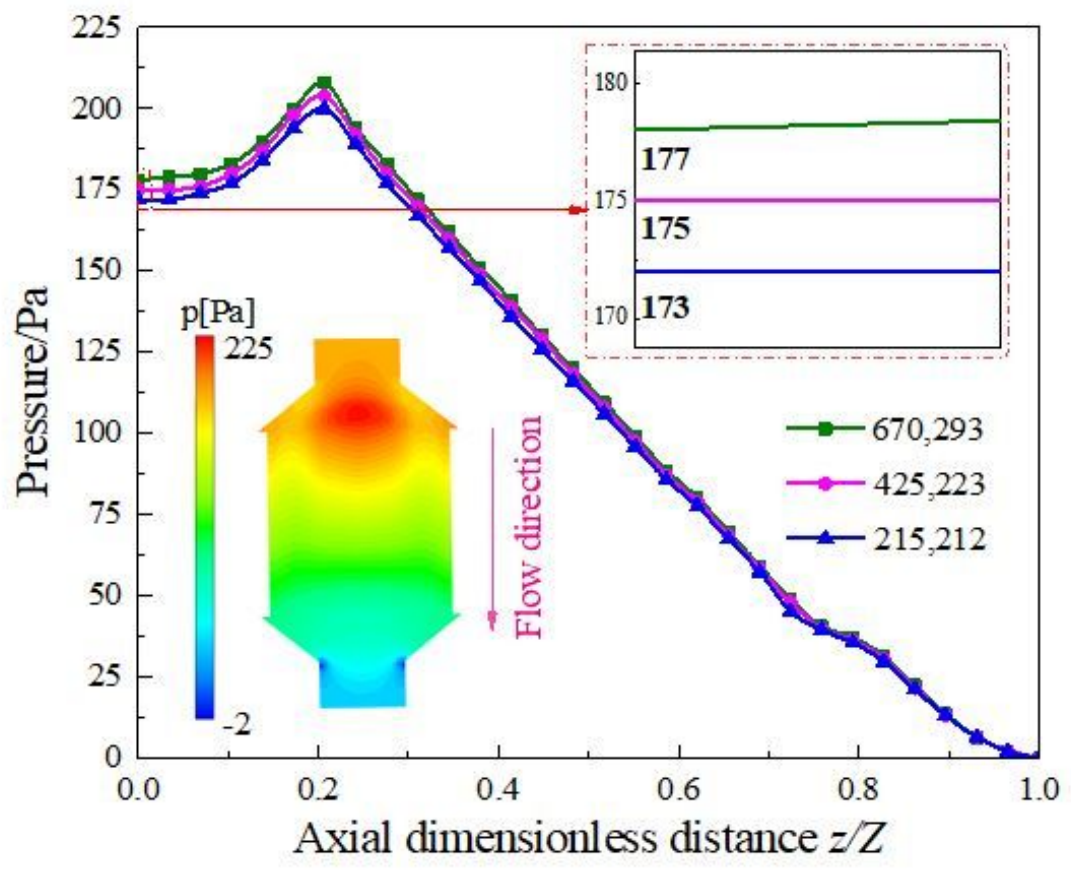

(a) Axial distribution of pressure

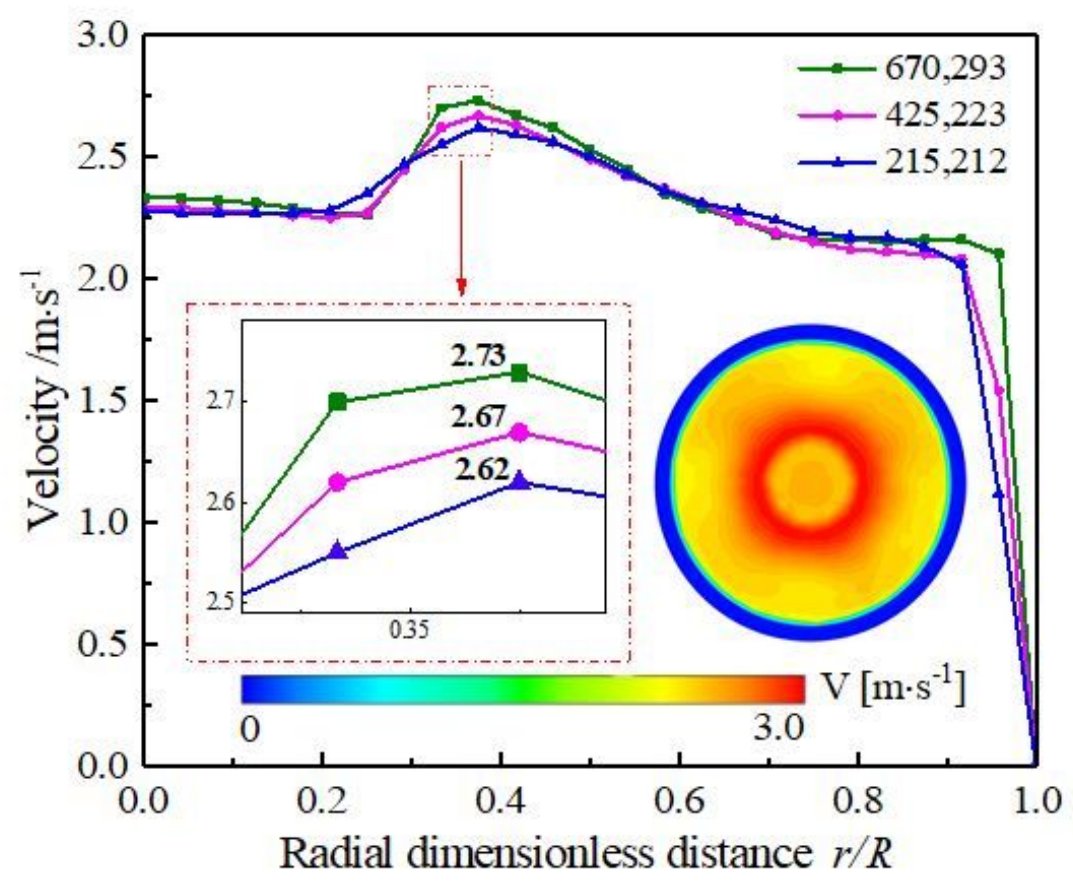

(b) Radial distribution of velocity

Figure 3

Grid independence verification 


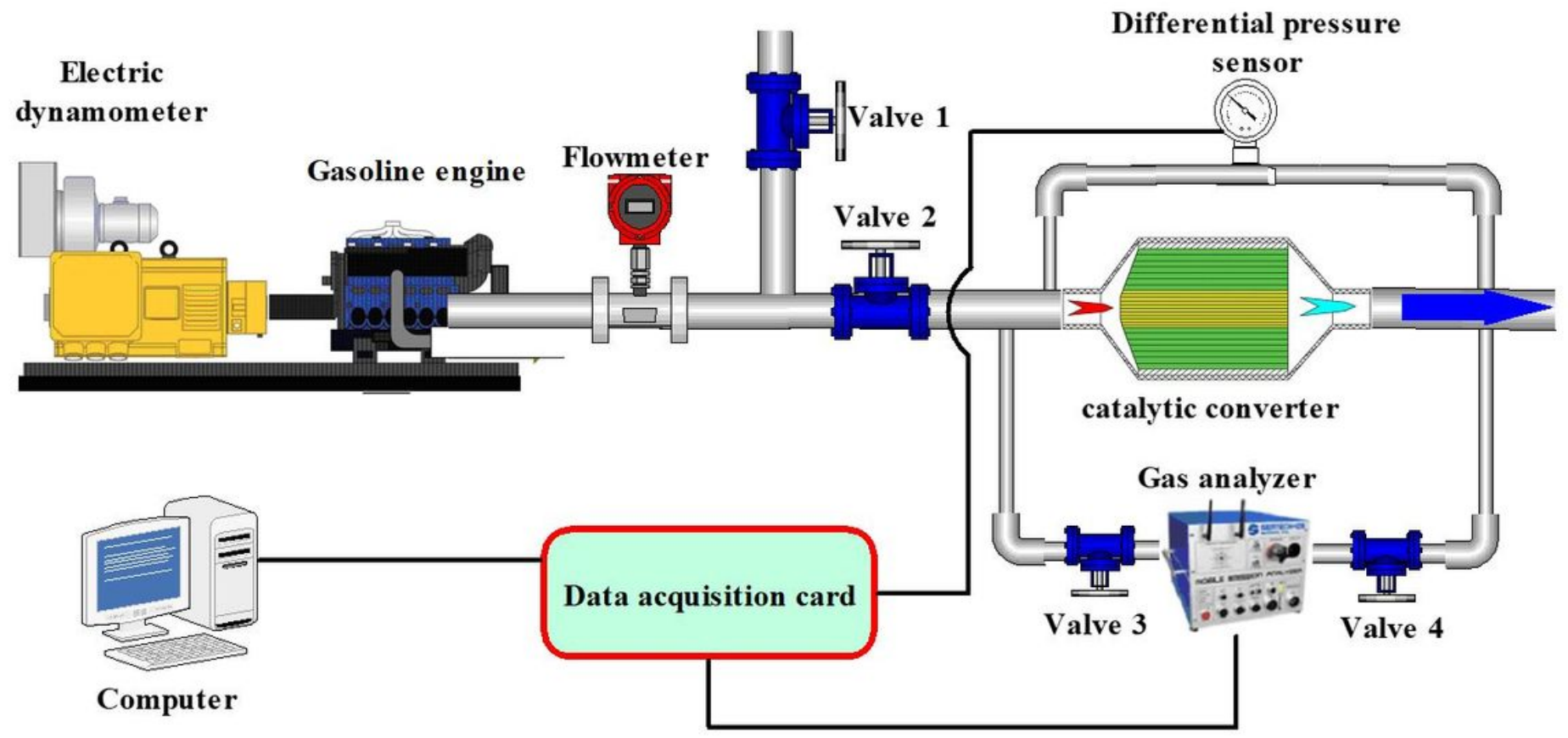

Figure 4

Schematic of the experimental apparatus 


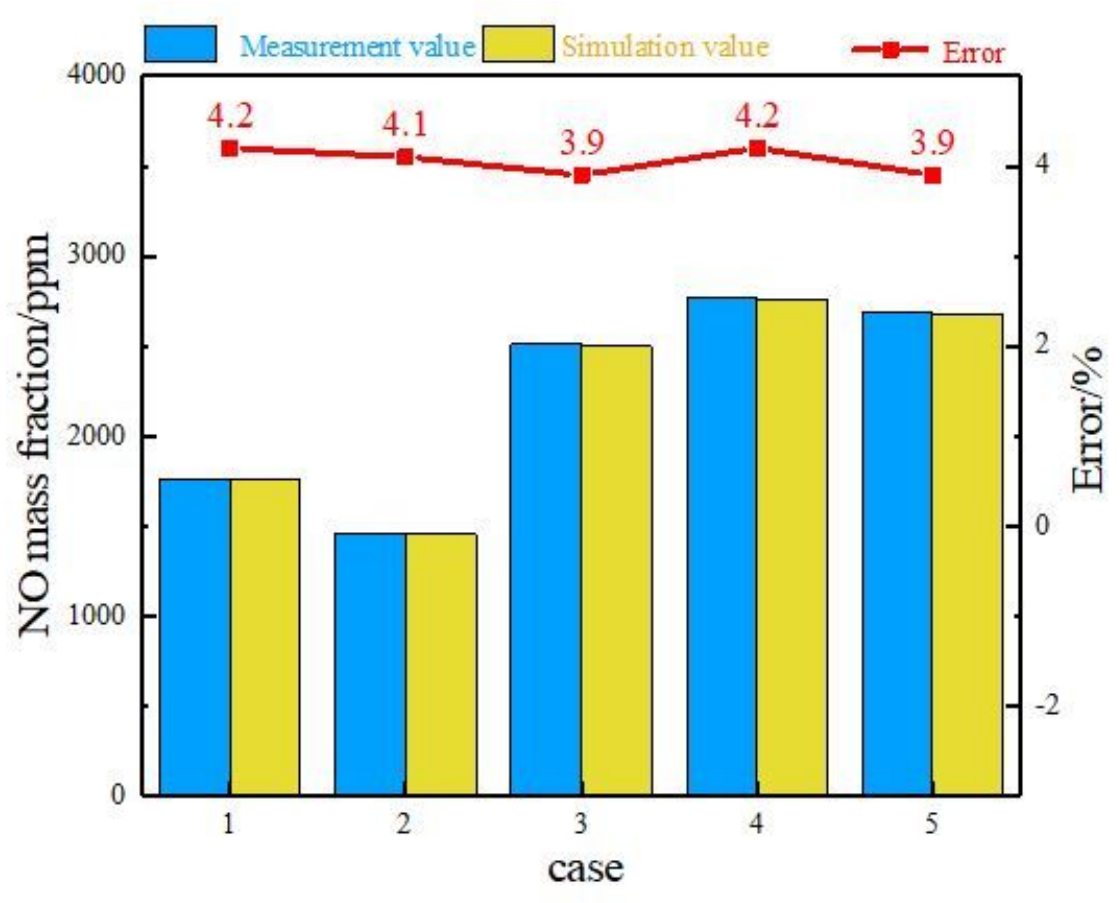

(a) NO mass fraction and error

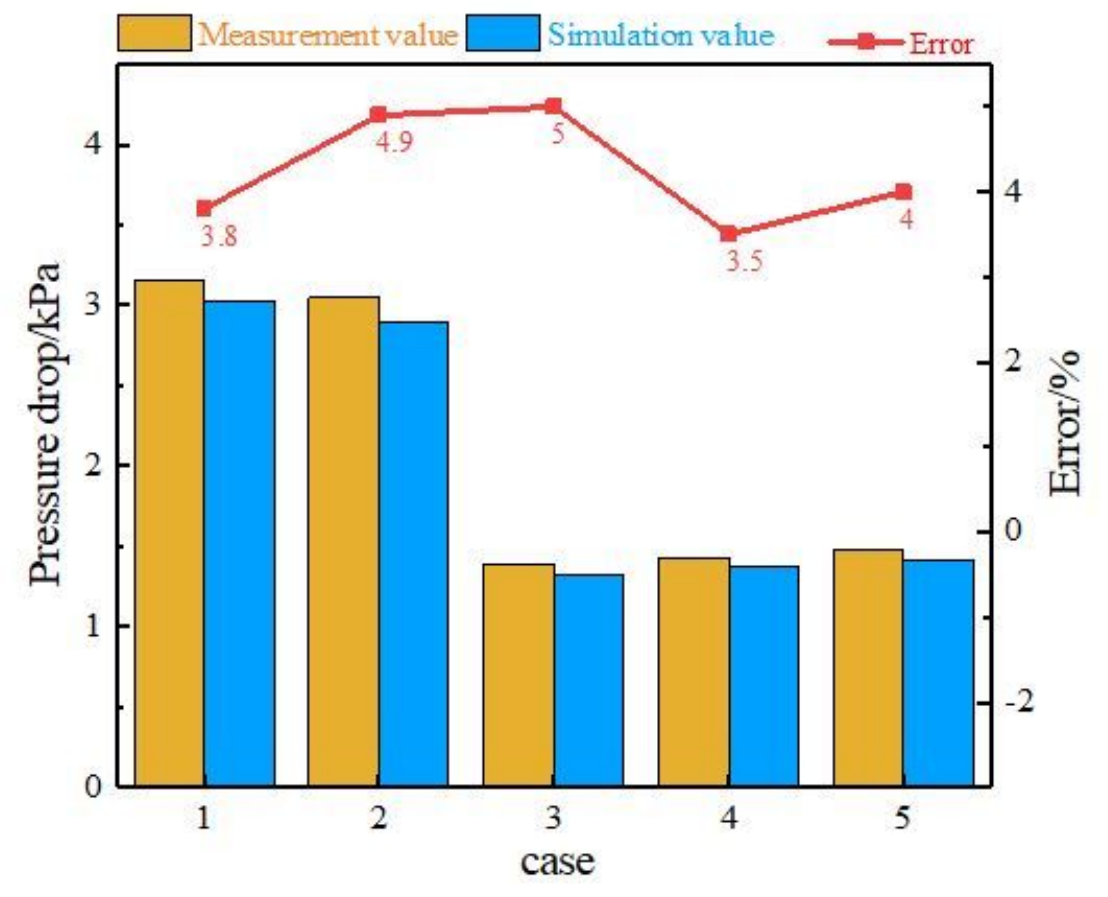

(b) Pressure drop and error

Figure 5

Catalytic converter outlet NO mass fraction and pressure drop 


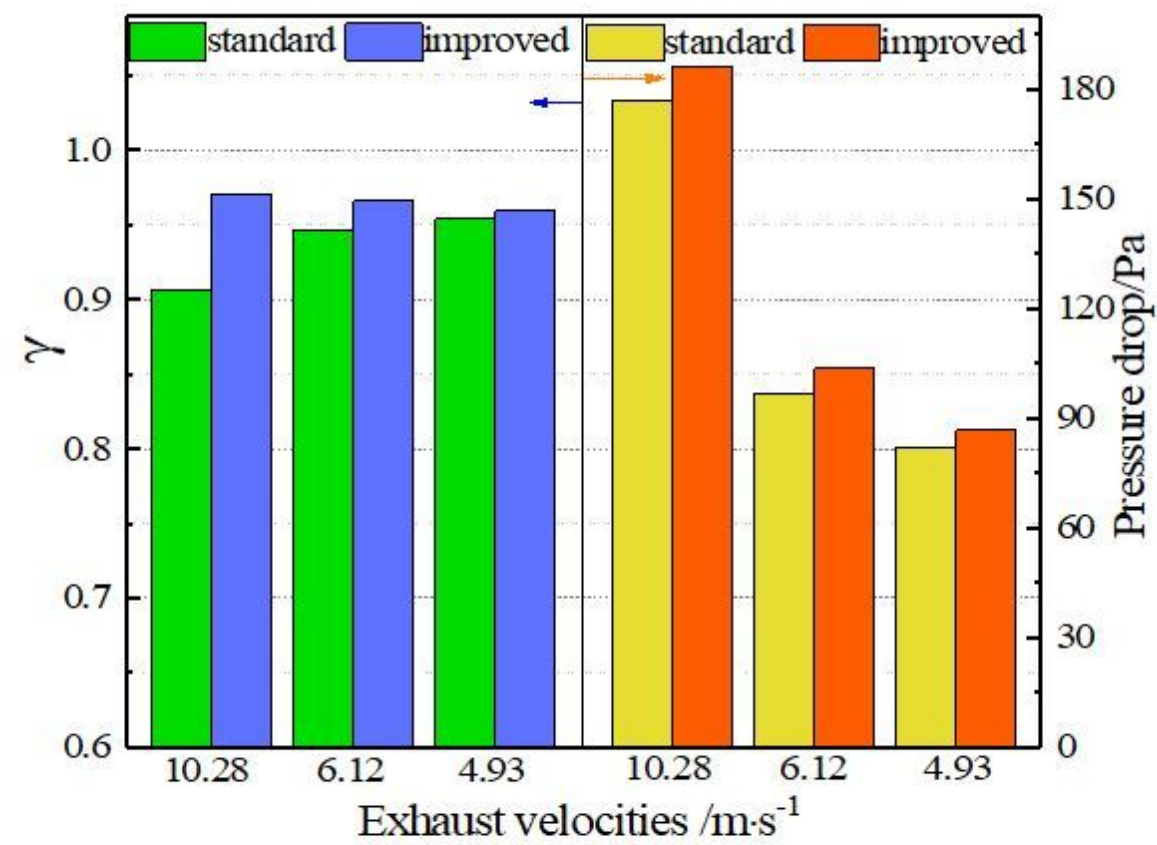

(a) Carrier pressure drop and gas uniformity under three cases

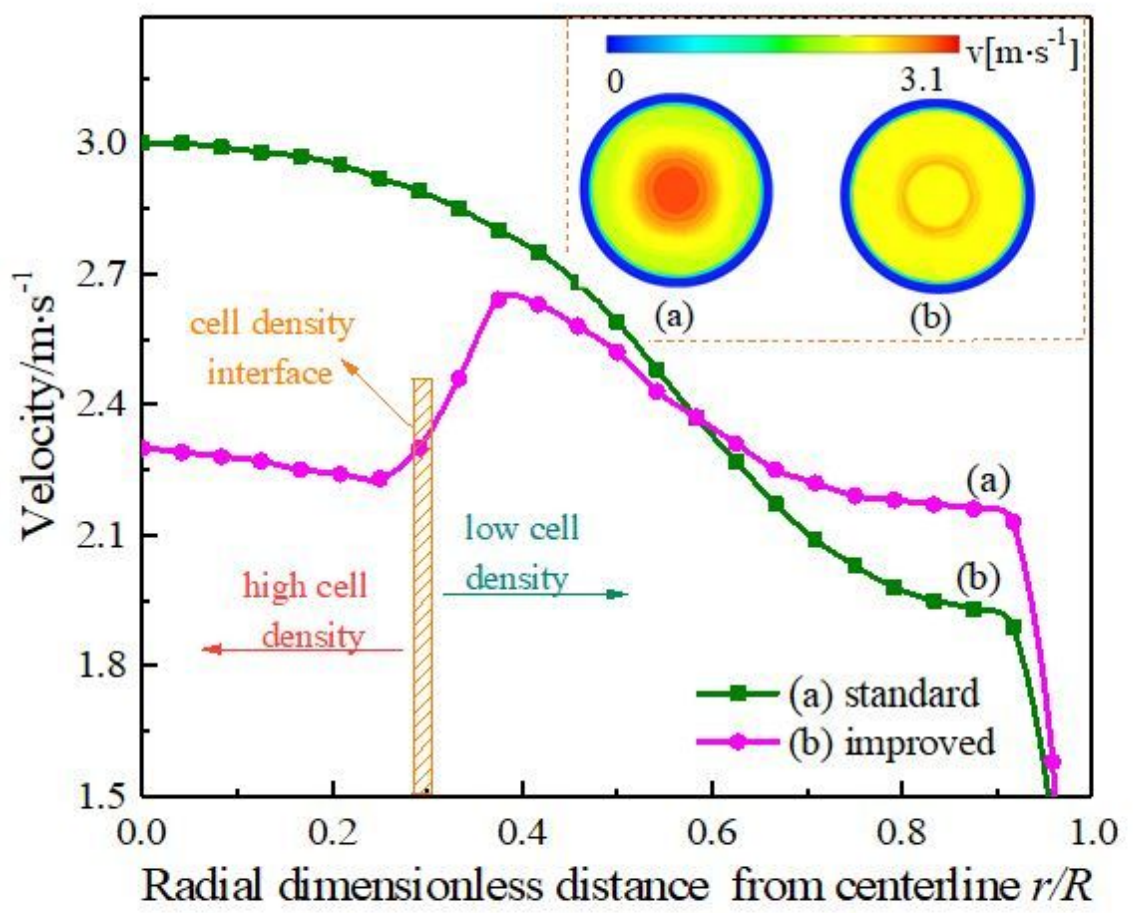

(b) Radial distribution of velocities at the carrier outlet

\section{Figure 6}

Comparison of gas uniformity and carrier pressure drop 


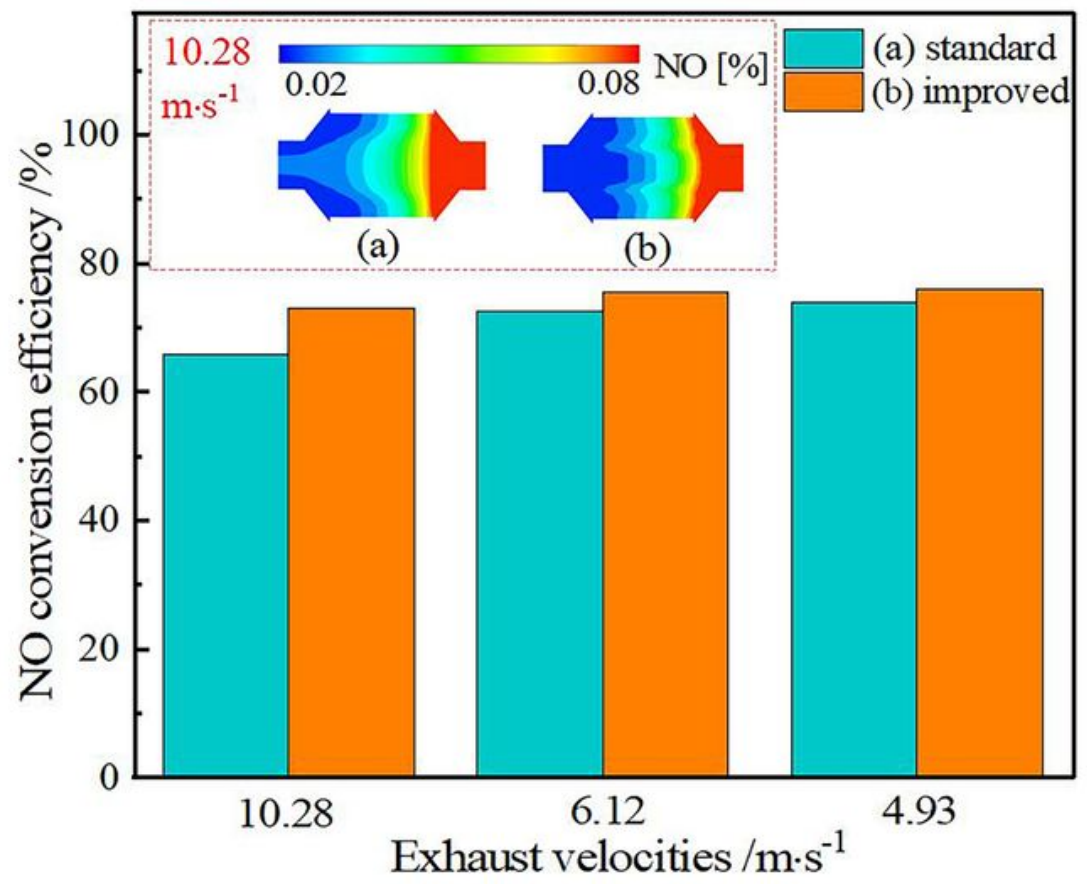

(a) NO conversion rates under three cases

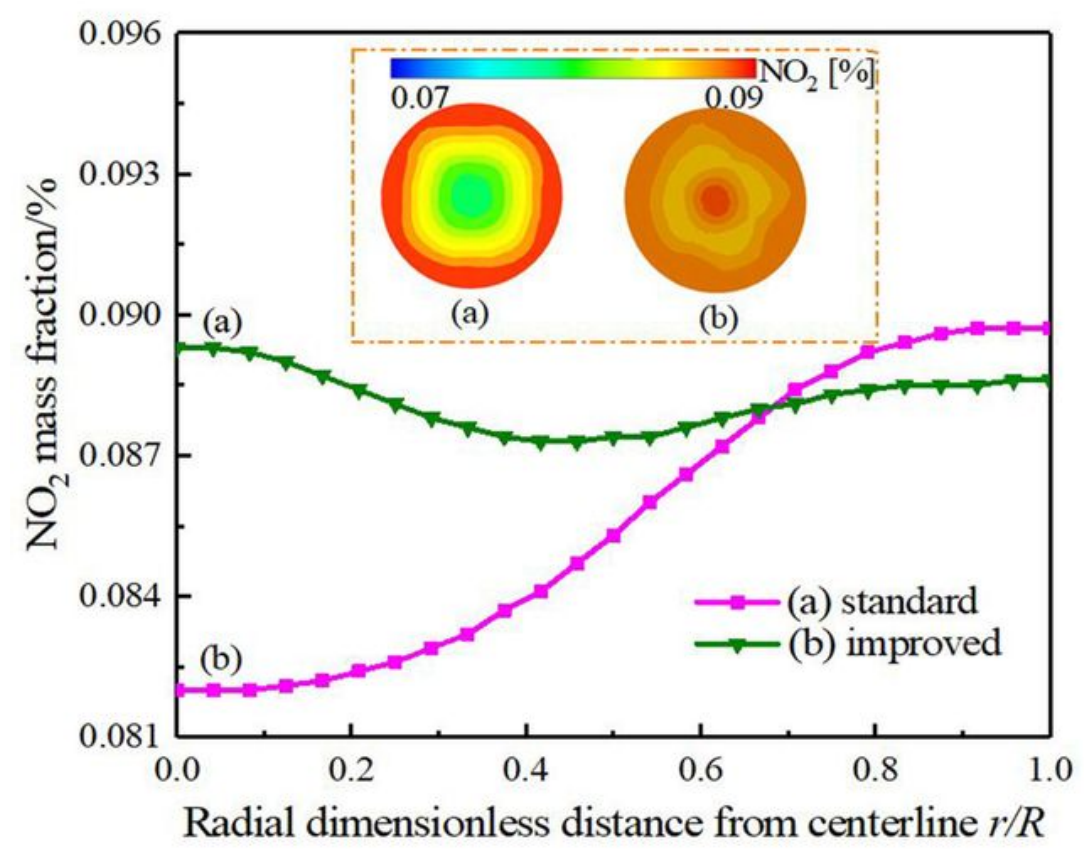

(b) Radial distribution of $\mathrm{NO}_{2}$ mass fraction at exit

Figure 7

Comparison of NO conversion rate and NO2 mass fraction 


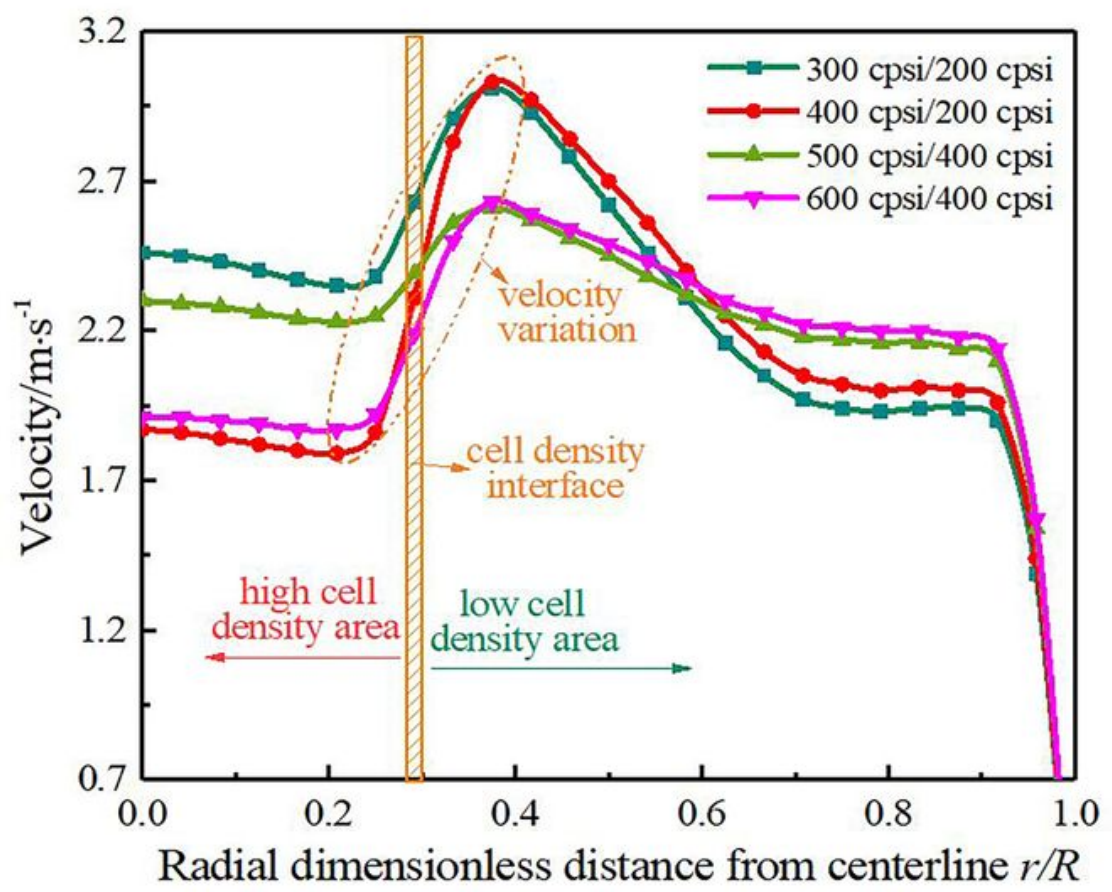

(a) Radial distribution of carrier outlet velocity

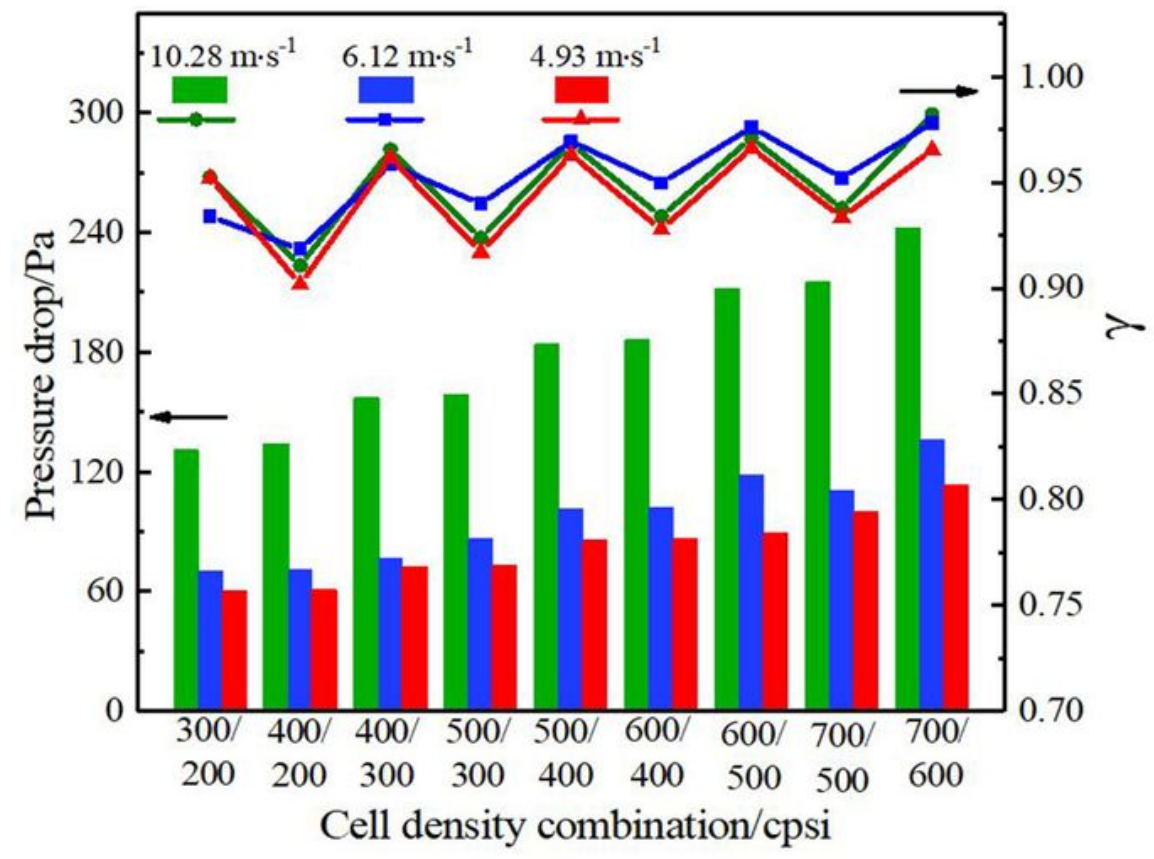

(b) Carrier pressure drop and gas uniformity

\section{Figure 8}

Gas uniformity and carrier pressure drop 


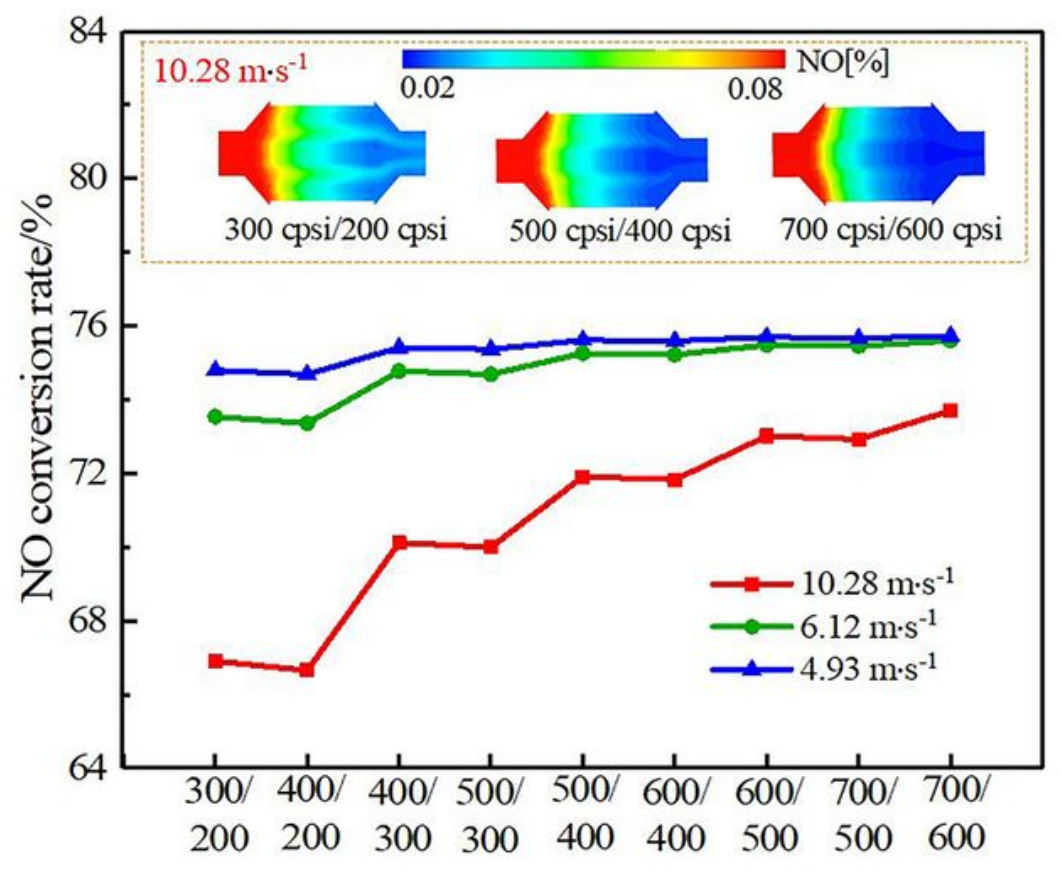

Cell density combination/cpsi

(a) NO conversion rate

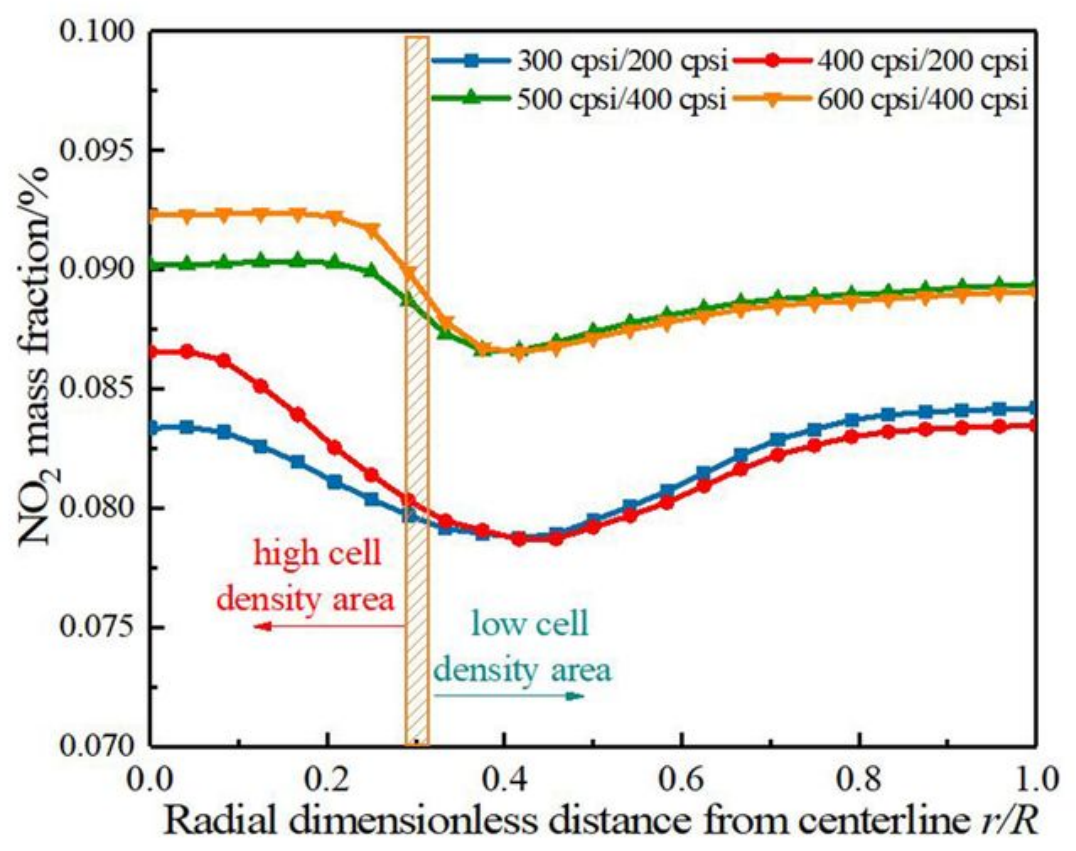

(b) Distribution of $\mathrm{NO}_{2}$ mass fraction at export

\section{Figure 9}

NO conversion rate and $\mathrm{NO} 2$ mass fraction 


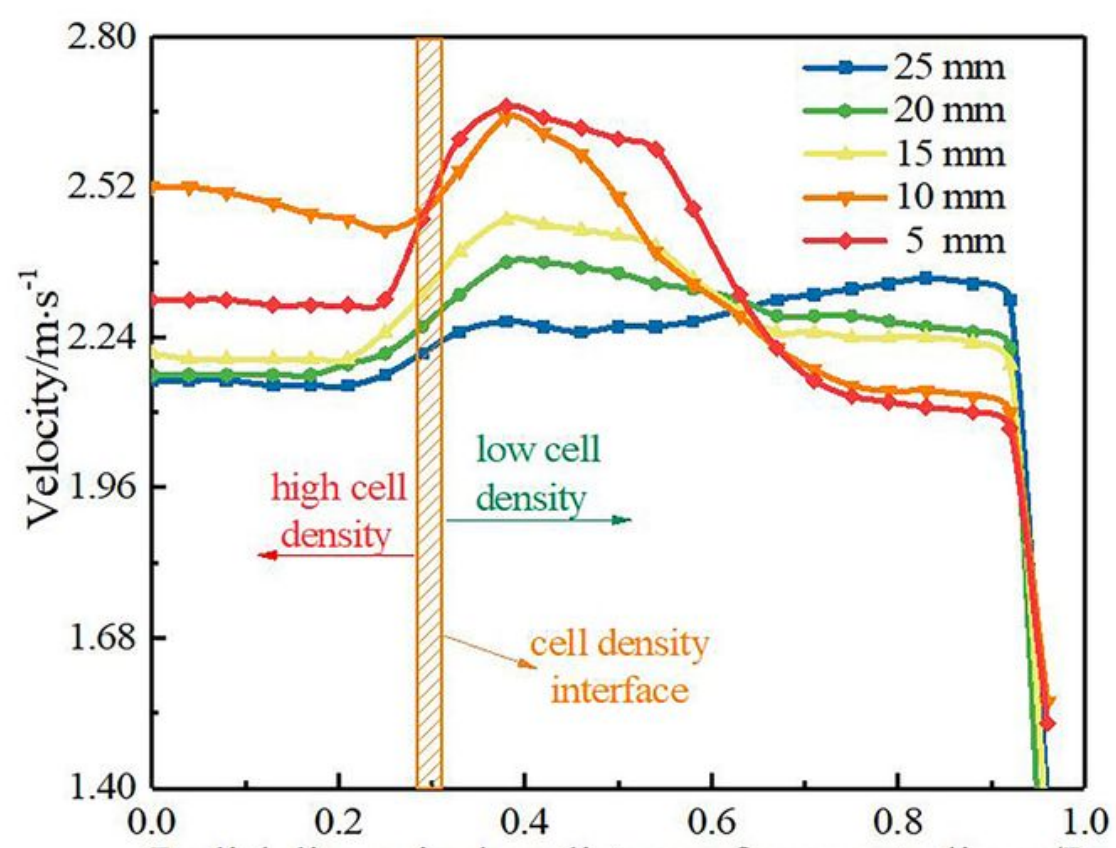

Radial dimensionless distance from centerline $r / R$

(a) Radial distribution of velocity at carrier exit

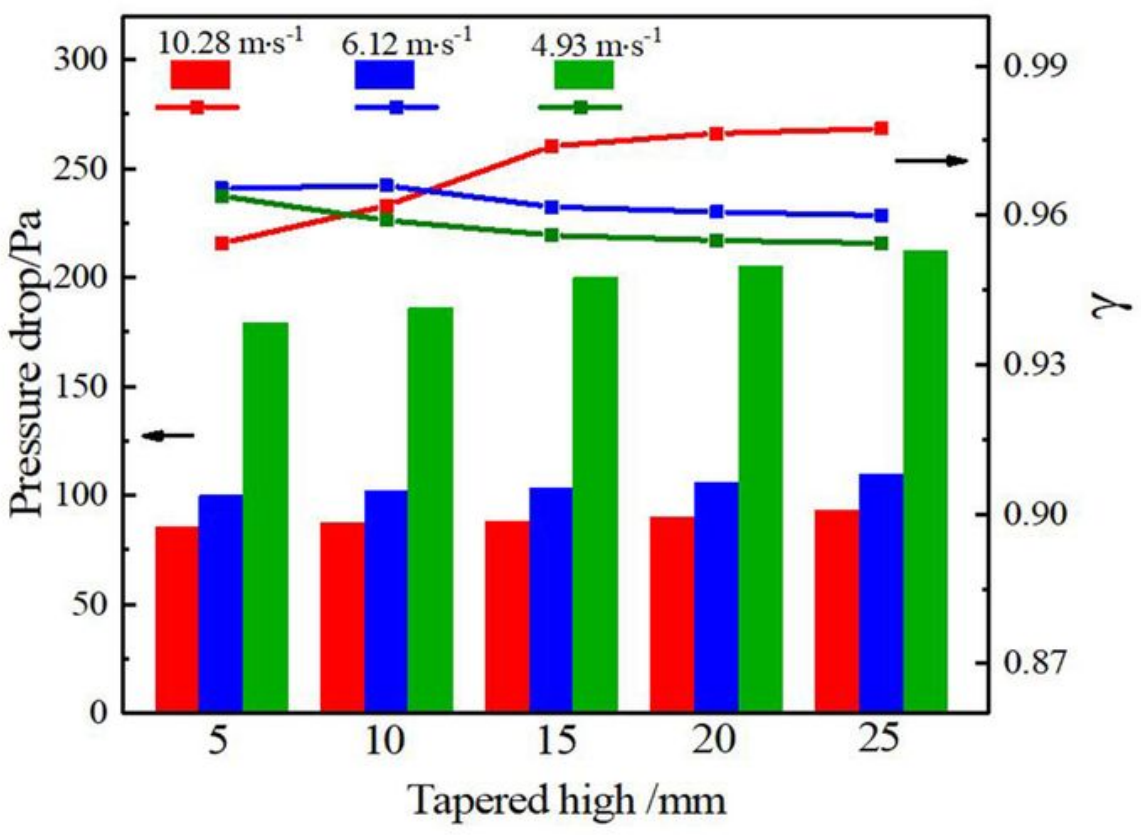

(b) Gas uniformity and carrier pressure drop

Figure 10

Gas uniformity and carrier pressure drop 


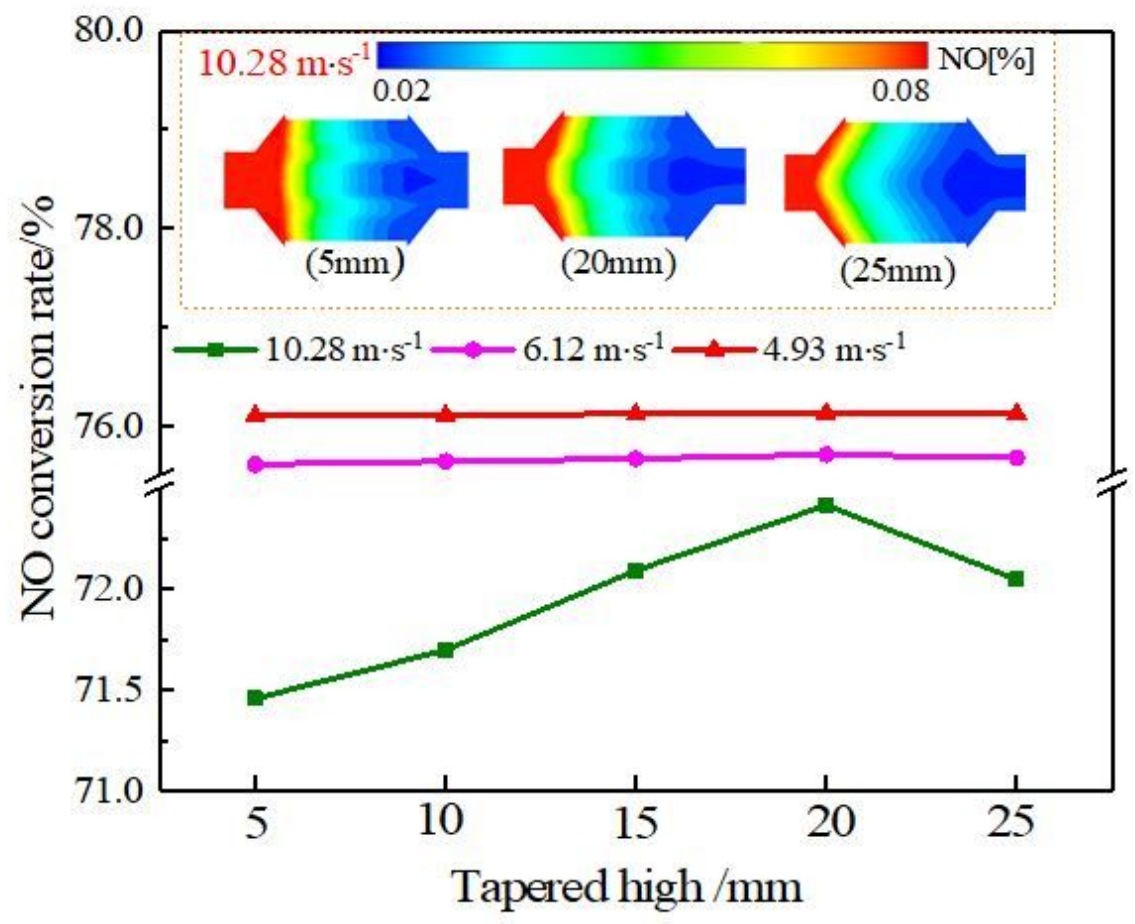

(a) NO conversion rate

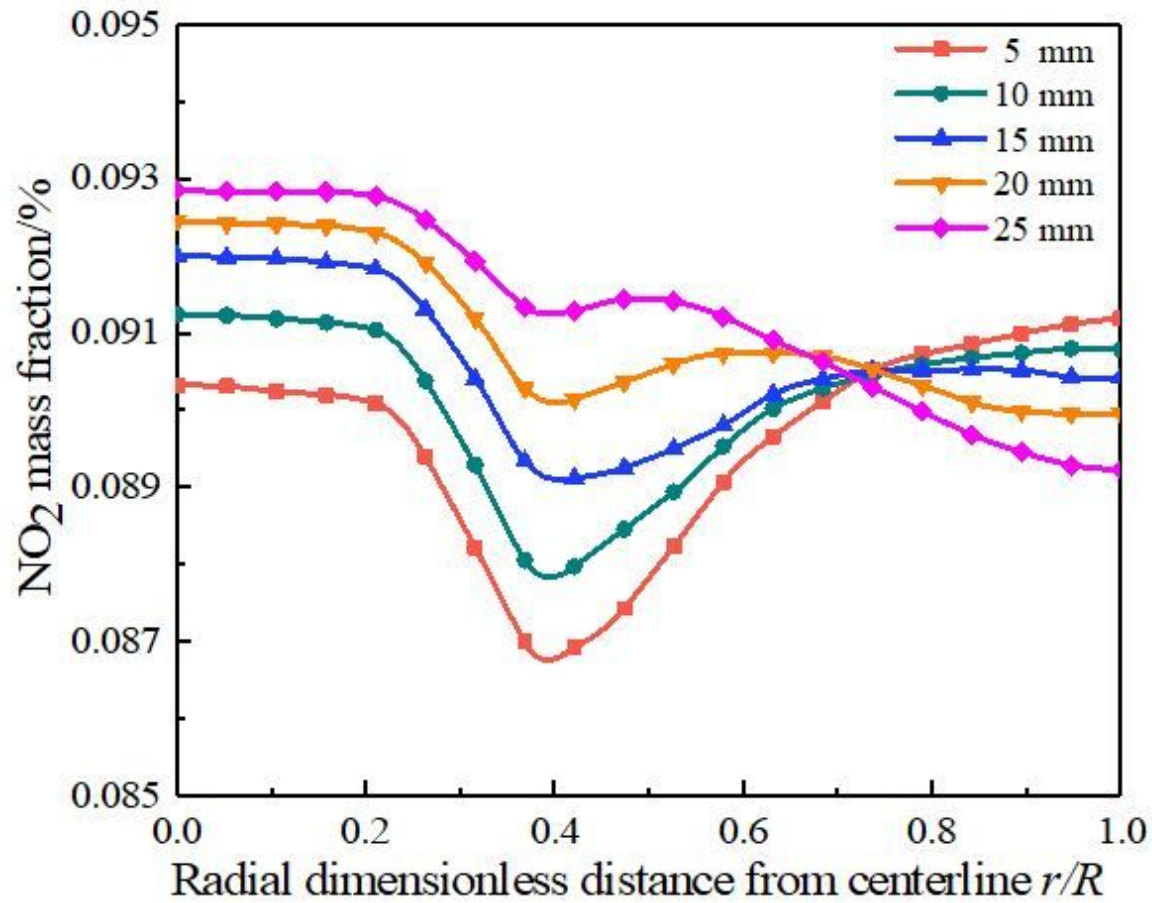

(b) Radial distribution of $\mathrm{NO}_{2}$ mass fraction at carrier outlet

Figure 11

NO conversion rate and $\mathrm{NO} 2$ mass fraction 


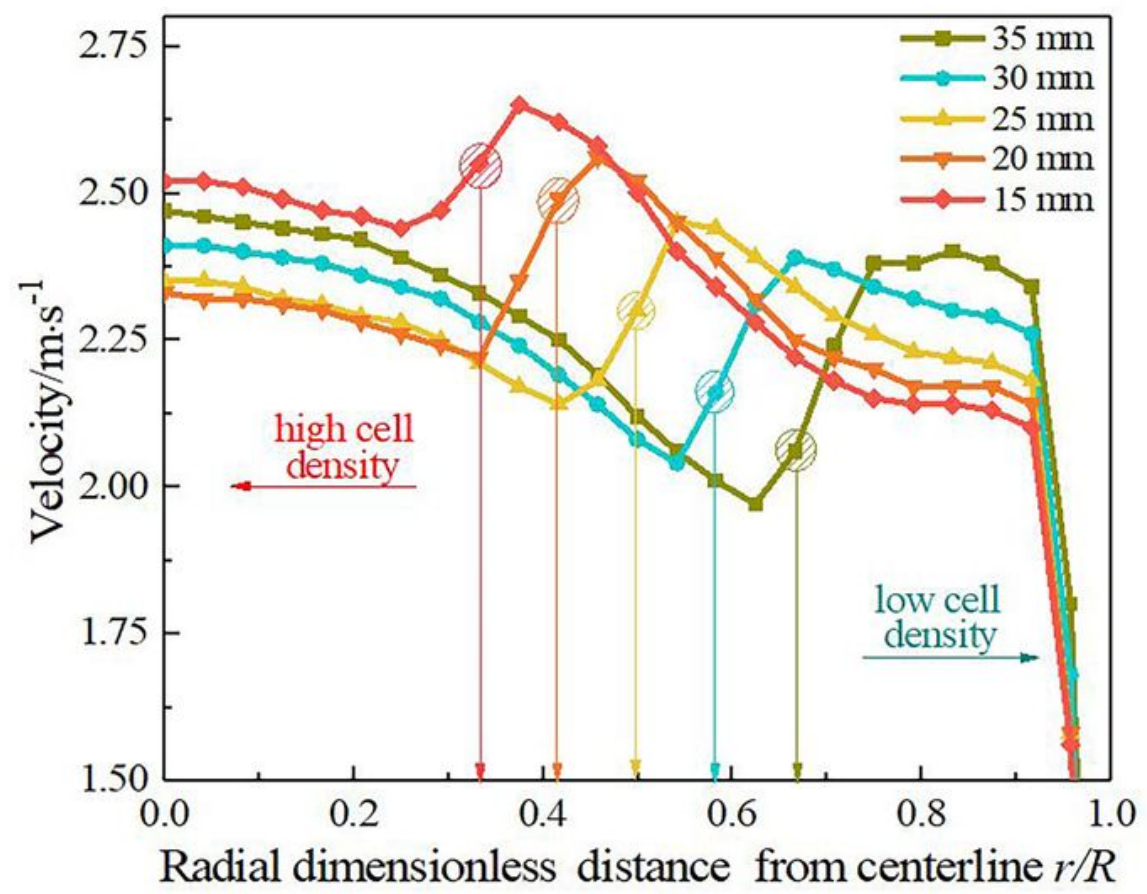

(a) Radial distribution of velocity at carrier exit

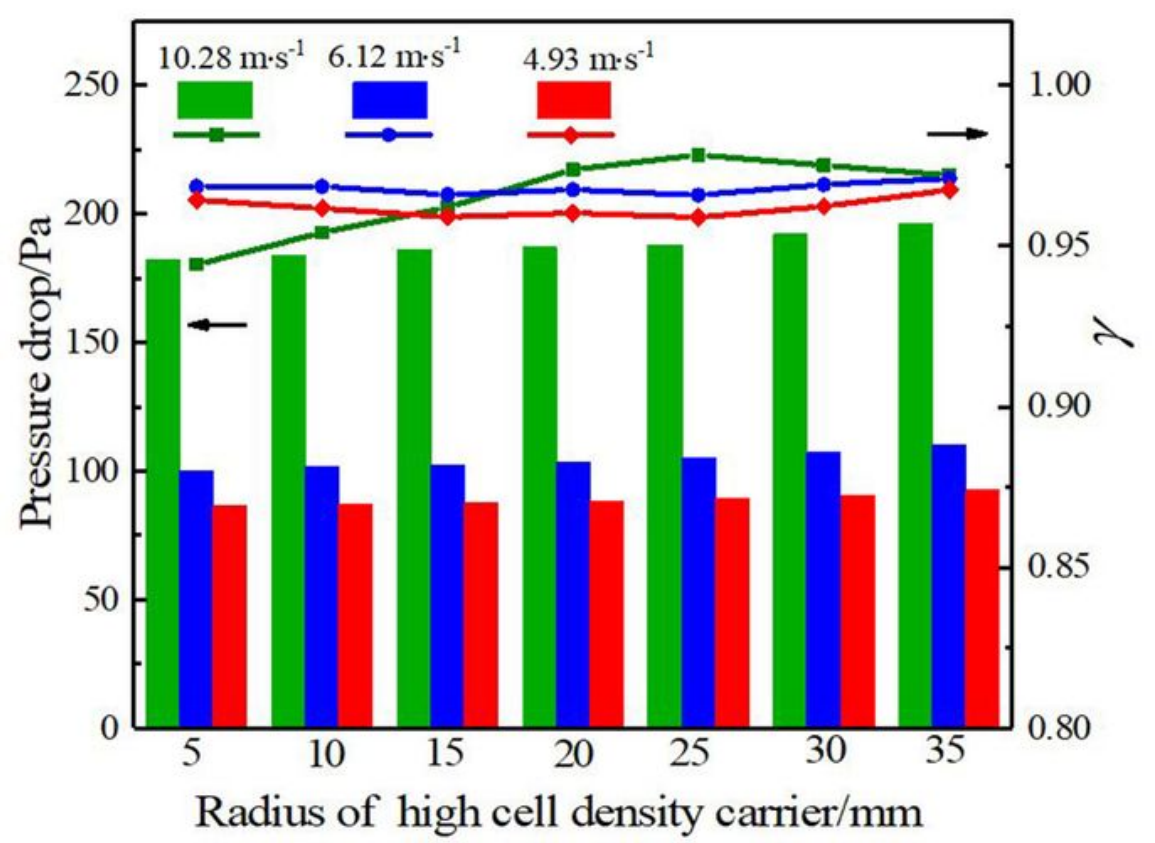

(b) Gas uniformity and carrier pressure drop

Figure 12

Gas uniformity and carrier pressure drop 


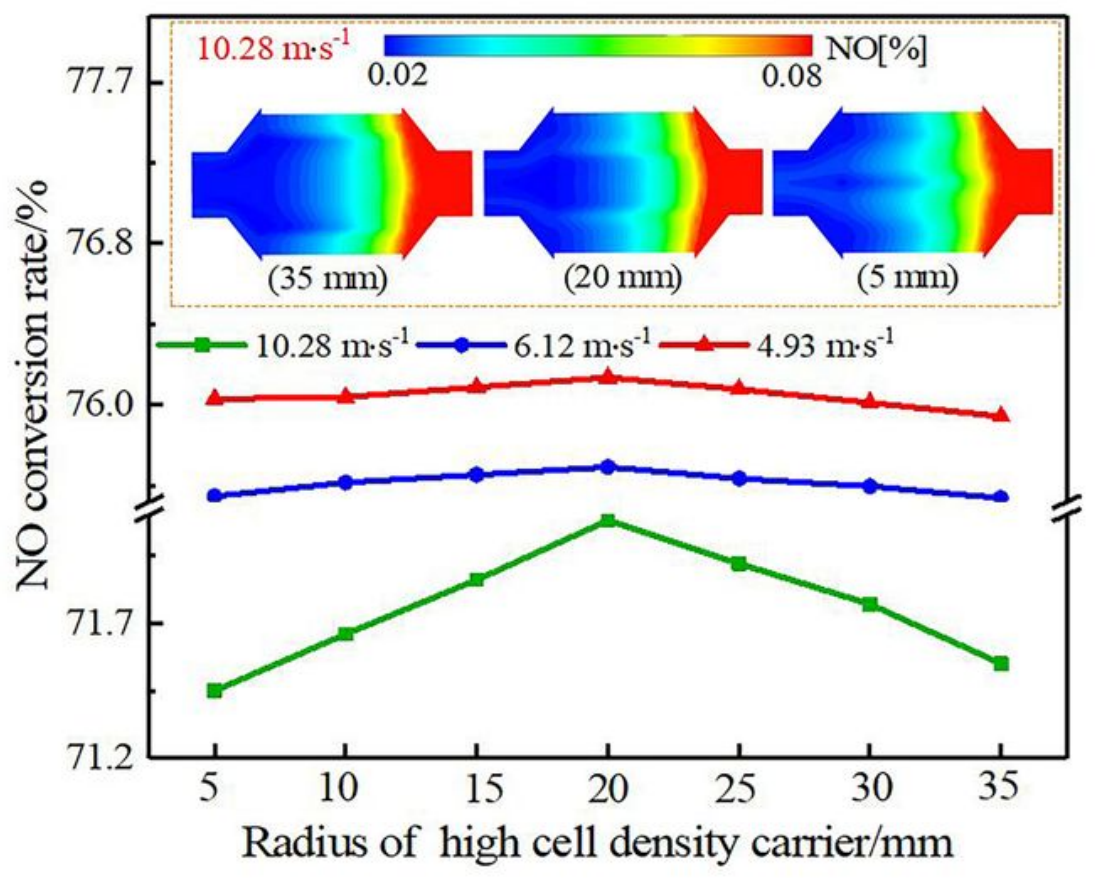

(a) NO conversion rate

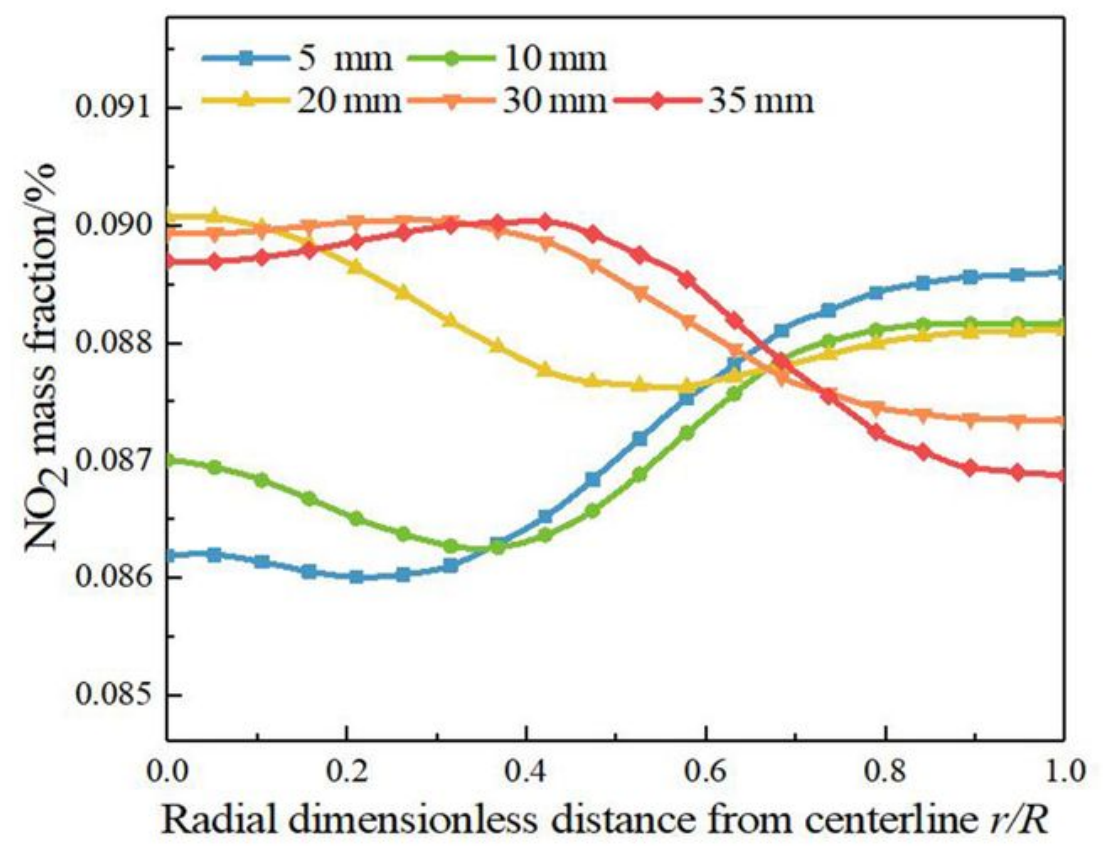

(b) Radial distribution of $\mathrm{NO}_{2}$ mass fraction at the outlet

Figure 13

NO conversion rate and $\mathrm{NO} 2$ mass fraction 


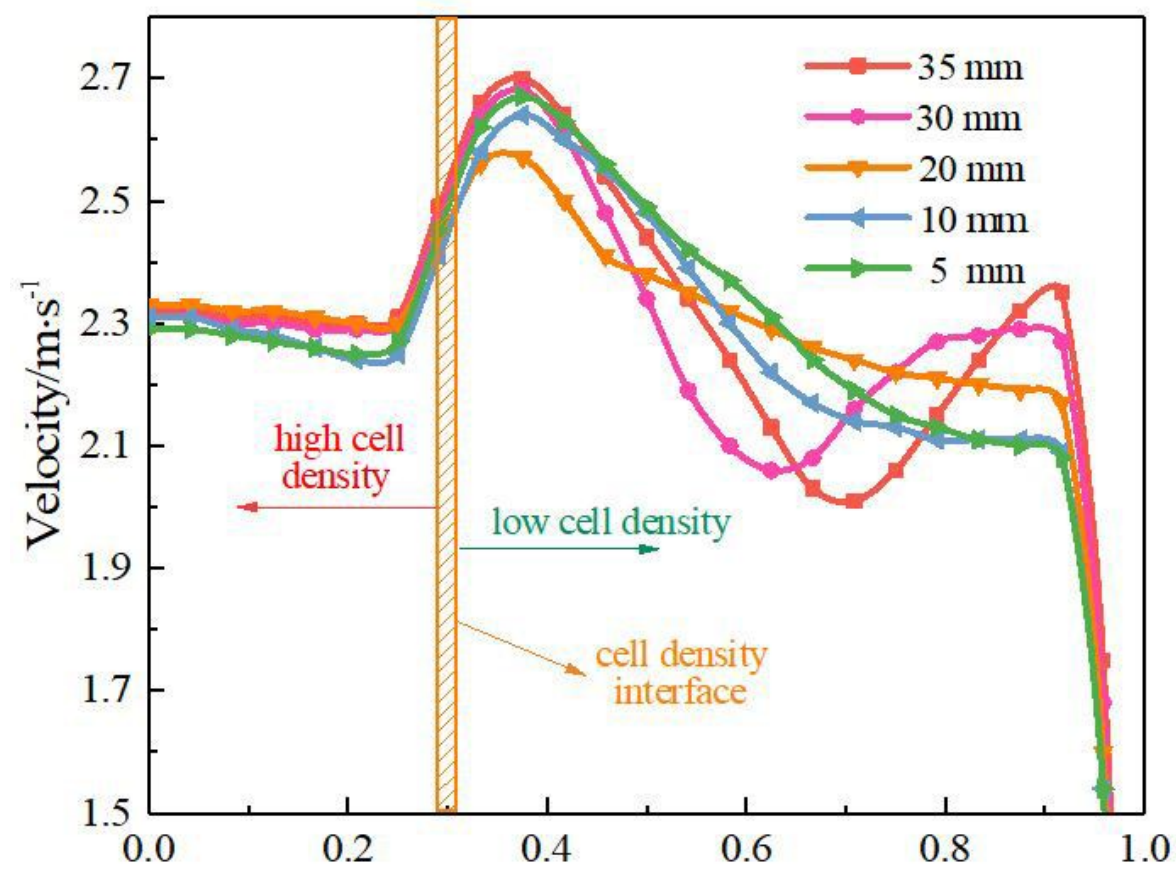

Radial dimensionless distance from centerline $r / R$

(a) Radial distribution of velocity at carrier exit

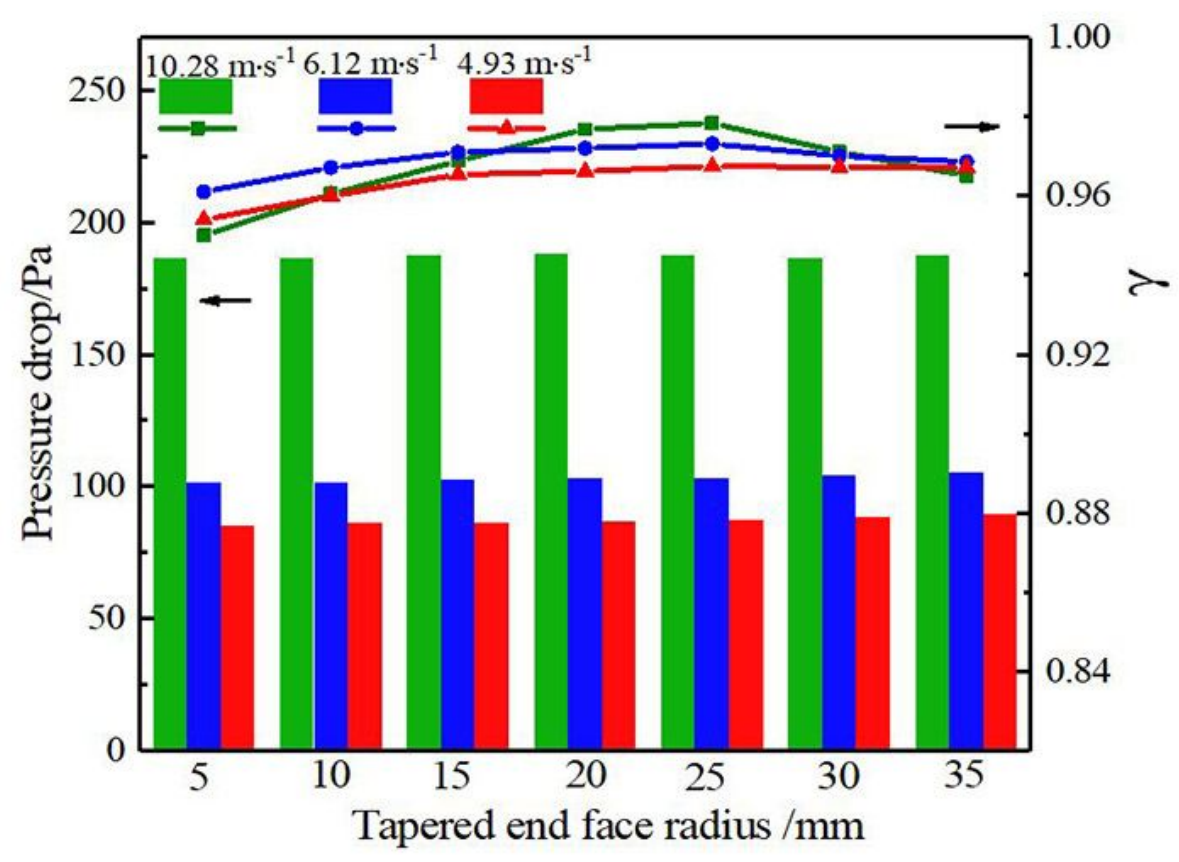

(b) Gas uniformity and carrier pressure drop

Figure 14

Gas uniformity and carrier pressure drop 


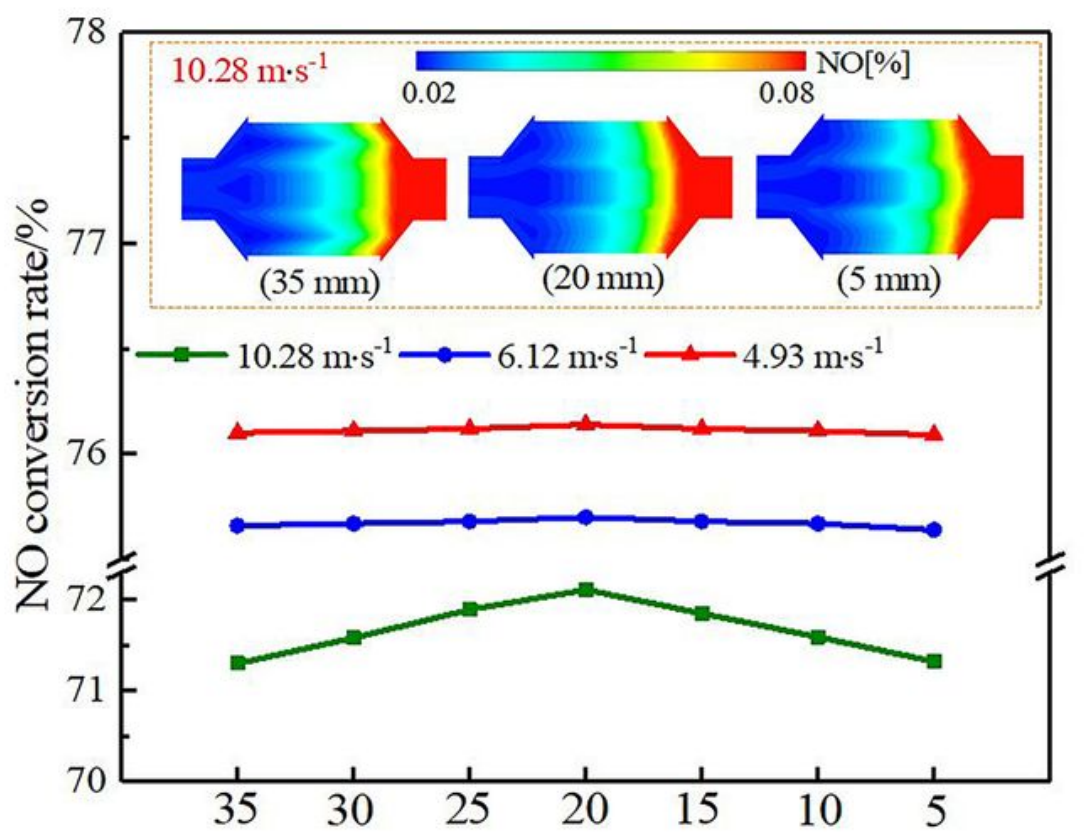

Tapered end face radius $/ \mathrm{mm}$

(a) NO conversion rate

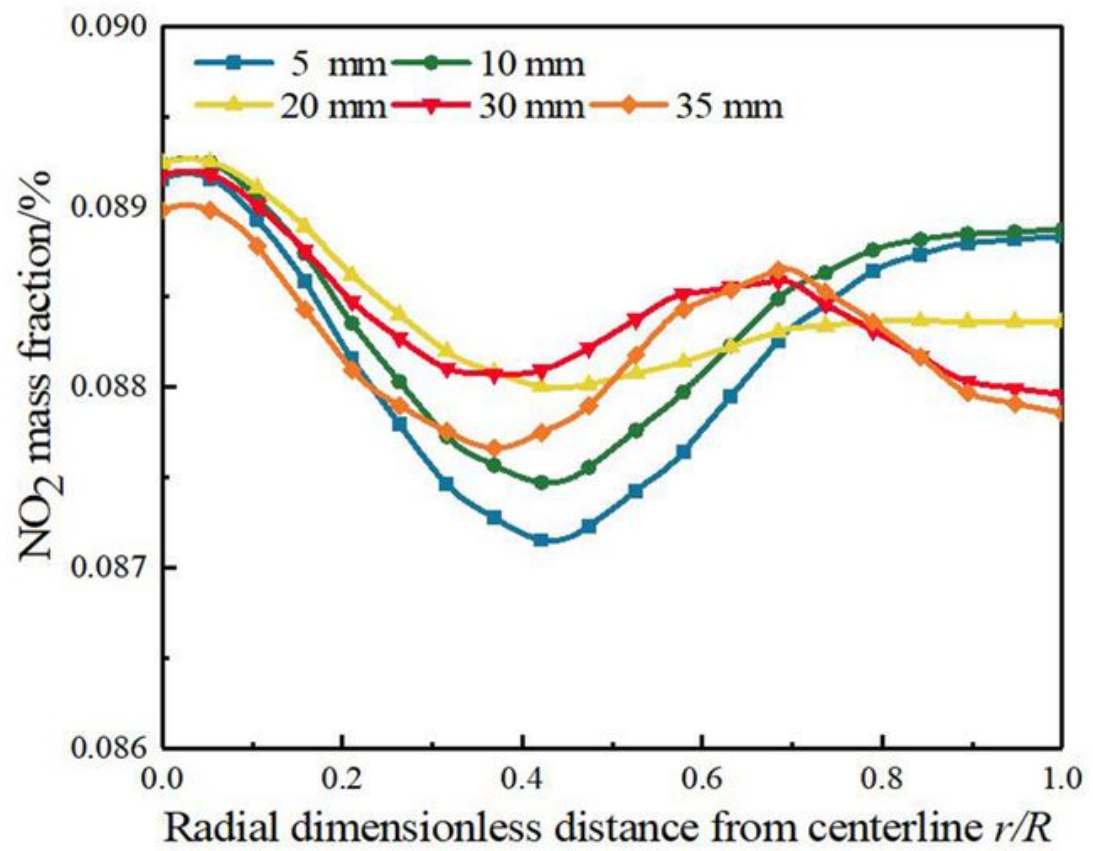

(b) Radial distribution of $\mathrm{NO}_{2}$ mass fraction at outlet

Figure 15

NO conversion rate and $\mathrm{NO} 2$ mass fraction 


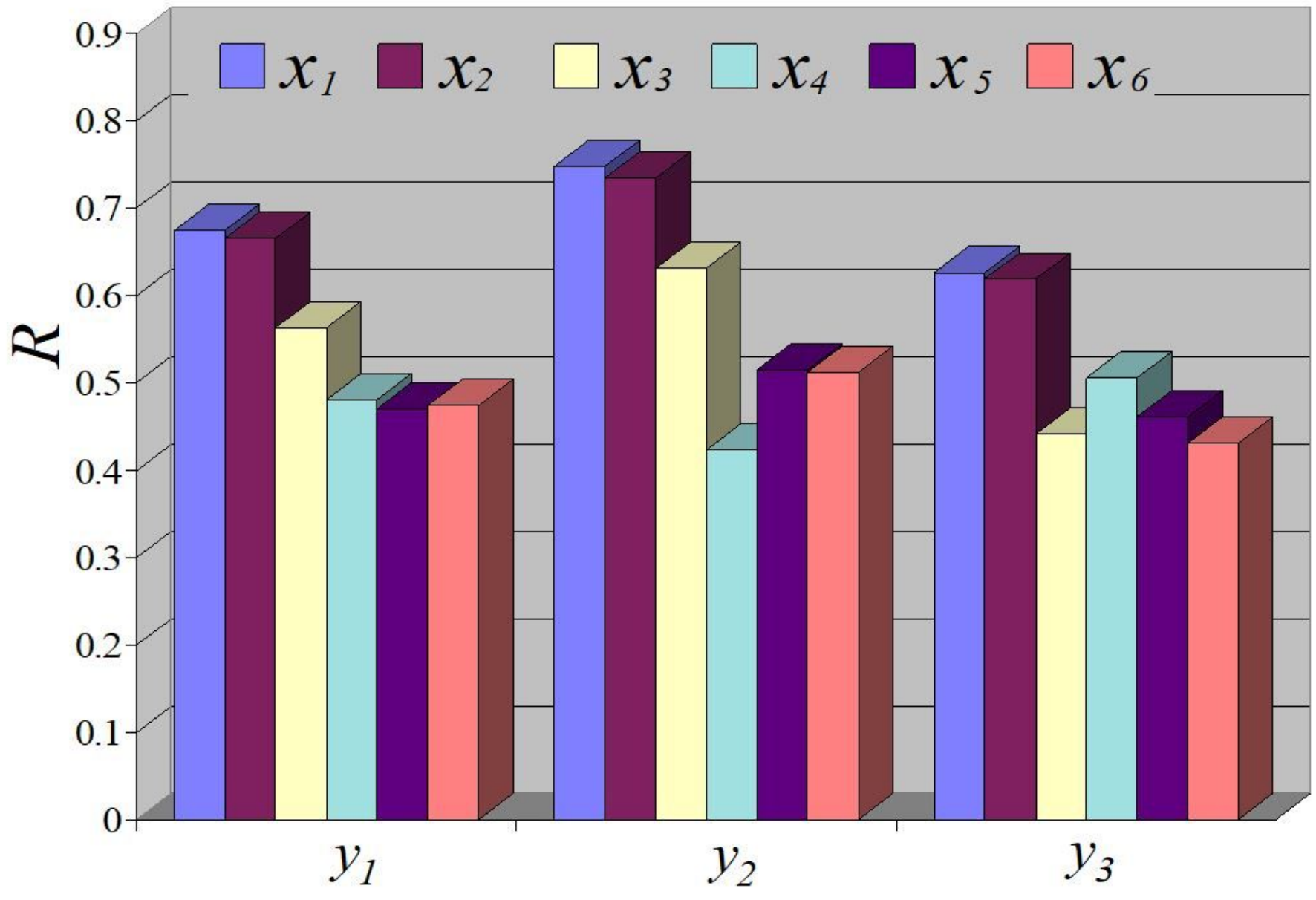

Figure 16

Influence correlation degree 